University of Rhode Island

DigitalCommons@URI

Open Access Dissertations

2017

\title{
Investigating LGBTQ Advocacy Efforts Among Heterosexual Parent Allies
}

Amanda Elizabeth Ramirez

University of Rhode Island, ramirez.amanda04@gmail.com

Follow this and additional works at: https://digitalcommons.uri.edu/oa_diss

\section{Recommended Citation}

Ramirez, Amanda Elizabeth, "Investigating LGBTQ Advocacy Efforts Among Heterosexual Parent Allies" (2017). Open Access Dissertations. Paper 565.

https://digitalcommons.uri.edu/oa_diss/565

This Dissertation is brought to you for free and open access by DigitalCommons@URI. It has been accepted for inclusion in Open Access Dissertations by an authorized administrator of DigitalCommons@URI. For more information, please contact digitalcommons@etal.uri.edu. 


\author{
INVESTIGATING LGBTQ ADVOCACY EFFORTS AMONG \\ HETEROSEXUAL PARENT ALLIES \\ BY \\ AMANDA ELIZABETH RAMIREZ \\ A DISSERTATION SUBMITTED IN PARTIAL FULFILLMENT \\ OF THE REQUIREMENTS FOR THE DEGREE OF \\ DOCTOR OF PHILOSOPHY \\ IN PSYCHOLOGY
}

UNIVERSITY OF RHODE ISLAND

2017 
DOCTOR OF PHILOSOPHY DISSERTATION

OF

AMANDA ELIZABETH RAMIREZ

APPROVED:

Dissertation Committee:

Major Professor Margaret Rogers

Mary Clair-Michaud

Ginette Ferszt

Nasser H. Zawia

DEAN OF THE GRADUATE SCHOOL

UNIVERSITY OF RHODE ISLAND

2017 


\begin{abstract}
Parent advocates play a key role in creating and promoting a supportive and accepting environment for their LGBTQ children (Bouris et al., 2010; Ryan, 2009). However, a limited number of research studies have investigated the development of parent advocates and allies within the LGBTQ community (Broad, 2011; Munin \& Speight, 2010; Saltzberg, 2009; Vernaglia, 1999). Further, these studies have not specifically explored the ways in which individual, family, and community level experiences may influence the development and experiences of parent advocates. The present study utilized an ecological-transactional framework to investigate the advocacy experiences of parents of LGBTQ youth. 12 parent advocates participated in qualitative descriptive interviews focused on the development and experience of parent advocates, as well as the meaning of those experiences at the individual, family, and community level. In the present study, parents described how understanding their child's identity and the needs of the LGBTQ community influenced their decision to become an advocate. These experiences coupled with community supports, family acceptance, and personal experiences with discrimination, among other factors, appeared to facilitate parent advocacy development. The transactional nature of family, community, and individual experiences provided parents with the support necessary to pursue advocacy-related activities. Parents also highlighted both personal and sociocultural challenges to pursuing advocacy, such as a lack of community resources, negative reactions by others, as well as difficulty navigating the legislative process. Additionally, parents noted meaningful changes at the individual, family, and community level as a result of their advocacy
\end{abstract}


experiences. Overall, the present study builds upon previous research literature and provides new insight in understanding the diverse experiences of parent LGBTQ 


\section{ACKNOWLEDGEMENTS}

I would like to extend a special thank you to my major professor, Dr. Margaret Rogers for providing support and mentorship throughout the past five years. Dr. Rogers has challenged me, inspired me, and supported me during my graduate studies. She has fostered my development as a researcher, an advocate, and a future psychologist. Dr. Rogers' commitment to multiculturalism and social justice encouraged me to pursue my interest in understanding parent advocacy for LGBTQ youth.

I would also like to thank my committee, Dr. Ginette Ferszt and Dr. Mary ClairMichaud, for their continued support, guidance, and thoughtful contributions to this project. Thank you both for always being available and willing to assist me throughout this process.

A special thank you goes to all the parents who participated in this study, without you this project would not be possible. Your passion for advocacy is both remarkable and inspirational. Through your work, you have brought about positive change for your children and the larger LGBTQ community. Thank you for trusting me with your stories.

Finally, I would like to thank my family. Thank you to my parents (Carmen and Edward), my siblings (Eddie, Jenny, and Adrian), and my nephew and niece (Alex and Danielle) for continuing to support me and believe in me when I did not believe in myself. Thank you for your countless sacrifices you have made to help me become the first in our family, but hopefully not the last, to accomplish such an amazing feat. Thank you for helping me to become the person I am today. I could not have done this without each one of you. 
To my husband, Jonathan, thank you for supporting me throughout the past six years. You were by my side when I submitted my application to URI, and you have remained by my side supporting me through every step of this process. You have encouraged and inspired me, supported me in my goals, and continued to love me throughout all of these adventures. Thank you for your unconditional love. I look forward to the journey that lies ahead. 


\section{DEDICATION}

I would like to dedicate this project to my parents, Carmen Galvan Ramirez and Edward Leo Ramirez, who have been my biggest advocates and allies. Mom, Dad, thank you for believing in me. I am truly grateful for your never-ending love and support. Throughout my life, you have always encouraged me to fight for what I believe in and speak up for those around me. You have been a model for selflessness and strength through your unwavering commitment to social justice and your unconditional love and compassion for both your family and others. Thank you for continuing to inspire me. 


\section{TABLE OF CONTENTS}

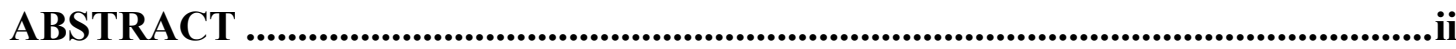

ACKNOWLEDGEMENTS .......................................................................................ii

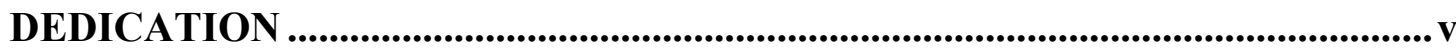

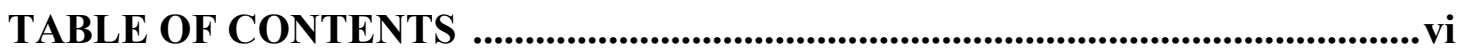

LIST OF TABLES...........................................................................................

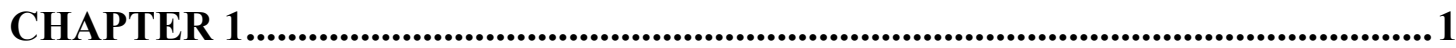

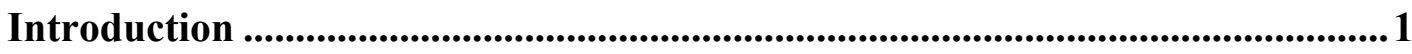

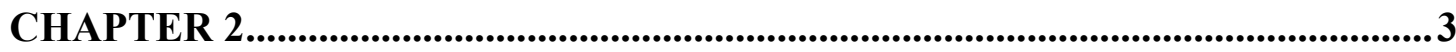

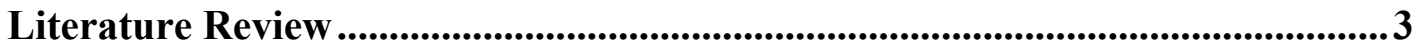

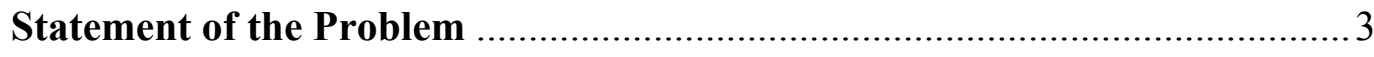

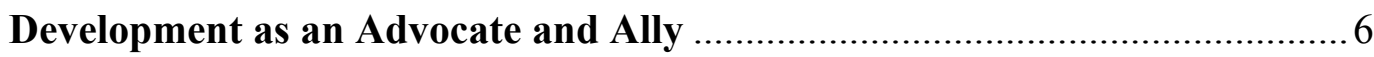

Barriers to Becoming an Advocate .......................................................... 11

Justification for and Significance of the Study .......................................... 14

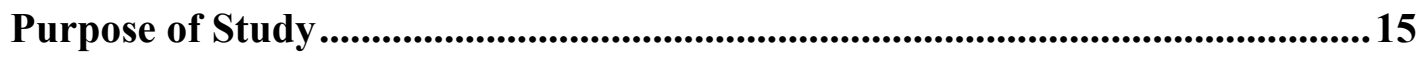

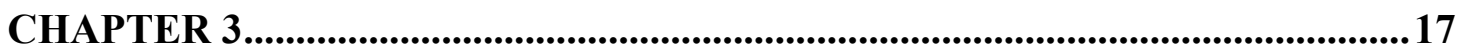

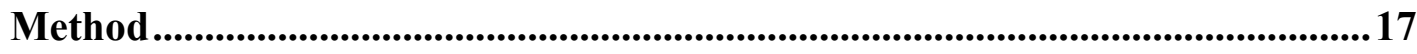

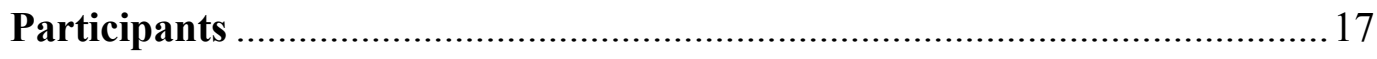

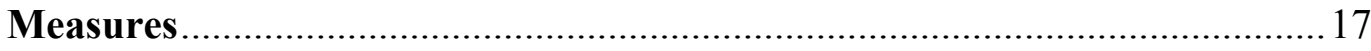

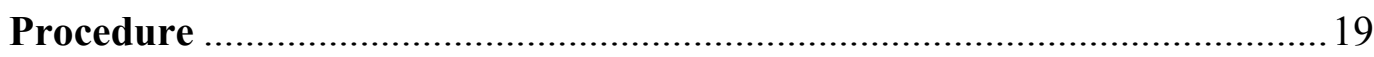

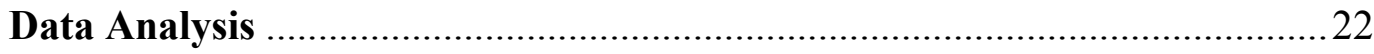

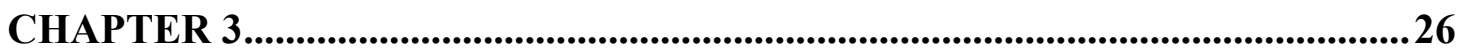


Results..........................................................................................................................26

Demographic and Contextual Data ...........................................................................26

Interview Findings ..........................................................................................................29

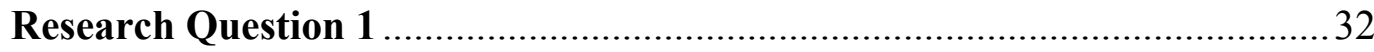

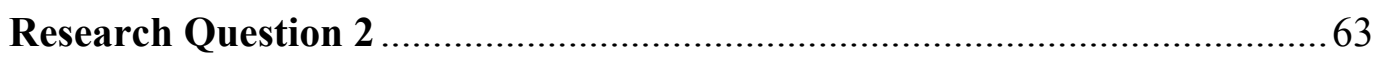

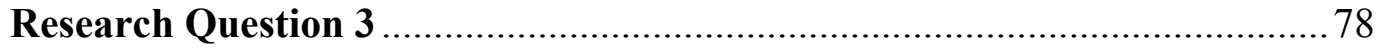

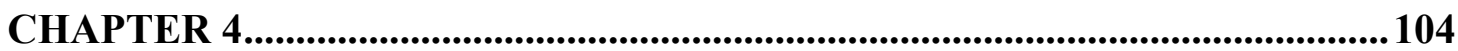

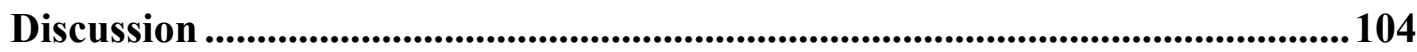

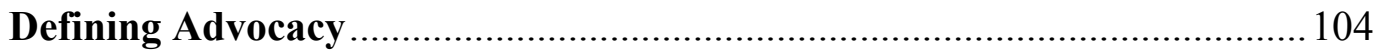

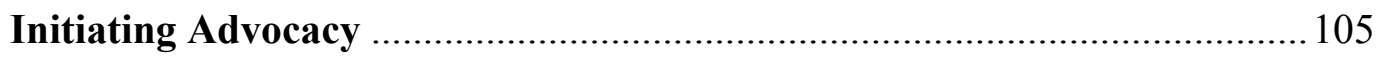

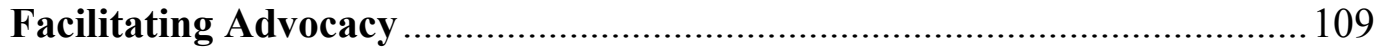

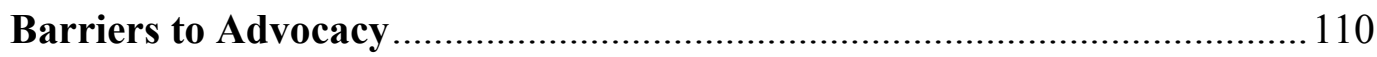

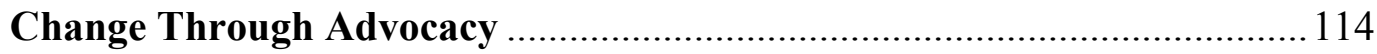

Recommendations for Other Parents of LGBTQ Children ..........................116

Limitations and Methodological Considerations.......................................... 117

Directions for Future Research .................................................................. 119

Appendix A: Demographic Questionaire ......................................................................121

Appendix B: Interview Protocol.................................................................................... 123

Appendix C: Recruitment Email Script .................................................................... 125

Appendix D: Recruitment Flyer........................................................................................126

Appendix E: Consent Form ............................................................................................. 127

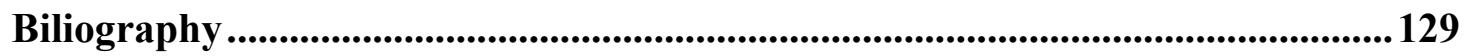




\section{LIST OF TABLES}

TABLE

PAGE

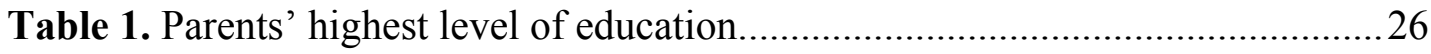

Table 2. Gender identity and sexual orientation of parents' children ....................27

Table 3. Involvement in advocacy groups/organizations ...................................28

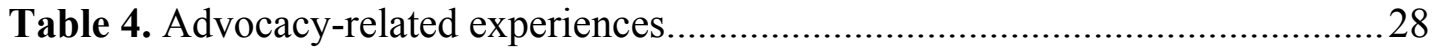

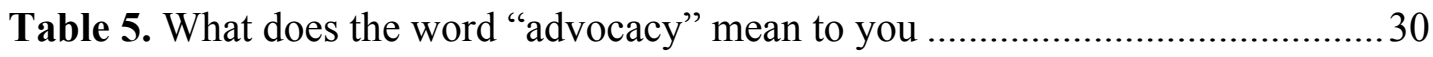

Table 6. Can you identify what influenced you to become an LGBTQ

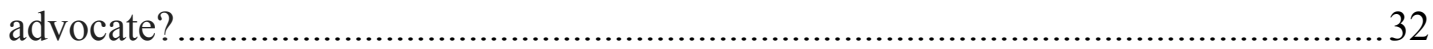

Table 7. How has your relationship with your child who identifies as

LGBTQ influenced your decision to become an advocate?

Table 8. What about your other family members, how have they influenced your decision to become an advocate?.... .40

Table 9. How has your relationship with others in your community influenced your decision to become an advocate?

Table 10. Have you experienced discrimination or isolation in your life?

Was that before you become an advocate? Did that come later? Do you think those experiences influenced you being an advocate now?

Table 11. Once you became an advocate, what experiences facilitated your continued involvement in LGBTQ advocacy efforts? 50

Table 12. How has your relationship with your child influenced your experiences as an advocate?

Table 13. What about your other family members and members of the 
community?

Table 14. What kinds of challenges did you encounter initiating and

pursuing advocacy-related efforts?

Table 15. What personal challenges did you overcome during this process?

Table 16. Did you ever find negative reactions by others in the community or in your family?. 70

Table 17. How did you end up dealing with those challenges? 76

Table 18. Do you think your view of yourself has changed throughout your advocacy experiences? Do you think your view of your relationships with others has changed?

Table 19. How have your experiences as an advocate impacted who you are as an individual?..

Table 20. Has your relationship with your child changed since becoming an advocate? How has this impacted your relationship with them?

Table 21. Have your relationships with your other family members changed since becoming an LGBTQ advocate? 88

Table 22. Have your relationships with those in your community, both the LGBTQ community and the larger community you referred to previously, changed since becoming an LGBTQ advocate?

Table 23. If you were in a room with other parents whose child identifies as LGBTQ, what would you want to tell them now? .96

Table 24. What would you like them to know about becoming an advocate? 100 


\section{CHAPTER 1}

\section{INTRODUCTION}

Parent acceptance and support serves as a protective factor for LGBTQ youth, who are at risk for a number of negative outcomes including but not limited to depression, suicidal ideation, and substance abuse (Coker, Austin, \& Schuster, 2009; D’Augelli, Grossman, \& Starks, 2005; Needham \& Austin, 2010; Ryan, Huebner, Diaz, \& Sanchez, 2009). Moreover, by becoming advocates, parents have an opportunity to support and protect their child from these adverse outcomes, while also advocating for the larger LGBTQ community (Ryan, 2009). These parent advocacy experiences remain important in understanding ways to better support LGBTQ youth and their families. Additionally, the individual, family, and community level experiences that influence parents' advocacy development, as well as their advocacy-related experiences, may help to build upon the current research literature.

In the present study, a constructivist paradigm was utilized in order to explore the multiple realities of parent advocates. I practiced reflexivity or personal reflection to identify potential assumptions and biases that may have impacted the present study. The identification and acknowledgement of individual background and cultural experiences helped to minimize the impact of subjective experiences on potential study outcomes. The following is evidence of the researcher's reflexivity:

The researcher is a currently a doctoral school psychology student at the University of Rhode Island. She also holds a Master's degree in social work from Boston College. Both degree programs have stressed the importance of social justice and advocacy-related efforts for multicultural groups. As an individual, the researcher 
identifies as a Hispanic graduate student from San Antonio. She also identifies as a bisexual woman in a heterosexual marriage. The researcher also identifies as cisgender, meaning her gender identity matches their sex identified at birth. Additionally, the researcher has led a number of LGBTQ organizations that sought to foster community and education. These experiences, in addition to her own personal development led her to the present research. Drawing from these experiences, she anticipated that a majority of parents might attest to challenges "coming out" as a community-based advocate. She believed, however, parents would display some variation in the degree to which they feel comfortable expressing these struggles. 


\section{CHAPTER 2}

\section{STATEMENT OF THE PROBLEM}

Over the last two decades, the United States has experienced a cultural shift in Lesbian, Gay, Bisexual, Transgender, and Questioning (LGBTQ) equal rights. As the culture shifts, the experiences of individuals, families, and communities have also changed. In 2014, an estimated 58\% of Americans believed being gay was morally acceptable compared to 38\% in 2002 (Riffkin, 2014). The 2015 Supreme Court ruling that legalized marriage between same sex couples also signified the changes in cultural norms (Obergefell v. Hodges, 2015). Moreover, a recent study found a decrease in suicide attempts, concentrated among sexual minority youth, in states that legalized same sex marriage prior to the 2015 Supreme Court decision (Raifman, Moscoe, Austin, \& McConnell, 2017). These findings indicate a relationship between LGBTQ-friendly legislation and mental health, Despite these indicators of progress, there are critical LGBTQ issues that remain, such as the lack of anti-discrimination laws and the creation of anti-LGBTQ legislation at local, state, and federal levels. In one case, in the midst of conducting the present study, North Carolina passed HB2: The Public Facilities Privacy and Security Act (2016-3), which eliminated anti-discrimination protections for LGBTQ people, and gave limited access to restroom and changing facilities in government buildings based on an individual's sex on their birth certificate. Given this legislation, among other LGBTQ equality issues, advocacy remains important to ensure equal rights for the LGBTQ community.

LGBTQ advocacy can also play a critical role in promoting positive outcomes for LGBTQ youth (Ryan, 2009). Recent research has found that LGBTQ youth are at-risk for 
experiencing significant challenges related to bullying, harassment, substance use, depression, and suicidality (Coker, Austin, \& Schuster, 2009). Youth who are rejected by parents and family members due to their LGBTQ status are also more likely to utilize illegal drugs, attempt suicide, and engage in sexual risk behaviors compared to LGBTQ youth with accepting parents (Ryan, Huebner, Diaz, \& Sanchez, 2009). Although these findings are concerning, parent acceptance and support has been identified as a critical mediator and protective factor against these challenges, as well as other challenges (D’Augelli, Grossman, \& Starks, 2005; Needham \& Austin, 2010; Resnick et al., 1997). Additionally, parents who support their LGBTQ-identified children by becoming allies and advocates within the LGBTQ community have been shown to improve their children's well-being (Bouris et al., 2010; Ryan, 2009).

An ally is a person from a 'dominant' group who endeavors to support and advocate for an otherwise oppressed group (Washington \& Evans, 1991). Allies may serve as a powerful tool in promoting perspective taking, reducing prejudice, and increasing support for equal rights (Brookman \& Kalla, 2016). In the present context, an LGBTQ ally may be a heterosexual cisgender person (an individual whose gender identity matches their sex identified at birth) who supports LGBTQ rights and the LGBTQ community at large. Parent LGBTQ allies have a unique opportunity to assist LGBTQ advocacy efforts while also supporting their children. In doing so, parents serve as a model for their children to also become future advocates for themselves, the LGBTQ community, and potentially other marginalized groups. Moreover, as an ally, parents take on a collective identity, becoming a support for both their children and the LGBTQ community as a whole (Broad, 2011). Within schools and communities, parents are often 
critical components to enacting positive change for both LGBTQ youth and the LGBTQ community (Watson, Varjas, Meyers, \& Graybill, 2010).

Although research describes parent advocacy as a positive experience for parents, LGBTQ youth, and the LGBTQ community, very few research studies have explored the experiences of parents as advocates and allies for the LGBTQ community (Broad, 2011; Munin \& Speight, 2010; Saltzberg, 2009; Vernaglia, 1999). Moreover, the 2015 National School Climate Survey found that $85.2 \%$ of LGBTQ students reported experiencing verbal harassment in school, with $27.0 \%$ experiencing some form of physical harassment (Kosciw, Greytak, Giga, Villenas, \& Danischewski, 2016). Of those students, 43.4\% reported it to their families, with only $53 \%$ indicating their family member addressed the issue with school staff (Kosciw et al., 2016). These findings indicate a continued need to understand parent advocacy for LGBTQ youth. Through studying and supporting parent advocates, LGBTQ youth may be better supported and protected at home and in school, thus increasing the number of protections for LGBTQ youth in the community.

The present study utilized an ecological-transactional framework to understand the process of becoming a parent advocate and the experiences of parent allies. The ecological-transactional model emphasizes the importance of understanding the transactional nature of individual, family, and community contexts on each other, as well as their influence on child development (Bronfenbrenner, 1979; Cicchetti \& Lynch, 1993). This model outlines risk and protective factors across four systems: the macrosystem (cultural practices and societal norms), exosystem (neighborhood and community), microsystem (family inter-relationships), and ontogenetic development (the individual) (Cicchetti \& Lynch, 1993). The various systems interact and transact with 
each other, shaping individual development over time (Lynch \& Cincchetti, 1998).

Systems may be influenced by both potentiating/risk factors and compensatory/supportive factors that can be transient (fluctuating) or enduring (more permanent) in its effects (Lynch \& Cincchetti, 1998). To date, studies on the ecologicaltransactional model have focused on the development of children and adolescents (Lynch \& Cincchetti, 1998). Using this approach, parent advocates may serve as an enduring compensatory factor within a LGBTQ child's exo- and microsystems. Given the role parents play in their child's development, it is increasingly beneficial to understand the role these contexts also play in supporting parent advocacy development, thus providing a more positive environment for their children. The present study uses the ecologicaltransactional model to understand advocacy development among parents of LGBTQ youth, as well as its role on parent-child relationships. In doing so, it builds upon the ecological-transactional literature and overcomes the limitations of previous research focused on parent advocacy at the individual level.

\section{Development as an Advocate and Ally}

Prior to becoming advocates, parents may identify feelings of social isolation as their child begins the 'coming out' process or the process by which their child voluntarily makes public their sexual orientation or gender identity (Sulzberg, 2009). As a parent of an "out" LGBTQ member, parents may also experience their own coming out, as they navigate this new identity (Broad, 2011; Fields, 2001). Broad (2011) notes that grief is a common experience for parents of sexual minority youth during this process. During the grieving process, parents may create walls or distance themselves from other family members or peers, fearing that family relationships will be forever impacted (Saltzberg, 
2009). They may also fear that conversations regarding LGBTQ issues would be too stigmatizing to discuss or explore (Saltzberg, 2009). At the same time, they may long for social connection and resources to help them understand and conceptualize their own experience (Saltzberg, 2009). As a parent conceptualizing the child's "outness," they may start to gain greater awareness of LGBTQ-related issues. This process of achieving greater understanding and knowledge serves as a stepping-stone for potential acceptance, and perhaps even advocacy efforts in the future.

Previous studies have also proposed that allies undergo a developmental progression in becoming an ally (Getz \& Kirkley, 2003; Washington \& Evans, 1991). For example, in an exploratory study of 20 Gay, Lesbian, and Bisexual (GLB) advocates, Getz and Kirkley (2003) identified five stages of development, starting with entry. Entry is the point at which an individual realizes they need to become more active as an advocate. Entry may include greater multicultural awareness and realization of privilege. Allies often share the previous experience with diversity, including experiencing marginalization, witnessing the discrimination of others, fear for child's safety, or having positive family modeling of multicultural awareness (Duhigg, Rostosky, Gray, \& Wimsatt, 2010; Phillips \& Ancis, 2008). Similarly, personal qualities such as faith, family influence, and realizations of otherness have been found to influence individual decisions to become allies within heterosexual communities (Munin \& Speight, 2010). These individual and family experiences may increase the likelihood of future parent advocacy.

The second phase of ally development is the "fear of the unknown," or fear of how LGBTQ community members as well as those of the larger community may react 
upon discovering their new identity (Getz \& Kirkley, 2003). This phase serves as a potential barrier to parent advocacy, but can be overcome with increased knowledge, awareness, and support (Getz \& Kirkley, 2003). The three remaining stages cover "acknowledgement of privilege," "engagement," and "self-identification as an ally" (Getz \& Kirkley, 2003). Through these phases, parents show increased awareness of their heterosexual privilege, begin to engage in increased advocacy efforts, and eventually become empowered to identify as an advocate to those around them. Together, these studies detail the process of becoming a parent ally within the LGBTQ community and lead to a greater understanding of ways to engage members of high-status privileged groups to support low-status groups prone to discrimination and injustice. Although these studies provide greater insight into the process of becoming an ally, their focus on ally development is limited in scope and understanding of advocacy-efforts, barriers to advocacy, and the impact of these experiences at the individual, family, and community level. The present study examines what it means to be an advocate, as well as the barriers to advocacy for parents of LGBTQ youth.

At an individual level, Vernaglia (1999) notes that a parent's personal background, which includes experiences with diversity and discrimination, and the coming out process of their child, can influence the process of becoming a parent ally. Utilizing a phenomenological life history approach, Vernaglia (1999) interviewed 13 participants, three men and 10 women, who identified as White heterosexual parent allies. The interviews reviewed the participants' life history prior to becoming an advocate, their advocacy-related experiences, and their understanding of those experiences. Overall, the study found that parents typically underwent two processes to 
becoming advocates. Vernaglia (1999) coined the "Social Justice Pathway" and the "Parent Loyalty Pathway." These pathways are further divided into three stages: "prediscovery," "discovery," and "post-discovery" based on the child's process of coming out to their parents. The "Social Justice Pathway" for parent advocacy indicated that parents already involved in advocacy prior to their child's coming out may seek to incorporate LGBTQ rights into their commitment to advocacy. The "Parent Loyalty Pathway" indicated that parent's loyalty to their child and their child's needs heavily influenced their motivation to becoming an ally (Vernaglia, 1999). However the shifts in both national policy and public opinion raise the question of whether the experience of LGBTQ parent advocates has changed since Vernaglia's (1999) study. It is therefore important to further explore the journey of becoming an advocate within the context of the social, cultural, and community level changes that have occurred over the past 15 years.

Further, Vernaglia's (1999) findings closely interlock with current research on Social Identity Theory (Tajfel, 1979). Social Identity Theory posits that an individual's sense of belonging within a group is measured by their social identity (Tajfel, 1979). This social identity is influenced by in-group and out-group comparisons. For in-group comparisons, the disadvantaged group (LGBTQ identified individuals) would evaluate and compare their social status to the in-group (the heterosexual dominant group). After this evaluation, out-group members may see their status within the group as impermeable and underserved, and may perceive injustices they experience as changeable (van Zomeren \& Iyer, 2009). Based on this appraisal, Social Identity Theory holds that the perception of injustice motivates and increases the likelihood of social collective 
participation, such as advocacy (van Zomeren \& Iyer, 2009). Although Social Identity Theory is commonly used to understand the experience of disadvantaged groups, similar motivational experiences might influence the call for advocacy among a high-status group such as heterosexuals.

Research on Social Identity Theory has found that individuals who socially identify with social movements (e.g., other forms of advocacy) and are actively engaged in social justice efforts are more likely to engage in future advocacy when compared to their in-group counterparts (van Zomeren, Postmes, \& Speads, 2008). In this sense, heterosexual parent allies belong to the heterosexual out-group, but may come to identify themselves as connected to the larger social justice movement for LGBTQ equality. This is similar to the findings of Vernaglia's (1999) Social Justice Pathway in which parent's already engaged in social justice are more likely to integrate LGBTQ advocacy efforts into their lives. As a result of increased LGBTQ advocacy, parent allies may begin to better understand their own individual heterosexual privilege in relation to the group. Acknowledging their privilege may serve as a motivating factor in the pursuit of social justice efforts among high-status group members (Mio, 2007; Roades \& Mio, 2002). The most prominent fault of this theory is the lack of attention paid to the diverse and fluid nature of group status among parent LGBTQ advocates. For example, parents may change in their out-group identification as their understanding of the impermeable injustices that may be experienced by their LGBTQ identified children become more salient, following the coming out process. This transition into becoming an ally may be further motivated by the affective understanding of these injustices. However, the present literature on parent advocates fails to account for these changes in identity and roles 
amongst parent advocates. By using a transactional approach, the present study accounts for the dynamic nature of identity and its impact on advocacy efforts.

Parents may also encounter barriers to advocacy that are compounded by their multiple identity status. More specifically, parent advocates are both in-group and outgroup members as LGBTQ allies, parents of LGBTQ youth, and heterosexual individuals. As such, the nature of their experiences that lead to advocacy cannot be fully explained using these theories alone. Moreover, their multiple identity status may be heavily impacted by a variety of individual, family, and community level variables. For example, in a qualitative study of 22 Gay Straight Alliance (GSA) advisors, Watson et al. (2010) found that school advisors negotiated multiple ecological systems to advocate for LGBTQ rights. This included sociocultural factors, school-based factors, and individual level factors that helped to both facilitate and hinder advocacy efforts. Although this study focused on GSA advisors from a purely ecological lens, the findings indicate that advocates may navigate multiple domains as they seek to support LGBTQ youth. The domains may influence each other (e.g., policy impacts school-based factors), as well as a parent's decision to advocate on behalf of their child. As such, an ecological-transactional framework coupled with Social Identity Theory provides a deeper understanding of parent advocacy that accounts for both the individual level experiences as well as the family and community level variables that may impact the individual.

Through qualitative interviewing, Watson et al. (2010) also found that GSA advisors considered parents to be both both facilitators and barriers to change efforts. They reported that parents had the ability to heavily impact the climate for LGBTQ youth within the school and community. It is, therefore, essential to also investigate ways in 
which parents may contribute to change within their environment. Through the use of qualitative interviews, the present study examined the facilitators and barriers to change

parents encountered as they pursued advocacy, which may offer a more holistic picture of parent contributions and advocacy.

\section{Barriers to Becoming an Advocate}

There are a number of barriers encountered when becoming an advocate. Heterosexual parents may identify injustice and feel a sense of obligation to participate in advocacy-related activities, but they may be constrained by both real and perceived negative consequences to advocating for LGBTQ youth (McAdam, 1986; Watson et al., 2010). Heterosexual allies may see advocacy for the LGBTQ community as more difficult due to perceived lack of credibility, difficulty knowing how to demonstrate their support for the LGBT community, fears associated with coming out as an ally, lack of interpersonal support, inability to have conversations about LGBT issues, and lack of knowledge surrounding LGBT issues (Ji, DuBois \& Finnessy, 2009). Further, experiences with LGBTQ advocacy may also be impeded by sociocultural factors such as long standing public policy that is counter to LGBTQ equality, limited community resources, and heteronormative cultural norms (Watson et al., 2010). Moreover, Beyerlein and Hipp (2004) note that factors, such as marital and employment status, may also hinder advocacy efforts as parents may be fearful of negative reactions or repercussions from both spouses and employers. These limitations may prevent individuals from becoming fully invested in change and mobilization efforts (Beyerlein \& Hipp, 2004). 
Glennon (2012) adds that parents often experience anger or fear that they may become targets of anger by others. This anger may come from people representing other groups, including those who do not share similar experiences, religious institutions, adults within schools, other parents of gays and lesbians, and even by some within the gay community (Glennon, 2012). Repeated exposure to hostility, negativity, and rejection may deter some parents from becoming allies. Moreover, parents may instead start to justify the hostility expressed by other community members, sometimes going as far as to advocate against LGBTQ rights (Glennon, 2012).

For some parents of LGBTQ youth, these barriers may be outweighed by the motivation and interest in protecting their child. Being a parent has been found to increase willingness to participate in protest efforts among married individuals, indicating that the role of a parent may be a driving force in future advocacy efforts (Beyerlein $\&$ Hipp, 2004). Vernaglia's (1999) "Parent Loyalty Pathway" to advocacy emphasizes that a strong parent-child relationship may serve as further motivation to advocate on behalf of LGBTQ rights. Therefore, parental identity may help to overcome perceived barriers to advocacy efforts. Additionally, van Zomeren et al. (2008) noted that parents' assessment of the costs and benefits of advocacy efforts are often outweighed by the concerns of the social-identity experience. Parents may, therefore, identify more closely with their social identity, focusing on the benefits for their children, rather then focusing on their individual costs when choosing to participate in advocacy efforts. Potential parent allies must weigh their social identification strength as a parent ally against the challenges of becoming an advocate before continuing on a path towards social justice. What is not yet known in the literature is how parents place weight on these factors based 
on their experiences and background. By inquiring about parent's barriers to advocacy, as well as the role their family and community played in their advocacy efforts, the present study can address this gap in the literature and help to better understand how parents balance these potential barriers with their desire to support their children.

At the community-level, parents may be able to overcome barriers, such as fears and experiences with hostility through group-based supports and advocacy efforts (Glennon, 2012). In a phenomenological research study, Saltzburg (2009) also found that parents were able to find mentorship, community, and information from other likeminded parents through organizations such as Parents and Friends of Lesbians and Gay Men (PFLAG). These groups allow parents to gain a greater sense of pride in both themselves and their children, while also encouraging them to question the status quo (Glennon, 2012). The development and identification of social support systems, such as PFLAG, may contribute to a parent's overall social identity and support a parent as they develop into an advocate. These community-level experiences may outweigh the potential barriers parents encounter as they develop into LGBTQ advocates. Still it is unknown how parents experience these obstacles using individual, family, and community supports. The present study examined what parents find most beneficial in overcoming barriers to advocacy for the LGBTQ community. The findings will highlight the community, family, and individual factors that have helped parents overcome the negative reactions and personal hurdles that they encountered advocating on behalf of LGBTQ issues. Such information deepens our understanding of ways to better support LGBTQ youth and their parents.

\section{Justification for and Significance of the Study}


Previous research about LGBTQ parent advocacy is limited in its scope and understanding of the complex environments parents may encounter as they advocate on behalf of their LGBTQ children. According to Vernaglia (1999), parents may pursue a "Parent Loyalty Pathway" or a "Social Justice Pathway" in an effort to advocate for LGBTQ youth. These pathways are influenced by individual level experiences and personal identities. However, the parent ally literature has yet to explore the individual, family, and community level environments that influence the likelihood of parent advocacy on behalf of LGBTQ youth, as well as the experience of parent allies. Moreover, although these various contexts may influence the development of parent advocates, researchers have yet to explore the way in which parents have changed their relationship with these systems as a result of their advocacy efforts. This study will seek to fill these gaps in the literature by utilizing a qualitative approach to understanding parent advocacy.

The previous literature exploring the experiences of parent allies, although qualitative in nature, was restricted in its exploration of the diverse experiences of parent advocates. For example, Vernaglia (1999) used a phenomenological approach to their inquiry, which limited the scope and level of inquiry. Through this approach, the data derived was less flexible and adaptable to individual differences. This approach prevented the researchers from exploring the complex experiences that parents encountered when advocating on behalf of their children. In order to overcome this gap in previous research, the present study utilized a qualitative descriptive approach. The purpose of qualitative description is to investigate the "who," "what," and "where" questions related to events or experiences (Sandelowski, 2001). According to 
Sandelowski (2001), this may be particularly important when the current theoretical research is unable to provide answers to these questions. In particular, this study seeks to capture the "who" and "what" experiences, motives, and views of parent advocates. In understanding who and what motivates parents to advocate as well as what types of experiences LGBTQ parents encounter, researchers may be better equipped to understand the diverse experiences of parent advocates.

\section{Purpose Statement}

This study utilized an ecological-transactional framework and descriptive interview approach to understand the experiences of parents and the processes of becoming an LGBTQ advocate, as well as the meaning of those experiences at the individual, family, and community level. In particular, this study documents the experiences of heterosexual parents of LGBTQ youth who engage in advocacy for LGBTQ rights.

This study sought to answer three overarching research questions:

1. What aspects of life (e.g., community, family, personal identity) help to initiate and facilitate LGBTQ advocacy-efforts among parents?

2. What aspects of life serve as barriers to initiating and pursuing advocacyrelated efforts among parents of LGBTQ youth?

3. How have parents' views of themselves and their relationships with others (e.g., family, children, and community members) changed throughout their experiences as LGBTQ parent advocates? 


\title{
CHAPTER 3
}

\author{
METHOD
}

\section{Participants}

A total of 12 heterosexual parents of LGBTQ youth participated in semistructured, audiotaped in-person interviews. All parent participants reported advocating for LGBTQ rights and having one child who identified as LGBTQ $(n=12,100 \%)$. The sample included female $(n=7,58.3 \%)$ and male $(n=5,41.7 \%)$ participants. Parents reported ages between $35-44$ years old $(n=2,16.7 \%)$, $45-54$ years old $(n=4,33.3 \%)$, 55-64 years old $(n=4,33.3 \%)$, and $65-74$ years old $(n=2,16.7 \%)$, with a mean age of 54.5. Parents identified their race or ethnicity as White/Caucasian American $(n=12$, $100 \%)$, with one parent who also identified being of Jewish decent $(n=1,8.3 \%)$. In terms of sexual orientation and gender identity, all parents in the study reported identifying as heterosexual/straight and cisgender $(n=12,100 \%)$ and married $(n=12$, $100 \%$ ). A total of 3 dyads or couples were recruited, with each partner interviewed separately. Among the sample, two (16.7\%) reported having one child, eight had two children $(66.7 \%)$, one had three children $(8.3 \%)$, and one had four children $(8.3 \%)$. With respect to their children who identified as LGBTQ, their ages ranged from 13 to $44(M=$ 21.8, $S D=8.16)$. All 12 parents lived in New England. In order to maintain confidentiality, a detailed breakdown of the states from which parents were recruited is not provided.

\section{Measures}


The parent participants in the study responded to 14 demographic and personal background questions and participated in one qualitative interview, about 60 minutes long, using the interview protocol (which contained 19 questions).

Demographic and Personal Background Questionnaire. Parent participants completed a brief demographic questionnaire regarding their age, gender, gender identity, sexual orientation, number of children, race/ethnicity, marital status, and highest level of education (see Appendix A). The questionnaire also obtained information about their child's age, gender identity, sexual orientation, and whether their child identifies as LGBTQ. Parents were also asked to detail their advocacy-related experiences and describe the advocacy groups/organizations they were actively involved in at the time of the interview.

Interview Protocol. The semi-structured interview protocol was based on the descriptive interview approach to qualitative interviews (Sandelowski, 1995). One interview, consisting of 19 questions, was conducted with each parent. Each interview began with an initial prompt, followed by several follow-up questions (Appendix B for the Interview protocol). The interview protocol focused on the individual, family, and community level experiences of parents prior to becoming an advocate and also as an advocate. The questions were informed by a thorough literature review in the topic area and through consultation with the dissertation committee (Cavanagh, 1997; Graneheim \& Lundman, 2004; Krefting, 1991; Lincoln \& Guba, 1985; Shenton, 2003; Sandelowski, 1995).

The interview questions provided insight into the meaning of their advocacy experiences at the individual, family, and community level. More specifically, the 
interview protocol began by asking parents to define the term "advocacy." Parents were then asked eight questions focused on understanding what experiences helped parents to initiate and facilitate their LGBTQ advocacy-efforts. Parents were asked four questions that examined what barriers they encountered initiating and pursuing advocacy-related efforts. Parents were then asked to reflect on whether their view of themselves and their relationships with those in their family and community changed throughout their experiences as an LGBTQ advocate. Finally, at the end of the interview, parents were prompted to provide advice for other parents of LGBTQ youth.

Interviews were later transcribed in their entirety. Participants were invited to review the interview transcript as part of a formal member checking process. Parents were able to clarify ambiguities in their transcript. They were also given time to reflect and add additional information that they deemed important to understanding their experiences as a parent advocate, such as information that was not reviewed in the interview protocol.

\section{Procedure}

This study employed a network sampling approach and a snowball sampling procedure. By using a network sampling approach, the researcher was able to identify parents based on recommendations from people within similar networks. Network sampling allowed policy members and LGBTQ groups to identify parents who felt comfortable sharing their personal experiences as a parent of an LGBTQ youth. To begin the sampling process, the researcher sent recruitment emails to professional contacts (e.g., individuals who the author knows from social justice activities, policy makers that share similar interests, etc.), to LGBTQ advocacy group organizations (e.g., Human 
Rights Campaign, PFLAG), and through LGBT-related LISTSERVS (e.g., the American Psychological Association's Division 44: Society for the Psychological Study of Lesbian, Gay, Bisexual, and Transgender Issues and Division 35: Society for the Psychology of Women ).

The recruitment email described the study's purpose and provided information regarding the researcher (see Appendix C). In addition, the email asked individuals to forward the materials to other programs or organizations that may be relevant. The email noted that interviewees had to a) be parents of LGBTQ, b) be 21 years or older, and c) have participated in LGBTQ advocacy efforts (e.g., actively participated in LGBTQ advocacy group(s), engaged in conversations with educators and teachers about creating a welcoming school/class, took a public stance on marriage equality, or participated in advocacy-related activities).

The advertisement also indicated that parents would receive $\$ 25$ as an expression of gratitude for their interest in the study. Additionally, the email contained a recruitment flyer for LGBTQ organizations to post at their sites (see Appendix D). After parents were identified, a snowball sampling technique was used. Parents were asked to identify other potential individuals that would qualify for the study.

Once parents were recruited, the researcher scheduled a mutually agreed upon time to meet face-to-face with potential parents. At the start of the in-person meeting, the written informed consent was reviewed and signed by the parent participant (see Appendix E). Individuals were also asked to fill out the demographic and personal background questions. Interviews were audio-recorded and lasted about 60 -minutes. The interviews were then transcribed by two undergraduate research assistants. The 
undergraduate research assistants were trained by the lead researcher to transcribe all audio-recorded interviews verbatim. All identifying information was removed to protect the parent's confidentiality. A pseudonym for each parent was also used in the write-up of the transcripts.

Additionally, parents were contacted following the transcription process to review their interview. This incorporated a formal member checking, which allowed parents to provide feedback regarding the accuracy of the transcript. The transcript was initially sent via email. All emails and transmissions were immediately deleted following confirmation from the parent. The participant had the option of participating in an optional follow-up discussion lasting approximately 30-minutes in duration via phone, email, or in-person meeting. A total of six parent participants chose to participate in the follow-up via email. Parents reviewed the transcript and clarified ambiguities within their transcript (e.g., clarifying the dates they participated in specific advocacy organizations). Parents were also given time to reflect and add information they deemed important to the interview process. The data collected in this study was only accessible to the principal investigator and the research team.

The lead researcher trained and mentored the two undergraduate research assistants both before and during the transcription process. The undergraduate research assistants were provided with relevant research literature to help inform the process of transcribing parent interviews. During the transcription process, one undergraduate research assistant was required to listen to each recording and transcribe the interview word-for-word. The second undergraduate research assistant then re-reviewed the interview recording and corresponding data, making edits and changes as needed to 
ensure that each interview was transcribed verbatim. Both research assistants were asked to track their changes, as well as any questions regarding the interviews. The lead researcher later reviewed these notes, along with the interview recordings, to ensure the transcripts reflected what was actually stated in the interview. Ultimately, the recordings and corresponding data were reviewed a total of three times by the research team, twice by an undergraduate research assistant and once by the lead researcher. The transcripts were then re-reviewed by the participant to ensure the appropriate information was obtained and correctly transcribed. Additionally, the undergraduate research assistants were trained in content analysis. The lead researcher mentored the undergraduate coder and provided the coder with research literature focused on content analysis and reflexivity. The undergraduate coder was also encouraged to take notes and ask the lead researcher questions during the coding process. As such, the lead researcher regularly referred back to the research literature and maintained regular contact with faculty mentors to ensure these questions were appropriately answered.

\section{Data Analysis}

The interviews were analyzed using a content analysis approach, a flexible method for analyzing text (Cavanagh, 1997). Content analysis allows for identification of both manifest and latent content, thus allowing for a deeper understanding of individual and group level experiences (Graneheim \& Lundman, 2004). Manifest content is defined as content taken directly from participant interviews, using their own words and language, while latent content refers to the underlying meaning of the text using inferences made by the researchers (Graneheim \& Lundman, 2004). This approach was consistent with Sandelowski's (1995) research recommending content analysis when 
utilizing descriptive interviews as a qualitative methodology. To begin data analysis, the interviewer re-reviewed the transcripts and recordings for accuracy. The research team members, consisting of the lead researcher and two undergraduate research assistants, then reviewed and re-read the transcripts individually to gain a holistic understanding of each interview and the overall data. Team members took notes of their initial impressions during this process. This information was then broken down into smaller meaningful units and codes were developed by each research team member. Interpretation and inconsistencies among codes were discussed among group members. The codes were then reviewed and discussed by the team members until at least $90 \%$ inter-rater agreement was reached.

Once the codes were developed, the information was documented within a codebook, which allowed for increased understanding and future reviewing of the data. The codebook served as an audit trail that included the meaning unit, condensed meaning unit, code, definition, guidelines of using the code, and examples. Quotes representing specific codes and questions were then highlighted word-for-word, directly from each parent's transcript and stated experiences. The application of codes were discussed, reviewed, and revised until 90\% inter-rater agreement was reached. The research team members compared and discussed the codes and their application to each transcript, until complete agreement was reached. This process was then utilized for each transcript, until all were coded and reviewed. The research team consistently referred back to the parent's own words and stories within the transcripts, staying as close to the data as possible. As the team members reviewed the transcripts, they also paid particular attention to the sequence and correspondence of responses, as well as the similarities and differences 
among parent responses. This helped to identify developing categories within the data. As such, appropriate quotes were selected among the transcripts to represent various categories.

Throughout this process, the research team (consisting of the lead researcher and at least one undergraduate research assistant) reflected on potential biases, beliefs, and values that may have effected the overall interpretation of the data. During regular research meetings, team members were encouraged to have ongoing discussions related to reflexivity, a process of attending to the construction of knowledge and the effect of the researcher on the data (Barry, Britten, Barbar, Bradley, \& Stevenson, 1999).

Trustworthiness. A critical component of qualitative research is the verification of trustworthiness (Graneheim \& Lundman, 2004). Credibility was established through the use of peer debriefing during the data collection and analysis process. In addition to peer debriefing, the researcher also engaged in referential adequacy, whereby the interpretation of the data was tested by reference to archived materials (Krefting, 1991; Lincoln \& Guba, 1985). A tape recorder was used to document the interview. Furthermore, the researcher engaged in member checks with the parents following the transcriptions (Krefting, 1991; Lincoln \& Guba, 1985). This provided the interviewee with an opportunity to add any additional information that may be helpful in the analysis and interpretation process (Lincoln \& Guba, 1985; Shenton, 2003). By utilizing member checks and referential adequacy, the researcher worked to ensure that the information is presented in a manner that represents the interviewee's true experience through their own words.

The researcher ensured dependability through the use of a qualitative research 
team, which established appropriate inter-rater reliability (Guba, 1981; Lincoln \& Guba, 1986; Shenton, 2003). Team members documented agreed-upon codes and categories. Any alterations or decisions were documented appropriately. In order to establish transferability, the selection criteria, culture, and content of the research methodology and analysis were clearly defined to allow for future replication. Finally, to establish confirmability, reflexivity was practiced throughout the pre-implementation, data collection, and analysis process. The researcher worked to identify ways in which her own assumptions impacted her understanding of the data. This process was also incorporated into all research team meetings and peer debriefings (Guba, 1981). A confirmability audit trail was also utilized during the course of this study (Guba, 1981; Shenton, 2003). The audit trail was created and updated weekly during the data analysis process by an undergraduate research team member. 


\section{CHAPTER 3}

\section{RESULTS}

\section{Demographic and Contextual Data}

The parents provided demographic and personal background information concerning their (a) highest level of education, (b) their child's gender identity, and (c) their child's sexual orientation. They were asked to (d) detail their advocacy-related experiences, as well as (e) the advocacy groups and/organizations they were actively involved in at the time of the interview. As shown in Table 1, there was variability in the highest level of education they reported.

Table 1

Parents' Highest Level of Education

\begin{tabular}{lcc}
\hline Highest Degree & $n$ & $\%$ \\
\hline Master's degree & 6 & $50 \%$ \\
Bachelor's degree & 4 & $33.3 \%$ \\
Some college, but no degree & 1 & $8.3 \%$ \\
Associate's degree & 1 & $8.3 \%$ \\
\hline
\end{tabular}

Note: $\mathrm{N}=12$.

Table 2 provides a breakdown of the gender identity and sexual orientation background of the parents' children. It is important to note that some parents were unaware of their child's current sexual orientation and/or gender identity given the fluid and ever changing nature of identities and terminology. Parents did their best to respond 
appropriately given the information provided by their children.

Table 2

Gender Identity and Sexual Orientation of Parents' Children

\begin{tabular}{lcc}
\hline Child's Gender Identity & $n$ & $\%$ \\
\hline Transgender male & 6 & $50 \%$ \\
Cisgender male & 3 & $25 \%$ \\
Cisgender female & 1 & $8.3 \%$ \\
Non-binary & 1 & $8.3 \%$ \\
Gender-fluid & 1 & $8.3 \%$ \\
\hline
\end{tabular}

Child's Sexual Orientation

\begin{tabular}{lcc}
\hline Gay & 4 & $33.3 \%$ \\
Lesbian & 2 & $16.7 \%$ \\
Pansexual & 2 & $16.7 \%$ \\
Queer & 1 & $8.3 \%$ \\
Fluid & 1 & $8.3 \%$ \\
Straight & 1 & $8.3 \%$ \\
Unknown & 1 & $8.3 \%$ \\
\hline
\end{tabular}

Note: $\mathrm{N}=12$.

Table 3 provides a breakdown of parents' involvement in local advocacy groups and organizations. On average, parents reported participating in multiple advocacy 
groups and organizations $(M=2.16, S D=.83)$. More specifically, most parents $(n=11$, 91.79\%) reported being actively involved in their local PFLAG organization.

Table 3

Involvement in Advocacy Groups/Organizations

\begin{tabular}{lcc}
\hline Advocacy Groups & $n$ & $\%$ \\
\hline Local PFLAG organization & 11 & $91.7 \%$ \\
Local LGBTQ equality organization & 5 & $41.7 \%$ \\
Transgender rights organization & 3 & $25 \%$ \\
Non-LGBTQ advocacy group & 3 & $25 \%$ \\
\hline
\end{tabular}

Note: Total does not equal $12(100 \%)$ because some parents reported more than one response category.

In regards to the type of advocacy involvement, parents reported a number of experiences, which most often included facilitating parents groups and lobbying for legislation. On average, they engaged in more than two types of advocacy-related experience $(M=2.58, S D=.90)$. Table 4 details their advocacy-related experiences. Table 4

Advocacy-Related Experiences

Types of Experiences $\quad n \quad \%$

Parent group facilitator

Lobbying for legislation
11

8
$91.7 \%$

$66.7 \%$ 
Organizing and outreach

Writing and/or blogging

Consulting and speaking engagements

Fundraising

Marching in the local pride parade

Organization leadership

Sharing of experiences

Note: Total does not equal $12(100 \%)$ because some parents reported more than one response category.

\section{Interview Findings}

The results of the interview findings are organized around three research questions. For each research question, descriptive tables are utilized to summarize the findings by categories developed from the parent responses. Prior to responding to the three research questions, parents were asked to define the term "advocacy." Their answers fell into six categories, as detailed in Table 5.

\section{Table 5}

What does the word "advocacy" mean to you?

Categories $n(\%)$


Note: Total does not equal $12(100 \%)$ because some parents reported more than one response category.

Acting towards change. The majority of parents indicated that advocacy meant acting towards change. This included the efforts made to change people's attitudes and make the world a better place. One parent spoke directly about efforts to change legislation:

But the end goal is to get the law passed and to result in people's lives making a lot more sense, being more comfortable, people being free to be who they are in a safe and comfortable way.

Other parents stressed the importance of acting towards change to better their children. For instance, one parent noted that advocacy meant "trying to make a better future for my son." Another parent explained the importance of advocating for their child at school: "It means proactively working with his school and his teachers to make sure that his space there is safe and to make sure that it's supportive."

Equal rights. Parents also described equal rights as a core component of advocacy. For example, one parent noted that access to equal rights would support both their son and other LGBTQ children. She explained that advocacy consisted of fighting for "equal rights so that my kid and other kids like my kid will be safe in the world." Similarly, another parent explained how his advocacy included both equal rights for his 
gay son, as well as equal rights for other communities:

So, in the case of my son, it's advocating for equal rights for him and anyone else in a similar situation. I work with blind people, so in the case of blind people it'd be also advocating for, you know, just equal rights that people are treated the same...that sort of thing. So basically getting so that we all can live the same life; we can all have the same opportunities and potential.

Recognizing marginalized groups. Five of the parents reported that advocacy

involved recognizing the experience of marginalized groups. In order to advocate, parents described the need to first recognize when inequality existed for a marginalized group. One parent explained the importance of recognizing the "underdog:"

I always think that you have to stick up for the underdog. Many people can't advocate for themselves. In other words, they can't stick up for themselves, they can't stand up for themselves, and they need someone to do that for them. Either because they're just - either physically or mentally not capable, or they're, you know, kind of a shy type of person, or they don't know how to work the system.

Supportive and Accepting Allies. Some parents described the term "advocacy"

as being an accepting ally, who is able to provide social and emotional support for others.

One parent explained how being supportive serves as a foundation for becoming an advocate by stating "You can be an advocate and you don't necessarily have to do a lot of work, you can just say, 'I'm an advocate, I support.' Almost using the word for support." Another parent discussed what it meant to be an advocate for the LGBTQ community by saying "Simply being an ally — and certainly in the case of LGBTQ, I think about it in terms of ally."

Standing by your beliefs. Four parents expressed the importance of standing by your beliefs and values as an advocate. One parent described their approach to valuesbased advocacy as "It means standing strong on your beliefs and not being swayed or intimidated by resistance so advocacy mainly involves, you know, standing your ground; 
I think that's it." Another parent explained how her political beliefs guided her advocacy efforts:

The other part of it is it's the right thing to do. It's the right thing to help someone else out, especially when you think that what is against them shouldn't be. And being a very extremely liberal Democrat, that's what Democrats do. That's what we do.

Education. Two parents stated that advocacy entailed educating other people.

One parent noted the importance of dispelling myths and providing accurate information:

So you might share information on myths about a particular thing, probably pertinent to our topic today, say for example, the idea that there's no such thing as being transgender, it's, you know - the chromosomes tell the whole story. Well, talk to a biologist or a doctor. Chromosomes haven't ever told the whole story and they're really not your gender identity anyway...But sharing information like that might be a daily activity around advocacy, or educating about a law that's about to be passed and what the real effects of it that could be harmful, it could be, or what the real effects of it that are desired could be.

Research question \#1: What aspects of life (e.g., community, family, personal identity) help to initiate and facilitate LGBTQ advocacy-efforts among parents?

To answer this research question, parents were asked, "Can you identify what influenced you to become an LGBTQ advocate?" Table 6 provides a breakdown of parent responses into six categories.

Table 6

Can you identify what influenced you to become an LGBTQ advocate?

Categories n $n(\%)$

Learning from the community (e.g., the LGBTQ community, $10(91.7 \%)$ professional resources, witnessing or experiencing injustice)

Doing advocacy before child came out 

out')

Note: Total does not equal $12(100 \%)$ because some parents reported more than one response category.

Learning from the community. Ten parents reported that learning from the community influenced their decision to become an advocate for the LGBTQ community. One parent described how joining their local PFLAG chapter provided the support they needed to start advocating at a legislative level:

Belonging to this PFLAG parent support group that I joined just a couple of weeks after my kid came out actually and many of the parents who at that time were peer facilitators were people whose kids had come out some years earlier and they were older, they were farther along their journeys. And there was a-you know and they were doing sort of political lobbying for the Transgender Equal Rights bill back in the day, four or five years ago when the first bill was passed. And so they were role models for me in terms of getting involved, so it was like, "Oh come to the state house with us," and I'm like, "Okay, I don't know," or like, "I've never talked to any legislatures, that sounds scary". Anyway, turns out they're just people too.

Another parent explained how finding community support was only the first part of their journey as an advocate:

So, it's really not that rare and what I noticed was that all of the people who were at these meetings were very nice, wonderful, dedicated people and they were all normal people like your family, your neighbors, your friends, and that made me a lot more comfortable and it was a good way to hear other people's story, take 
comfort from them, learn and, you know the first step in advocacy is education. So that's really was my path in.

Parents also reported learning from the community after witnessing others being discriminated against or encountering barriers related to access to care. One parent advocate stated that witnessing inequality when she was younger propelled her into becoming an advocate later in life:

Growing up in New York in the city, and growing up in the 1950's, when things were very different than they are now, I was always aware of how people who were in any kind of minority were treated differently and how people lived in neighborhoods and they were very insular and I never understood that. Even as a kid I just never got that and so I guess I was always out there and different. And I always said to myself, "That's not the way it should be." So it started that way and then - and then I grew up in a neighborhood not being like anyone else so that also, you know, it was personal really.

Doing advocacy before child came out. Other parent advocates indicated that they participated in advocacy-efforts before their child came out. They reported that for them it was only natural to continue their advocacy work with a focus on LGBTQ equality. One parent explained that before becoming a parent advocate, she chose to engage in LGBTQ advocacy as a teacher at her local school:

And so, being a parent advocate came far later than being just a generic advocate because at that time I didn't have any kids. So, you know, it was actually after I was doing the advocacy work that my daughter came out to me as a lesbian.

Another parent added that advocacy is a skill that she developed after supporting her older child in the schools. She noted that this helped her to later advocate on behalf of LGBTQ issues:

Now, I have to tell you I had to advocate big time for my third child, so I knew how to do it because I think it's a skill....and so I was able to like, because theythe school knew me as an advocate and were good with me then they allowed me to sort of change everything for this child.

Wanting to support and protect. Parents also reported that their need to support 
and protect their child influenced their decision to become an advocate. Parents explained that they felt it was their natural instinct as a parent to want to protect their child:

But my son - when my son informed me that he was part of this LGBTQ community, what does a parent do? Some parents say "Well that's the end of it" which I think is - I can't even imagine that. And then it's "Okay, how do I help him? What do I do for him? How do I keep him safe? How do I make sure that the world is lined up so that he's not discriminated against?" So it just was natural as a parent to take care of your child. I mean, you don't even think about that.

Other parents discussed how their need to protect their child's privacy influenced how and when they decided to become advocates. One parent explained, “And although we certainly have told family and friends since then, at first we didn't have anyone else to talk to, it was just the two of us."

Recognizing a need. Prior to advocating on behalf of the LGBTQ community, parents reported recognizing a need in their community. This often included a feeling of responsibility to give back to the community that supported their family through the 'coming out' process. One parent explained that after receiving support through a local LGBTQ organization, he began to recognize a greater need for education within his community:

Then I saw how many families there were and how a lot of these kids are struggling and just how much education needs to be-get out there...And so, there was a need. There was a need and there was a venue to help.

After recognizing the need for change, parents were often motivated by the hope that they could usher in positive change for both the LGBTQ community and for their children.

For parents, advocacy meant the potential to make a positive impact for their children and others. One parent reported 'I felt like, I don't know, maybe it's my way of trying to help my child by making it a better world for him as he grows up."

Speaking up for what you believe. Consistent with the parents' definitions of 
advocacy, several parents reported feeling obligated to stand up for their beliefs:

And not just him, but transg - it's not just and it's not just transgender or LGBT, it's what I think is fair. What I think is, you know, the best of American ideals are invite like, you know, any religion who wants to be here-fine, you know. Any sexual orientation - fine. Not bothering anyone else kind of thing, you know. And there are a lot of political and other types of forces that are pushing against what I believe in, and I strongly believe in that.

Another parent reported that as a child he was encouraged to stand up for his beliefs, even when others didn't agree by stating:

I've grown up in a family where we did believe it was important to speak up and if that creates a better understanding, wonderful, if it sometimes creates some discomfort, that's okay, sometimes conflict is needed to get through something.

\section{Emotional processing following their child's 'coming out.' Four parents}

discussed the ways in which they processed their child's 'coming out.' One parent noted that his ability to process his child's 'coming out' became easier over time:

The first few PFLAG meetings my wife would do nothing but cry half the time; she couldn't really speak. So I would do all the talking for both of us. But then those feelings, you know, quickly dissipate and what seemed abnormal and strange in terms of the adjustment felt normal for the first time.

Miscellaneous. One parent replied in a way that did not fit into any other response category. However, their contribution provides a greater understanding of how advocacy grows over time. She noted, "So, it was because our son came out that I started to join PFLAG and then, you know, mushrooms..." The researcher clarified, "mushrooms?" She added, "Mushroom—well then it just kind of gets bigger and bigger."

In addition to asking parents what influenced their decision to become advocates, parent participants were asked four follow-up prompts. The first probe asked parents to describe how their relationship with their child, who identifies as LGBTQ, influenced their decision to become an advocate. Only 11 of the 12 parents were given this prompt, 
as one parent discussed his relationship with his child during the initial question. A total of six categories emerged from parent responses. These categories are detailed in Table 7.

Table 7

Has your relationship with your child (who identifies as LGBTQ) influenced your decision to become an advocate?

Categories $n(\%)$

Showing support

$7(63.6 \%)$

We are on this journey together

$6(54.5 \%)$

The relationship aids in advocacy efforts

$4(36.4 \%)$

Respecting their child's needs

"Doing it for myself"

Miscellaneous (e.g., changed support to specific advocacy)

$3(27.3 \%)$

Note: Total does not equal $11(100 \%)$ because some parents reported more than one response category.

Showing support. Consistent with the initial question, a majority of parents reported wanting to support and protect their child:

I mean it's kind of basic like, you know, he's my child and pretty much I-from the moment he was - existed, my commitment to him has always been to advocate for him and to support him and to, you know, stand behind him and instill, you know, values in him that will make him a productive and happy adult and really - it's not necessarily exactly about my relationship with my son, it's my relationship with a child so I would do this for any child of mine and I would advocate for any...you know for any child but specifically there's a really special parental - to me it's like an instinct and drive to protect and support you know, your children to be their true selves. 
We are on this journey together. Six parents also reported that they are learning and growing alongside their child. One parent described how their relationship with their child influenced their experiences:

Well I have a very positive relationship with my kid. I think they're fantastic and they-they actually enjoy spending time with me, which I'm very lucky about. And I feel-when they-you know when they first came out it felt, I guess it felt good to be-that we were on this journey together. And it's a journey for-for a parent of the trans kid, it's definitely a journey for the parents as well as for the kid.

The relationship aids in advocacy efforts. Several parents reported that their

relationship with their child helped them to become better advocates:

My relationship with my daughter is actually a very useful thing to talk about when we're having PFLAG support group meetings and, you know, people have questions and I have information from her-things that she has told me - that I can share with the group that is helpful to the parents who are coming to the group. So, it has been useful as an advocate to have her background, so to speak.

Another parent noted that their child gave them courage to face their fears:

And I feel like-and it's-the world is scary for trans people and for parents of trans people (laughs) so I think my caring for my kid really helps me to overcome my fears of how scary senators might be in order to, you know, advocate for-for their rights.

Doing it for myself. Three parents reported that their advocacy has been a way to find support and connections they wouldn't have otherwise. These parents noted that their advocacy efforts were mostly independent of their relationship with their child. One parent indicated that advocacy for the LGBTQ had become a personal passion that had been previously missing:

For me, I had been looking at any way for something to do that I was passionate about to give back. I was reaching a stage of life before my kid came out that that was kind of on my mind, it was on my bucket list, you know, I haven't really done much besides writing a check when somebody said, "Hey, I'm walking for cancer," or, "I'm riding for ALS,"...but I was never personally invested in something that, you know, meant something to general society and I wanted to 
be....And so this was my-it was like an Aha, it was like a perfect opportunity it's probably a few months after he first came out as gay and before he came out as gender queer and eventually transgender where I was like working out on my treadmill and I said, "Of course! I've got to get involved in LGBT support and advocacy in some way." This is my thing; this is going to be my thing because I'm passionate about it.

Another parent stressed the importance of advocacy for her own benefit:

But I also needed to make connections with that community because it was important to me. So it was - in some ways it was helping myself. So, I feel like I'm doing it for myself, not for him, even though I say (laughs) that I'm doing it for him...but it's really for me.

Later she added,

So I'm kind of going back to thinking well, if my child asked me not to be an advocate, I would have to say, "Well, this is important for me because I get support knowing there are other parents out there. I'm struggling being the parent of a transgender child, I need support."

Respecting their child's needs. For some parents, the responsibility of respecting their child's needs and privacy influenced their decision to become advocates. One parent explained, “And that was hard, actually, at times because he didn't want any publicity, he just wanted to - he's basically living stealth at this point and so he, so I had to sort of respect his needs." Another parent noted that their child was sometimes annoyed by their perceived over-involvement in advocacy-related activities. They noted, "And sometimes he says, 'Well, do you have to be so much as an advocate?"'

Miscellaneous. Three parents provided responses that did directly respond to the question. Two parents reported that their advocacy efforts changed to a more narrow focus for the transgender community after their child 'came out'. One parent discussed how his interest in LGBTQ rights morphed into an increased focus on transgender issues after his child 'came out':

It's a little more targeted and a little more in-depth. For example, you know, at the 
drop of a hat now I can produce PFLAG media guidelines on terminology and if somebody's other than, you know, an educated researcher...like if just some reporter is interviewing me I can say, "Hey listen," you know, "As you're writing about what you're asking me about, you know, you may consider that - these

guidelines"... Like I wouldn't have had that just handy a year ago, and now I do.

Other parents discussed issues and personal experiences that were not related to the initial prompt. For example, one parent discussed her child's 'coming out' process:

Unfortunately for him, when he four - just turning fourteen, like within a couple of days of his birthday, I was diagnosed with cancer and he said, "I can't tell them," and he waited two years before he told me. So, but, you know, what do you say to a kid when they tell you? If he said he was gay, I'd say, "Okay, great," if he said he was purple, I'd say, "Okay, great."

Another parent detailed her motivation to support her other LGBTQ children:

And other people's children are just as awesome so they need to be supported also. So yes, I know you can shut the door, kick them out, and say I'll never speak to you again, but that's not gonna be me.

The second prompt asked parents to identify how other family members have influenced their decision to become an advocate. A total of six categories were identified. Table 8 provides a breakdown of parent responses.

Table 8

What about your other family members? How have they influenced your decision to become an advocate?

Categories n $\quad n$ (\%)

Supportive and beyond supportive

$10(83.3 \%)$

Role of spouse and immediate family

$6(50 \%)$

Invalidation and non-acceptance

$4(33.3 \%)$

Miscellaneous

$4(33.3 \%)$ 
Note: Total does not equal $12(100 \%)$ because some parents reported more than one response category.

Supportive or beyond supportive. A majority of parents indicated that their family members were supportive or beyond supportive of their advocacy over time. One parent explained how her husband and daughters were supportive, but did not have as much interest in advocacy. She stated, "My husband just kind of goes along with whatever I'm doing I guess...He doesn't quite understand it but that's okay. And the girls - they support." One parent explained how her mother and extended family gradually become more informed and more supportive of her son's transition, as well as her advocacy efforts. She explained that after expressing herself through poetry her family became more understanding:

My mother for example, like, she witnessed my life like, and she was so nasty and then she was always invalidating, you know, whatever. Not only my mother but just like everyone, even if they were polite, they were invalidating and horrible and then when they read the poems they were like okay I get it, okay, that's it. I was like, what, like why would it take a poem for you to come around. But, it did.

Conversely, other parents noted how their family members helped them to become more involved in advocacy efforts. One parent expressed, "my wife was initially more of the promoting advocacy and I sort of followed up on her coat tails and started getting involved in some things... and now I'd say I'm more of an advocate in my own right."

Role of the spouse and immediate family. Half of the parents in the study reported that their relationship with their spouse and immediate family members played a 
vital role in helping to create a supportive and caring environment. This positive family environment fostered their development as an advocate. One parent discussed the role his wife played in promoting his development as an advocate:

Well, you know, we'd go to meetings - it was something we did together...A lot of times in these meetings you see couples come in, and sometimes there's not as many dads as we would like to see. And in fact, we're starting a new group for dads, and I'm one of the organizers of that...in order to make it more comfortable. Sometimes, I think it's, you know, I think it took me a little longer than my wife to become, you know, fully accepting and, you know, understanding, including occasionally giving myself permission not to understand everything.

Invalidation and non-acceptance. Some parents reported experiencing invalidation from family members, as well as a lack of acceptance based on either their advocacy-efforts and/or their child's identity. One parent described her experience with family rejection, noting that they did not influence her decision to become an advocate:

We have really great friends, most of whom we've met really through this community, but in terms of blood relations, my family and - we have not seen each other coming up on almost four years. [My child] has grandparents who have rejected him, and part of it, and I so they didn't influence me to become an advocate at all because they just don't get it.

Another parent discussed how her experience with invalidating family members motivates her to address the invalidating when it occurs:

So for example, if you know, we have like an older-generation relative who, you know, doesn't really understand it really but loves their grandchild and wants to support them, but doesn't make the transition like with the pronouns. So if the grandparent a year later is still saying 'she' you know, on a regular basis instead of 'he'-not intentionally but there hasn't also necessarily been the intentional work on their part to not make that mistake. So my advocacy in that role is to not let it go, to correct it, to you know, point it out because I feel like every time someone uses the wrong pronoun, and it's I would say it's like $99 \%$ of the time not intentional, but if I let that go and I don't correct them then I just didn't advocate for my child, like I didn't stand up for who he is. Even though I'm not fighting against someone who's resisting necessarily but I'm also not challenging them to like - to get there.

Miscellaneous. One parent did not provide a direct response to the question. This 
parent described uncertainty over his family's influence as he recalled an experience from his past:

My short answer is I'm not sure if they did. The reason I say that is that when I was the teenager I mentioned that I had a friend that was gay and I had a friend that was bisexual. Now, so I was probably 16,17 at the time when I first learned from the friend who was bisexual that he was bisexual, he told me that he was. And, I don't know that I necessarily understood what that term meant probably. But he explained to me and that was fine and I was like "Okay, no big deal," you know, and I said "Just for the record," I said "I am not; I am straight." And he said "Yep, of course, no problem" and we continued to be friends. I shared with one of my grandmothers some months later the fact that this friend of mine was bisexual. I didn't think anything of it; again it was nothing special in my opinion. My grandmother shares that information with my parents and long story short my father basically calls me having learned the news and says "while you're living under my roof you will not see your friend anymore. I'm not having you see someone who is bisexual."

Three other parents described factors unrelated to the prompt. For example, one parent discussed the role of the church in their decision to become an advocate:

Later, I got involved after same sex marriage was legal here in [STATE]...But during the time that there was a campaign to have a vote to repeal it. And so, I'd say early 90 s, but I'm not exactly sure what years. Somebody from [Local Equality Organization] called our church and said can we do a signature drive at your church, can we come and bring petitions and have people sign. And I said, well yeah, we're having a gender free square dance Saturday night, why don't you come and have a table at our gender free square dance and we'll encourage people to come sign the petitions. And from then, we worked at it for about three years or so, and that was a big focus of our welcoming congregation committee work. And, I think I stopped doing that in about 2005, maybe.

Experiences related to 'coming out.' Processing a 'child's coming' out appeared to be a reoccurring category within question two and its prompts. Parents reported that family members impacted the ways in which they processed their child's 'coming out.' These experiences influenced their eventual decision to participate in LGBTQ advocacy efforts. For example, one parent noted that her daughter encouraged her to use poetry as a way to cope: 
I was like even afraid to write it 'cause if I wrote it, it would be real, and then it would might happen, like it was like my nightmare. But, my daughter was like very supportive, she's like, you just need to like write - witness what there isand when he grows up and he's trans, then he will know that's how he's always been, and that's who he is and you just witnessing for him, and I thought that was very powerful.

No impact. Two parents reported that their family did not influence their decision to advocate. One parent explained, “I don't really feel like they've played into it that much. I guess they haven't gotten in the way of my being an advocate." Similarly, the second parent noted, "I think it helps that I have their support, but again, I'm doing something to take care of myself and (laughs) and I would do it no matter what they thought."

The third prompt asked parents to discuss how their relationship with those in the community influenced their decision to become an advocate. Table 9 provides a breakdown of parent responses.

\section{Table 9}

How has your relationship with others in your community influenced your decision to become an advocate?

Categories $n(\%)$

Community connections

Note: Total does not equal $12(100 \%)$ because some parents reported more than one 
response category.

Community connections. A majority of parents indicated that being connected to the community, both the LGBTQ community and the larger community, impacted their decision to become an advocate. A number of parents reported that some of their first exposures to advocacy involved 'coming out' and connecting to others in the community.

One parent explained this 'coming out' process:

So, I had to advocate every day. Every day I had to go to school and corner every mother and say, you know, my daughter identifies as a boy. I don't know, that's just how it is. I went to every single party, I told every single mother. I have never left my son on the soccer field alone. I, like, you know, I went to every party, I was there at every party and I was like that's my kid and so, for [my child's] safety, like, I was like, I mean, so that they know. And so that was the first and last, and then he was like, you know, he can't go to parties, like he...he can't go to girls' parties, like he's not going. And so, I had to explain that he identified as a boy. But I had to like talk to every parent and... bond with them like, truly.

One parent discussed the role her local PFLAG played in becoming more active:

I guess, you know, I feel like the real influences were the parents in this PFLAG group and they, you know, I did feel like belonging to that community was, was very important to me when my kid first came out because-because I really needed support and it was awesome to be in a group of people who were either going through or had been through that experience because it's an unusual experience (laughs). It's just not everybody on your block who's been a parent of a trans kid so - and there are a lot of feelings involved so they really helped to normalize that and-so being a part of that community to sort of go through that process was really important to me.

Community Climate and Culture. Parents also discussed how their community

climate and culture helped to share their advocacy efforts. Some parents identified a need for change within their community, whether it be a need for leadership or a need for a more inclusive environment. One parent explained how she realized the importance of creating an open and welcoming community while on a walk with her son:

Well, maybe one thing is that I remember walking down the street, with my son soon after he transitioned, and he was uncomfortable with - he had a friend, good 
friend from during high school, and the friend's mother was walking down the street and he was afraid to encounter that person. And, I don't want him to be uncomfortable.

Conversely, a few parents expressed living in a community that was welcoming of

LGBTQ children and families helped their development as an advocate. One parent explained that the community created a positive environment for her to feel comfortable advocating on her child's behalf:

Yes, I think it has. A lot of other people in my community, whether it's the school community, neighborhood community, my community of friends. There's a pretty immediate and pervasive acceptance and like love of my son and that just made advocacy so much easier 'cause you had this whole swarm of people behind you whereas if you're advocating sort of against the tide and see how that would be even more important but equally if not as hard to reach people - to feel like you're reaching people. And I feel like immediately with our community I was reaching people and they were responding so positively that it kind of lit the fire to do things, you know.

Working together. Four parents discussed working and educating those within

their community. One parent described how becoming an advocate and educator created positive working relationships:

The next thing you know, I've got people who weren't interested, interested...in learning more and then you can tell a subtle difference in their respect for me in the way they work with me and the way, you know, the way they see me.

Another parent emphasized the importance of initiating an open dialogue in order to maintain his friendships and bridge a sense of understanding:

And by, you know, talking about it with some passion and interest and most importantly, some understanding. So, my relationship with him, that I know I love him I know I accept him no matter what, I hope he feels great about me and yet we have completely different understandings of the world, so why don't we share our understandings. And I- to me that counts as advocacy.

Miscellaneous. Two parents replied with experiences that did not fit into any other response category. For example, one parent discussed reaching out to a former 
friend for advice following their 'child's coming out,' but not receiving a response:

You know, it's-I do have, as I've said, friends who are gay, you know I actually mentioned to them when my son came out-I kind of - I called this one friend of mine, actually the one from high school who was gay and I called and left a message and I said I wanted to speak to him and he didn't respond to the message interestingly enough, just saying "Hey, you know, my son just came out as being gay and I was wondering if I could just kind of speak to you I'm just kind of curious to know a couple things." I didn't hear back from him.

The second parent discussed how living in a diverse family transformed her perspective:

Well, interestingly, through, you know, you'd say anything that's unusual, you'd say to yourself "Perhaps this is not a blessing to be in my family, to deal with something out-of-the-ordinary." In some ways it has been, I mean I've certainly learned a lot, I've become much more accepting, I've become much more understanding, and I think it's helped me in that way. So, it's had a positive effect on me.

The final prompt for question two asked parents to describe their experiences with discrimination and isolation, and whether those experiences influenced their decision to become an advocate. Table 10 details the parent responses.

Table 10

Had you experienced discrimination or isolation in your life? Was that before you become an advocate? Did that come later? Do you think those experiences influenced you being an advocate now?

Categories n $n(\%)$

Self-awareness

$7(53.8 \%)$

Yes, it has an impact

$6(50 \%)$

Little to no influence

History of witnessing discrimination

$3(25 \%)$ 
Note: Total does not equal $12(100 \%)$ because some parents reported more than one response category.

Self-awareness. A majority of parents described experiencing a greater sense of self-awareness following their experiences with discrimination and isolation. They reported experiencing greater empathy and recognition of their own privileges. One father reflected on his perception of gender norms. By recognizing these norms, he became motivated to start a father's support group in order to reduce the cultural and societal expectations placed on fathers of LGBTQ youth.

I think that, you know, that amount of discrimination I think is also motivation for...you know it's like saying get the men together and you say "It's okay to be sensitive, it's okay to be yourself. You're actually a stronger person if you, you know, are not," don't have this veneer of...cultural, you know, imprinted stuff, you know. So, that's part of the motivation really.

One parent reported that witnessing his own child's courage, in spite of the potential for discrimination, resulted in greater sense of self-awareness:

This person can have so much courage to look in the mirror and say, "What I see in that mirror, what other people see is commonly referred to as this, but that's not who I am, that's not who I feel. I'm going to dress different; I'm going to try everything I can to convince people to look at me differently and live differently and be authentic about that in the face of ungodly and sometimes true violence." You know, ungodly rejection, violence by society, all that. If she can have that kind of courage, I can certainly examine myself...once in a while and say, you know, "Are you living the way you wanted to live when you were 19 years old? Is this the 54 year old you envisioned yourself to be?" Yeah so it has, it's been an odd kind of backwards journey having a trans kid.

Yes, it has an impact. Half of the parents reported that their experiences with discrimination and isolation had an impact on their decision to become an advocate. One parent explained how her experiences helped her to become more empathetic to others: 
I think when I was newly out of college I felt isolated, not connected, it was-I was single and the work, yeah I was used to being at school all my life and you meet friends through school, but then meeting friends through work didn't always-I was in engineering and so it was a lot of men who were married (laughs) and older. It just-yeah, so it was, I didn't really know where to reach out. So I would say I felt isolated. I felt discriminated as a woman in science and engineering or just a woman in our society growing up...I think it helps me be empathetic to what somebody else might be going through.

Little to no influence. Five parents reported that they had few, if any experiences with isolation and discrimination. Further, these parents reported that their experiences with discrimination and isolation played little to no influence in their decision to become an advocate. One parent tried to recall potential experiences where he might have encountered discrimination:

No, I haven't. I have to say that, you know, I've-while we do occasionally get a parent or two that will come to PFLAG who is struggling with their child coming out as whatever in the way I imagined my father would have done if I had been gay, let's say. Most of the time, I tend to find it is simply not an issue for anybody.

History of witnessing discrimination. Some parents described witnessing discrimination in the past, often times amongst peers and colleagues. One parent recalled instances in which they chose to address the behavior they witnessed:

If I hear someone kind of start talking about gay people or whatever, I generally tell them my son's gay before it goes any further. And I always tell them, I say "Listen, I think you're a great friend and I don't expect for a minute you would have said anything but I would hate for you to have said something that would be derogatory about a gay person and for you then to learn that my son is gay and then feel bad about that because I know you're not that sort of person." And people have generally taken that - I say generally_people have unanimously have taken it well so that's never been a bad thing.

Miscellaneous. One parent replied in a way that did not fit into any other response category. They described fearing negative reactions from their family and friends after 'coming out', but instead finding both welcoming and supportive responses: 
Like we tell friends and we always like - there's always this sense of 'oh my god I wonder how someone's gonna react and then you tell them and they just totally surprise you. I was in the UK just two weeks ago and I was - I told myself that I was gonna tell my father about my son. I planned to several times before and I never could bring myself to do it. And I couldn't do it then, couldn't do it. So in the end I emailed my father and basically just said "Hey here's something I've been meaning to tell you for a long time so here it is: your grandson [my child] is gay." And you know, I felt more bad that I hadn't told him than anything else. My father called me within five minutes of me sending that email saying "Hey, you know," he said, "please, you know, let [my child] know that we love him unconditionally and you know, we're so proud of him for being so courageous to come out" and stuff. Not the reaction I was expecting. It was certainly the reaction I had hoped for and that was great and everything.

He continued,

I told my brother while I was in the UK and he was like, "Really? Why didn't you tell me already?" I was like "Well, you know, [my child] hadn't come out to everybody so, you know, I don't wanna be the one to kind of bring him out of the closet if he-you know, it's at his pace." But any friends that we've told, everyone's been like, you know, they almost don't care what you say. It's likeand again I think part of it's being here in [our state], the state's of course more liberal than most and socially we're, I think as a state, more forward looking than others. There's certainly room for improvement, but by and large I haven't come across anyone that has been discriminatory. No one has said anything bad.

Sometimes we'll tell people that my son is gay if we start hearing them-no one has said an inappropriate joke about a gay person that I've heard in recent years. Now when I was younger, it would have been perfectly acceptable socially to tell a joke about a gay person. That was just the way it was. I wouldn't dream of telling those jokes today, but when I was in my teens there was absolutely nothing wrong with that, you know.

The third interview question asked parents what experiences facilitated their continued involvement in LGBTQ advocacy efforts. Table 11 provides a breakdown of their responses.

Table 11

Once you became an advocate, what experiences facilitated your continued involvement in LGBTQ advocacy efforts?

Categories $n(\%)$


Seeing the need for change

$6(50 \%)$

Community support

$5(41.7 \%)$

Impacting others

$5(41.7 \%)$

Strength and knowledge

$5(41.7 \%)$

Positive outcomes

$4(33.3 \%)$

Miscellaneous

$1(8.3 \%)$

Note: Total does not equal $12(100 \%)$ because some parents reported more than one response category.

Seeing the need for change. Six of the parents reported that seeing the need for change in their community facilitated their continued involvement in advocacy-related efforts. One parent explained, "I think having a purpose was very important in the continued work." Similarly, another parent described his experience witnessing the passage of the North Carolina Anti-LGBT/Religious Freedom Law:

Well, hearing about laws that are being passed like in North Carolina, you know and, you know, like I said, the potential discrimination that can happen. Actually, [my wife] and I went down to a it was a lobby day and it was a hearing, judicial committee I think, you know, the ones who have to approve it to put it out on the floor. At a hearing it was like about eight hours and we sat there and we heard the hate from the other side (laughs) and I'm hearing all this stuff, you know, and I hear it from, you know, from North Carolina. But I heard it directly from the people who were testifying and that's an impetus to keep going with advocacy, and you know, this is just...I'm not saying, you know, it's really hard to - I would love to find some magic wand to change the sensibilities and the heart of these people who are just, I can feel they're coming from fear and hate, and I don't have the answer, but I wanna be aware of it but it does keep me you know wanting to advocate, wanting to raise awareness. I even looked into a little bit about how we can change, you know, the representatives, you know.

Another parent noted similar frustration with the same law, while expressing motivation 
to continue advocating on behalf of LGBTQ rights initiatives:

And then you see some things go backwards like North Carolina, you realize the fight's still on, you know, kind of across the country and so it kind of feeds on itself and makes you want to stay involved, be involved.

Community support. Other parents noted that receiving and utilizing community

supports helped to bolster their advocacy efforts. One parent stated that learning from

others in the community encouraged him to continuing his advocacy-efforts:

You know, really learning from other folks and PFLAG's been a great experience. There's a variety of reasons people get involved and a variety of things they bring to the table, so you know, our three pillars are support, advocacy, and education. Some are much more involved in the education, some in the support, some in the advocacy. So from a couple of the board members who are really deeply involved in true advocacy, you know, understanding the laws, understanding what it takes to change a law, you know, attending rallies, going to the statehouse and personally lobbying, organizing campaigns to contact the legislators who are on the fence, all of that stuff is, you know, to me, you know, the pure literal definition of advocacy.

Impacting others. The idea of giving back to other families contributed to

parents' interest in advocacy initiatives. One father described his motivation to help

others, just as those within the community had helped him:

That's real easy. Every month, when we hold our meeting, we don't know if we're going to see any one-day. Some months we hold a meeting and it's the usual suspects, the same six or seven people would go every single month and we're all friends and when that happens we all just agree to kind of have a quick chat and catch up on news and we're done within an hour and we go home. But, more times than not, someone new comes along who is a parent of someone who is gay, lesbian, bisexual, transgender or what have you. Might be someone who is one of those things and they come along at the end of that meeting and tell us how much better they feel and how great it was that they found this group and it's for that person. Because I view it as an opportunity to kind of give back the way this group gave to me and my wife, you know, when we were kind of going through that transition at first so that's why. Sometimes, again, nothing new might have happened/might not happen but then all of a sudden you get this new person. I've also done one-on-one phone calls with parents. Sometimes parents will call and often request a father of someone who is gay, for example. In those instances I'll be asked to phone someone. So I've done those, where I kind of had lengthy oneon-one conversations with parents, too. Same thing: I don't look at it as being a 
chore or a hardship or anything like that.

Another parent described the rewarding feeling that comes with helping others:

You know, I see parents who come for the first time and I remember what it was like. I see people walk in the room all tense and kind of miserable, and then I see them walk out a little bit more relaxed. And you can see they have the feeling, 'this is gonna be okay.' You know, doesn't always work out that way, but when it does, it makes you feel very good that you're giving back and helping others... So that's definitely a motivation to stay involved.

Strength and knowledge. Parents reported that emotional strength and

knowledge provided the support needed to advocate on behalf of the LGBTQ

community. One parent described the way in which he built the emotional strength and

energy to become an advocate:

I think at this point, and I would say - it's been four years now so, the first year I was just in more shocking and coping and getting through and trying to figure out what he needed. And then the last two years or so I've been more-had more energy and experience and he's kind of settled and I could-had the I guess the time and the emotional strength to...be an advocate. I think it really helps that people before me had done so much, so it's really easy now, there are a lot of venues...out there.

Another parent stated that his educational experience and personal growth helped him to become a better advocate. He describes one college course, in particular that shaped his understanding of advocacy:

I took one of her very popular classes, and she, and a lot of the people that attended the classes, were strong advocates, and I think I learned almost-almost everything that I've learned about the kind of advocacy I've done since then through them, other than what I would say I've learned from the lab - the educational lab that I worked in before then. And I learned that it's a long game and that people follow whatever path they follow, that, you don't meet someone and then five minutes later just 'cause you've really researched something and you're really passionate about it, doesn't that they change their mind...in that conversation. It could be a decade later; it could be an hour later!

Positive outcomes. Several parents reported being motivated to advocate after witnessing positive outcomes. One parent reported how she was encouraged to continue 
advocating after achieving successful results:

Well, like when I brought in the person and I advocated at school and then they changed the curriculum. When I did that, then they changed the court system. When I did this, like, I only have good results, like do you know? Like, success! Yeah.

Another parent described the positive legal changes that have occurred over the past few years:

Just seeing the movement. I mean, it's so exciting, you know when two years ago or year - when the first court case that started the movement and then last June when the Supreme Court affirmed, you know, with their rulings on those two cases that marriage, you know, same-sex marriage was going to be the law of the land one way or the other... When you start to see that progress, when you see 17 states, you know, pass the right trans legislation, knowing that 33 still haven't passed, you know the right-including the one we live in.

Miscellaneous. One parent discussed the personal benefits of advocating on

behalf LGBTQ community. She recalled a conversation with her son:

And I said to him, 'I'm not doing this for me, I'm doing this for you because I need for you to be protected and I need for you to be safe. And if that's the way you feel about it, then I'm done, I'm not doing this anymore." He said "What do you mean?" I said "Well, I'm not going to PFLAG meetings anymore and I'm not doing-" and I gave him the whole list of what I'm not doing. And I didn't go for a couple of times. And he didn't seem to be much bothered and finally I got really angry and I said to him, "You know I've realized, you're right. I am doing this for me, not for you. You know why? Because I'm doing this for me so I am convinced that you will be safe." And I started going again.

Question three contained two additional prompts. The first prompt asked parent advocates to identify how their relationship with their child influenced their experiences as an advocate. Responses fell into five categories, detailed in Table 12.

Table 12

How has your relationship with your child influenced your experiences as an advocate? 
Insight and inspiration from child

$8(66.7 \%)$

Positively changed relationship

$6(50 \%)$

Continued advocacy is not dependent on child

Doing it together

Miscellaneous

$2(16.7 \%)$

Note: Total does not equal $12(100 \%)$ because some parents reported more than one response category.

Insight and inspiration from child. Parents described seeing their children as motivators to continue their work as advocates. Parents added that their children provided the insight and inspiration needed to help others going through similar situations:

I'm always quick to tell people, I'm in a really good place today. I feel perfectly happy about my son, I love my son, I don't doubt that he can do the exact same things that I imagined he would do the day before he came out as being gay. He can still get married if he wants to, he can still not get married if he wants to, he can have children, more likely gonna be adopted but he can certainly do all those things. So, the dreams are the same as they once were. It just took me, you know, a few-I don't think it took me years - I would say within the first year I kinda came to that level of comfort with the situation. So I kind of say to people everyone's journey is different, but I can assure you one day, I can't tell you when, but one day you will be in the same position that I'm in which is you'll be fully accepting of the situation. You won't even think it was a situation. Your son is your son, nothing changed. And so, I will use that.

Another parent described learning from her daughter's experiences:

I think the biggest one has been my work with PFLAG. Especially when I'm hearing people asking questions about, say, transgender people, and I can quote my daughter and say, my daughter always says, "Defy the gender binary." And then I can go on and say what that means to people who are having trouble struggling with, you know, what's going on with my child. So, my daughter went to [a well respected college], and so there's a lot of things that she learned at Smith about gender identity and things like that, and advocacy, that have really helped teach me so that I can teach my people... So, that's been very useful. 
Another parent described how she uses her son as inspiration to continue advocating:

I mean he's sort of the basis for my experience as an advocate...because the idea of somebody hurting him or rejecting him or my relationship with him is such that would be devastating for me. So you know, it's one thing to be an advocate on a topic that you care about but when you look every day into the eyes of someone who is the reason for that advocacy or the beneficiary of the advocacy, the person who's - you're fighting for, it makes it feel almost like desperate, like I can't stand the idea of somebody hurting him or rejecting him; to me it like hurts; it like cuts to my core so I can't—-so it's all about my relationship with him.

Positively changed relationship. Half of the parents reported that their advocacy

positively impacted their relationship with their child. Some parents expressed feeling

closer to their child as a result of their advocacy involvement. Other parents were

encouraged by the idea of making their child proud. One parent described how he grew

closer to his daughter throughout the course of his advocacy experiences:

And it was troublesome, more troublesome for my wife than it was for me, more bothersome for her. She constantly would say to me, you know, "You don't pay enough attention to [child's previous name]," [child's preferred name] now but you know, at times I would get very defensive about that because I've wanted to have a great relationship with both of my kids. One of them wanted to do everything Daddy does, and the other one didn't. So I wasn't going to force my son, you know what I mean? Like hey, the kid's not interested in baseball, that's fine. If your kid's not, you know, if [child's previous name] doesn't want to ask me about what I do for work when he turned 14, that's fine, not interested. My older one was so it's you know, but this is our thing now, you know? And her being-I'm sorry, I get a little emotional-you know her, from the minute she came out as a gay kid, gay son, almost five years ago now, it is five years ago now, you know to now, it's just kind of been a constant evolution of getting closer and we're honest with each other and better relationship, more able to talk. And it's still challenging because she has mental health issues, as well so... sometimes she doesn't want to talk (laughs) doesn't want to share, you know, what's going on with her.

Another parent described advocacy in terms of efforts to make their child proud:

I think probably makes me feel better about talking with my son, and maybe makes... In fact, you know sometimes I tell him about like I'm going to the state house, we were there for eight hours and part of that is I want him to know that I'm putting in the effort to advocate for him, you know... and I think the other part of it is, if I advocate for him, then I feel a little stronger in my support for him, 
even talking on the phone. So, I think it's both ways.

Continued advocacy is not dependent on child. Some parents stated that their work as an advocate has become independent of their child. Instead, some parents have chosen to focus on the idea of helping other families, rather than strictly focusing on implementing change for their own family. One parent noted that as her child started to get older, her advocacy became less about him and more about the other children she might help in the process:

Well, since he came out when he was 26 and he lived in [another city], and he was away from home, it's not quite the same where as if...he lived in the same town so we don't see each other very often...we still connect but it's...yeah, I don't know, I think our relationship's the same as it was. I don't feel like I'm advocating for him, in the beginning I was but not now, not anymore. It's other people's kids, it's the other kids...

Doing it together. Two parents reported that since becoming an advocate, their

child has also become involved in advocacy initiatives:

We do at times, yeah. We've been together too, we've been to the statehouse together, we've been to a roundtable of Maura Healey, we went to a thing just a week and a half ago that Harvard Pilgrim Health sponsored, a nice symposium and roundtable on transgender health issues where 440 you know, transgender people and some parents, you know, caregivers... attended and gave feedback. Yes, so we do persuade together and quite a few things.

Miscellaneous. Two parents described experiences that did not fit into a traditional category. One described how the relationship he developed with his son could serve as a model for other families: "I suppose the experiences that we have had serve to at least model for other people what being a parent of someone who is gay can look like after a period of time." Another parent discussed issues related to respecting their child's privacy, as well as its impact on their advocacy-related activities:

I would be a much bigger advocate if I wasn't conscious of [my child]. Because [mild child] doesn't identify as trans...He like identifies as a boy, like he just 
doesn't, like, it's weird, like he just does not—and he doesn't want to go to trans events to advocate. He's just a boy, he's just not, and like sometimes my husband and I find it frustrating 'cause like and it-you know... And, but I'm very conscious like I've never like, often people ask me can you be like in my new article, or, the radio, on T.V. I don't-I never like do-I only do things that are like very - there's no media, like no-like that are very low key. I always say don't put my picture in the newspaper, don't use my name, like, or I'll do something like that I was asked to write for the [Medical Website] and I used my real name because I thought that was a really important thing, so I like did that. Like it has to be a really high bar to use my name, and I didn't think it mattered. Like, but I'm not gonna be on YouTube, like I don't-I would be a much bigger advocate if I wasn't conscious of like keeping [my child's] privacy.

The second prompt asked parents to describe how family members and members of the community influenced their experiences as an advocate. Table 13 provides a breakdown of parent responses.

Table 13

How have your other family members and members of the community influenced your experiences as an advocate?

Categories n $\quad n$ \%)

Strong community relationships (e.g., relationships with the LGBTQ $12(100 \%)$ community, school, church)

Supportive family members $9(75 \%)$

They are now a "leader" in the community $6(50 \%)$

Rolling with resistance $5(41.7 \%)$

Little to no influence by family $3(25 \%)$

Role models $3(25 \%)$

Note: Total does not equal $12(100 \%)$ because some parents reported more than one 
response category.

Strong community relationships. Parent participants described how their strong community relationships helped to influence their decision to become an advocate. One parent discussed how she regularly collaborates with school organizations in order to support one another in their advocacy:

The advisors for the Gay Straight Alliance at the high school, there was one for a number of years, and then there's another one that took over that job, and both of them have been a really good ally for advocacy work. You know, I will do things to support them, and they will do things that support my programs, and we've worked together on things like that. So that's been nice to have, an ally in the school building.

Another parent described the role of the church in facilitating their continued advocacy efforts:

But it does feel really nice that my church community supports this LGBT advocacy and they believe in equal rights and that is not true for some of the other parents in my PLFAG group, for example, who had to leave their church communities when - or who decided to leave their church communities because the, you know, the religious leaders in their community said, "If your kid is trans, that is absolutely not okay," and they were like "Well, you know, what's more important? Church or family?" and I guess for some people that's a really hard decision and for these other parents and, you know, peer facilitators...in my PFLAG group are like family is more important than church. So I do feel very-I feel blessed that my community is in support of LGBT rights.

While some parents found strength in their churches and schools, other parents described developing a greater relationship with those in the LGBTQ community. One parent discussed the role PFLAG played in his ability to become an advocate and leader in the community:

So you might say you know the organizations are having a tremendous influence, not just because they're like a portal for me, you know that's how I find out about where to go to lobby and all that, but also because it's trickling down. You know, PFLAG provides the support groups. They're kind of sponsoring my 'fathers' group. 
Supportive family members. Nine of the 12 parents described family members that either actively participated in advocacy-related activities, or were supportive of their advocacy efforts. Parents described how the family support gradually progressed over time:

Okay, I push him more than he pushes me. And I have done more things than he has because he's not as outgoing as I am. But like I said, he does do a lot and he's totally on board, but he's marched in Pride Parade the last several years, three or four years. At the beginning, [my child] and I would go to [city] Pride without him, and now he's not only going, he's marching with PFLAG, so you've got to give him points! So that's good, so that's really good.

Another parent described what it meant for him to have a supportive sister-in-law attend a local LGBTQ event:

[My wife's] sister from [a nearby state] came all the way up here just to attend it, and she was in a session and I was there and I guess, I forget what the question was, you know, Why you're here? Why you're advocating? You know, why you're attending? And she said something like "I love my sister very much, and my sister has a transgender child," and she said" I can't imagine not being supportive to this child." You know, strong, strong support. And so, I can say to myself, you know if my child's aunt is being so supportive, you know, I can't sit back here, you know, so to speak. You know, it's a little, it's kind of an influence. You know, so it's heartfelt and that was great.

They are now a "leader" in the community. Fifty perfect of the parents stated that they were now considered leaders or 'experts' within the community. Parents described providing advice and resources for those needing extra assistance. One parent described how her advocacy efforts led to a community award, named in her honor:

It's the [Paticipant's Name] Advocate Community Ally or Advocate Award, so it's for someone in the community. Last year, I sort of suggested it be our congregational minister who is openly gay with his husband, [congregational minister]. And I figured, he's a really good representative of the gay community for students so last year he got that.

Another parent described an experience in which they were able to become a leader in their workplace: 
So anyway, we were the two speakers on that day so unlike most events where maybe 50 people show up, we had 400 people and I spoke for about, normally I would only speak for about five to seven minutes if it was a PFLAG engagement...I gave the long version because I had the time, so I gave a 15minute talk about [my child] and my relationship and why I was involved in PFLAG and all of it. And it kind of went a little viral at work and I had people dropping by who I didn't know, so thrilled that a senior leader stood up and did that.

Rolling with resistance. Parents discussed their experiences with resistance from others in their family and community and how they responded. One parent described people's reactions when advocating at the legislative level:

It's very hard going against people who don't understand. Then I haven't run across a lot of those but though in the statehouse, yeah, there are some (laughs). And you start to realize, it's not logic, you can't use logic, so there's some kind of fear or just...um...I guess fear-based or they're stuck and they just can't change the way they're thinking.

As parents encounter these reactions, they also discussed the ways in which they rolled with resistance in order to change the perspective of those around them. A few parents emphasized the importance of providing education and information to those in their community in order to reduce the potential for resistance. One parent explained, "There has been needed to be a little bit of education, but not too much." Another parent recalled maintaining patience with his extended family's reaction after his child 'came out:'

I have relatives who I consider fairly open-minded who had a longer struggle with mourning the relative they thought they had and then when they thought-well it was a girl — and fantasies and images and dreams that they might've had about a future, female [child's name], it never was going to exist and didn't exist, but that in their minds, they had created. And how they were relatively open-minded informed people, but that for them there was a mourning process, and it took longer and it was harder than it even was for me... and it's my child. So, some patience and understanding came there.

Little to no influence by family. Three parents described situations in which their family members were either absent or did not influence their advocacy experiences. 
One parent described the efforts she took to facilitate a positive dialogue with family,

following their child's 'coming out':

Well let's see... so the family...there is no experience. I mean the truth is partly, we've been rejected, both of us. And I've been trying to sell this rejection to [my child] as saying "They're not rejecting you, they're rejecting me".... So I wrote a letter explaining the whole thing in really nice terms, it went on and on and on, and I asked my sister who's not that helpful, but I asked her to read it to them. I mailed it to her, read it to them to prepare them, let them have a few days to let it sink in, and then we'll come down, [my child] and I will come down to visit we'll get it all out. And she did that and we went and my mother said "I don't understand what this means, but whatever it is or isn't I still love you," type of thing. And my dad wouldn't talk to either of us for a week, and we left. And then I went back a few months later by myself and he accused me of making him this way and allowing quack doctors to do this to him. And then [my child] and I went back a few months after that together and he didn't talk to us for a week and we've never been there again. So I can't talk about them as influencing me because they're doing the opposite.

Role models. Three parents discussed learning from advocacy role models. One

parent described learning how to advocate from other family members:

I have some nice role models within my extended family who have spent lifetimes doing good. I have an aunt and uncle here in the [local] area, my mother's sister, who they've been part of Doctors Without Borders, you know, a physician.

Conversely, another parent described the importance of being a role model for her youngest son.

I'll say that our younger child, so his little brother, he influences our need and our desire to become advocates because we want to role model for him what it means to be an advocate and what it means to stand behind what you believe and - to the way you treat people in the world and for him to see us advocating. It's really important just for the fact that he's that next generation of the advocacy chain, and when I can't necessarily influence the older generation, he's definitely influenced by it and his experience being in a family that advocates for, you know, things they believe in, I think that will shape the adult that he'll become and the impact that he'll have on the world.

The second research questioned was aimed at understanding potential obstacles

parents may encounter initiating and pursuing advocacy. This may include negative 
reactions, personal difficulties, as well as ways in which parent advocates overcame those barriers. The findings for this research question are detailed in Tables 14-17.

Research Question \#2: What aspects of life serve as barriers to initiating and pursuing advocacy related efforts among parents of LGBTQ youth?

To answer this research question, parents were asked to describe what kinds of challenges they encountered initiating and pursuing advocacy-related efforts. The majority of parents reported challenges related to people with differing opinions and provided examples on how they addressed those challenges. Table 14 provides a breakdown of their responses.

Table 14

What kinds of challenges did you encounter initiating and pursuing advocacy-related efforts among parents of LGBTQ youth?

Categories $n(\%)$

People with differing opinions

$8(66.7 \%)$

Addressing the challenges

$8(66.7 \%)$

Organizational and logistical issues

$6(50 \%)$

Fear and Insecurity

$5(41.7 \%)$

Politics and legislation

Overall frustration

$4(33.3 \%)$

Note: Total does not equal $12(100 \%)$ because some parents reported more than one response category. 
People with differing opinions. Parents reported challenges related to differing

opinions and viewpoints. One parent indicated experiencing frustration with those within

the larger community who hold different priorities and beliefs:

There are some people, they tend to come mostly from the religious right, they tend to come from the center of the state, rather than so much, and a little bit from the north shore and the south shore, you do find some people, it's a small group of people and their sensationalizing these issues around...And they're worried that their female family members are gonna be attacked by people posing as trans women in restrooms. The attorney general, who we know very well, has been very supportive. The chief of police in [the city] and every chief of police in every town and city in the state have submitted testimony that this has never happened...And having people's rights rejected, doesn't all of a sudden give people the idea that they should, you know, do kinds of strange things to make people uncomfortable, or attack them, or whatever. So that bothers me a lot, that's an impediment.

Meanwhile, another parent reported challenges working with fellow LGBTQ parent advocates with different viewpoints:

You know, there are some people who are, you know, there's just chemistry like they're on board, you do it, you can work with them. And other people, you know, they're kind of sitting back out of, I don't know anxiety or fear, whatever. Or they have their own agenda, or they have their walls up a little bit and you know that's part of the challenge, you have to deal with that.

Addressing the challenges. When discussing challenges encountered as advocates, several parents contributed examples of how they overcame barriers in order to continue their advocacy initiatives. One parent explained how he addresses potential challenges in his parent support group:

Though, I do stress to people, and we do this a lot in our group, is to say to parents 'the very fact that you're here is a huge first step.' I mean that says a lot about you, right? It clearly says that you love your child and you want to get beyond the place that you're at. So that's-so acknowledging what people have done, even while at the same time trying to steer them in the direction of things they've yet to do, I would say is one of the bigger challenges that we face.

Another parent explained a multi-faceted approach to addressing challenges: 
So, you know, what can we do, we write letters, we talk to various people, but most of our particular reps are very supportive. And, you know, we'll attend hearings, we'll—my wife has testified, we've written—we've sit at a written testimony, all of those kind of things.

Organizational and logistical issues. Half of the parents indicated challenges

related to organizational and logistical issues. One parent reported physical distance as a hindrance to advocacy: "Sometimes it's just physical distance...Y You know, like there's something really good, say, going on in Hartford, CT. I don't think I can get there!” Another parent noted problems finding the time to advocate:

And then, I mean the other challenge for me is just, you know, I work full-time and I'm a parent and sort of, like finding time is challenging for me. I mean, it's important. It's not the most fun thing I've ever done (laughs), I think fun is also important. So like singing and dancing are like really important. So I love it when Freedom Massachusetts sends me something and I can just spend ninety-five seconds filling something out and emailing it or whatever, right? Like that's nice when it's a minimal time commitment. So I think that—so I guess that's another challenge that I face.

Another parent noted difficulty identifying how to most effectively advocate:

I guess, you know, some of it is, other than PFLAG is knowing how to get involved. Where and where would it, you know, where would it make a difference? Would writing in my blog make a difference? No, most of the time not, you write something, you publish it out through Facebook, or I started using LinkedIn believe it or not as a social platform to say, "Hey, my new blog post is here." Only one or two of them really struck a nerve, but when they did, you know, it really was a good feeling to see I got 285 views but I don't know 285 people so this must have gone to some other people you know.

Fear and insecurity. Parents also reported challenges related to their own

personal insecurities or lack of knowledge. One parent described how he struggled to step outside of his personal comfort zone:

Inertia, general inertia...I mean I never was like an activist kind of thing. I always kind of felt a little bit like I saw both sides of everybody's story so I didn't know where to jump in (laughs)...Although, now I know where to jump in. Not just LGBT, but I mean, some people have a personality where it takes a lot more-it takes some more energy for them to get over that inertia hump to advocate. So, I 
could say that was part of my - part of me. And I see it in other people. I saw it more in men and that you know.

Although parents advocate for LGBTQ rights, they may still struggle with their inability

to control or change the environment for their child. One parent expressed the fear

associated with their lack of control:

The most challenging moments are moments when [our child] is afraid, when he has to make a decision that he feels very vulnerable about. He feels not certain about what he wants out of it and very uncertain what kind of support he's gonna get. Which dorm to stay in on a school trip, what the ramifications are if he chooses to play on the girls' softball team, then how coaches from other schools are going to treat him. And same thing if he chooses the boys' team, that even more so, he could be outside of safe environments. Those have been challenging because we can't protect [our child] from all those situations, we don't have a direct influence, you know, we don't have control over everybody who's going to impact [our child]. And, regardless of how successful we would be in influencing that, he's afraid now.

Politics and legislation. Several parents reported problems navigating the

political and legislative landscape as advocates. One parent reported a lack of knowledge regarding legislative advocacy:

It's so funny, the guy who used to be the head of the [local LGBTQ political organization] would get up and talk about like the status of the legislation and it's all like political talk, and it's like they're all English words but I have absolutely-I don't understand what he's talking about at all (laughs). I can't even-I can't even generate it now. But anyway, so it's like I'm very-I'm relatively naïve about the political process and I know there are committees and then there are hearings and how bills work their way through the legislature. It's all actually pretty, pretty new to me.

Another parent described the impact of the current political climate:

Obviously the political environment that's out there right now, our governors and other legislatures are trying to pass laws restricting bathrooms and making people, you know, putting lip service to the idea that they're protecting religious freedom, and I really don't believe that's what they are doing and I don't believe they believe it. That's a challenging environment, too. It's - and it's personal because it affects me and my son, but that's a more general thing where I feel like I have a lot of friends, I have a big community, we're all trying to advocate for this. So it's challenging in its own way. 
Another parent expressed feeling powerless when participating in legislative advocacy:

Well going to the statehouse, you know, was one where you really start to feel powerless to the realities of politics, which always bother me. And, you know, this whole-it's a game.

Overall frustration. Parents also indicated challenges related to feeling

frustration and burnout. One parent reported feeling frustrated after witnessing the

differential treatment of an LGBTQ group and event within the school:

But it was very frustrating to hear that the group was being discriminated against and we were pretty confident it was because of the topic of the group and not because of just that it was students from outside the school coming.

Another parent expressed feeling exhaustion after constantly needing to advocate on behalf of her child:

Yeah, like I'm like yeah...Just like is it like being like is this the only thing in life? But, it's like - and I think oh, I'm just gonna take a break, and then my son's Lupron gets cut off again. Or like, and I'll be like ah, I just like wanna like not do transgender anymore and then, you know, something happens. Or I'll get a call from a Mom and she's desperate and they'll be like she can't get insurance and I'm like oh okay. So, it sort of like puts like just the burnout, like the constant like...getting burned out...that's my challenge.

Table 15 details the parent responses from the first prompt. Only 10 parents were asked what personal challenges they overcame during the process of initiating and processing advocacy efforts. The other two parents had previously endorsed personal challenges during question four.

Table 15

What personal challenges did you overcome during this process?

Categories n(\%)

Need for Knowledge

$5(50 \%)$ 
Note: Total does not equal $10(100 \%)$ because some parents reported more than one response category.

Need for knowledge. A majority of parents described a need for knowledge regarding how to advocate on behalf of LGBTQ issues. Some parents emphasized the importance of finding reliable and valid resources regarding the LGBTQ community in order to begin their advocacy efforts. One parent described this need for knowledge and information:

My challenges were around understanding, you know, it took me a while to understand that this was not a choice that people make, you know, this is one of the lies that you hear from the media, "Oh this is a lifestyle that people have and it's a choice that they make," and I've come to learn and, you know, education overcame a lot of my fears and misunderstandings, to see that it was not a lifestyle and it was not a choice. And forcing people to live an inauthentic life is a terrible thing to do to people, you know. And it's no wonder why that population has a lot of issues.

By gaining reliable and valid information, parents felt more able and willing to participant in advocacy efforts. However, several parents expressed personal challenges related to knowing when and how to advocate. One parent explained this difficulty when interacting with those in the community:

But for advocacy I would say just the group work and knowing when to say something and when not to say something. So that's another issue that always comes up when you meet people and they don't know, and it's like, well... And I feel like in a sense, I'm advocating. One point it was almost therapeutic to be able to tell people so that they would then know somebody who was - oh yeah, I know 
somebody who is-and then it wouldn't be as foreign, so in a sense, I felt like even on that little level I was advocating. But there were some times when it was uncomfortable or I never knew that this person that I was running into might not take it so well and did I really want to go through telling them? Or you're at the grocery store and do you really want to get into this conversation...So, it is kind of challenging sometimes to decide when to say what and when not to say anything.

\section{A lot of advocacy to do and not enough time or emotional energy. Several}

parents endorsed difficulty balancing the need to advocate and their emotional/physical well-being. One parent discussed trying to find a balance between what they can do and what they are able to do as an advocate:

I think my biggest personal challenge is being tempted to try to do everything myself, and it's been hard to keep a large enough membership in our committee to have other people also carrying some of the load. And so, a lot of things end up being me running the whole show.

Another parent noted how their participation in advocacy initiatives was dependent on their varied availability:

You know so I kind of, in my first two years, two to three years of just simply going out and speaking for PFLAG without really trying to understand more of what I could be doing... in my mind was more of a one mind, one heart at a time kind of approach. And it suited the amount of time I had to give to advocacy and felt like the best way within that time for me to make a difference.

Feeling discomfort. Some parent advocates indicated personal challenges related to experiencing discomfort due to inexperience, personality differences, or past regrets. One parent reported feeling discomfort when advocating, due to her tendency to be withdrawn and private:

I guess one piece about being an advocate is that you're giving up a little bit of your privacy and you're like anonymity and I'm a pretty private person. I'm not a particularly extroverted person; I don't love speaking in public, and I know not a lot of people do but a lot of people do thrive on that challenge. I don't-I don't enjoy it in terms of like being out there publicly.

Motivation to push past the challenge. Another four parents indicated a 
motivation to push past their personal challenges in order to advocate on behalf of their

child:

So, personally for me, that was a challenge to get past that... and I mean it wasn't just the trans advocacy stuff, you know, it's other you know I've always had to work on this...But, I would say that the trans advocacy part of it and that motivation to help my son, was a pretty good factor in helping me get past that kind of imprinted inertia.

He continued,

And I said, well, I said, I'm gonna go do it and I'm, you know, I'm matured enough to understand that I just need to deal with that. So, it helped me... I mean, so one of the challenges was social anxiety you might say, helped me, not that it was like a severe thing or anything but to some small degree I felt like my motivation was strong enough to go confront this stuff, confront people that maybe I wouldn't bother confronting before.

No challenges. Although some parents detailed their personal challenges, other

parents could not identify any personal barriers that impacted their advocacy experiences.

One parent noted that the support they received early on in their journey prevented any

personal challenges for arising:

Nothing that comes to mind, honestly...I mean I'm really trying hard to kind of think of a time when I was troubled. Not really. Again, you know, I took the initiative to kind of find support, immediately. I received that support immediately and that really, really helps.

The second prompt asked parents to recall any negative reactions by others in the community or in their family. These responses were divided into six categories, which are detailed in Table 16. Only nine parents were asked this prompt, as the remaining parents had already contributed their negative experiences and interactions with others. Table 16

Did you ever find negative reactions by others in the community or in your family?

Categories n(\%)


Note: Total does not equal $9(100 \%)$ because some parents reported more than one response category.

They just don't get it. Parents who responded to this prompt described how family members and members of the community just didn't understand their experience. One parent explained "I mean a lot of people just look at you and well, you can tell they don't get it, or they're against it or whatever." Another parent described situations where those around them didn't necessarily respond in the most appropriate manner:

I wouldn't say negative reactions, but you know, sometimes kind of the wrong thing said (laughs). You know, kind of like well "those people" or "they" or you know or "Don't you find it a little odd that a man at age fifty-two suddenly decides they're a woman?" Like you know, Bruce and Caitlyn Jenner thing....and I just see it as a lack of education, understanding, and experience. People, most people have not had the personal experience of knowing somebody that's transgender and you know so I kind of look at it, I kind of look past some of it. And I know I have friends who, it probably makes them a little uncomfortable if I talk about it at length.

Similarly, another parent described the subtle negativity she had experienced when interacting with family and friends:

When I've talked about [my child] or his, you know, his experience or his identity, I've had people say "oh, it could be a phase, like it could just be a phase, you know. I mean he's so young." And to-you know, people say “Oh don't 
worry, I think a lot of kids..." that to me is a really negative response. I mean it's basically a response of invalidating what he's told us, you know. He, you know, I think very few kids - especially transgender kids - go to the point of making a declaration about their identity...if they're not extremely —if it's not extremely important to them; they're very sure. And whatever the case, and even if it will fluctuate throughout his life I don't want to be comforted by someone who says he might not be who he says he is. Like to me that is not comforting that's invalidating. And even though they think it's comforting because they're saying "oh maybe he won't be like this forever" I'm okay with who he is and he's certainly okay with who he is so that kind of reaction is definitely negative.

Absence of negative reactions. A number of parents also described the absence of negative reactions from family and community members. For some parents, negative reactions were not an issue. One parent reflected on his personal interactions with family and friends:

Regarding my advocacy? No (laughs). And to some extent I may be a little narrow-minded and I would just not remember it or I wouldn't care and I would just move forward, but basically I would say...And my parent-my sisters have been very supportive of me and [my son] and my two kids, yeah. They've been great. So, I'm sure of I dig far enough I could probably come up with something but usually you try to forget it and move on. But I don't think there has been a lot, I've been pretty lucky.

Other parents indicated the absence of negative reactions because they believed that they probably would never find out if they had a disapproving friend or family member. One parent explained how those who disapprove would not likely say anything, in an effort to be cordial and politically correct:

And so I think that if there were people who do not - are not supportive, they tend to keep their mouth shut at church...so there's definitely peer pressure to be more P.C. I know there's a friend of mine who says, "Some people, you know, do not feel really comfortable," and I've recently thought, "I wonder if she's the one who doesn't feel really comfortable." But it's funny because like she used to babysit my kids, and like we'd go over there and she's very gracious, so I don't know...if it's her or if it's somebody else who's sort of disapproving of the fact that I have a gender nonconforming or a trans teen that I let transition as a teenager. [hand gestures quotation marks] "I let" [end quotation hand gesture] transition as a teenager. So, there may be some dissenters out there, but they're not in my face. 
Diversity-related concern and/or fear of discrimination. Three parents

indicated concerns related to diversity and fear of discrimination. One parent described

the hateful acts exhibited by members of her community after a rainbow flag was

displayed outside their church:

There has been some vandalism. A little over 10 years ago, we put a rainbow flag up outside the front of the church, and over the course of time, maybe four times or so, it has been stolen and we've had to put a new one up. So, there has been some - some response. And we've never seen anything happen other than the sign being stolen.

Being creative in their response. Parents also recalled how they creatively

responded to negativity or potential negativity:

So, it's interesting that my Dad was like, "Whoa, I don't know what to think about this. I'm going to have to think about it," (laughs) and then I started, and I'm like "okay." And then I, you know, at the-when I sent my Dad this email, I also figured, holy crap, like he was one of the first people. You know, my Dad, my brother, my Mom, and but I thought if I've let my Dad know, I need to let his sister know, because who can he talk to about stuff? And she's somebody that he really respects and so, you know, almost immediately I'm like, "Oh my God, I've got to get this out to like this person and that person, out to his sister and then to her daughter and..." So, you know, I started spamming like all of the aunts and uncles and all of the cousins and everything and so like while my Dad was kind of in radio silence waiting to decide how he was going to react to this, I was like, "Oh, I got this really nice letter from my cousin Laura," and she's like "Oh..." you know, really positive... and then, you know, some response from, you know, this auntie who is his sister and I'm like, "Oh, by the way, here's the response I got from Aunt Kay," so it's like, "You could think about responding this way, Dad." And like eventually, he's like, "Okay, well, you know, I guess I should be supportive," he says, " 'cause I guess I'd kind of be an asshole if I didn't," (laughs). Yeah, that's good, that's pretty good. "Yeah, I'm really glad you're (laughs) on board." So anyway, so I think it took him a while to figure out like, "Oh yeah, this is the way I should respond." And I was sort of giving him these hints along the way. So that - I don't know if that wasn't-I guess if it's just advocacy for my very own kid within my own family, that was the most tentative response.

Frustration with the legislative process. Two parents expressed their frustration with the legislative process, as well as negative reactions by state legislators. One parent 
explained the negative rhetoric used by community members when describing the

pending equality legislation:

But most of them really did not know what we were talking about and that makes it really hard, so you have to go back and back and back. Now I've written to [state Governor], I never got a response. I gave him my mailing address, my email address, my phone number, I mean I really didn't expect it, but nothing. But he's not on board and that's frustrating. I did get to testify at the - I've gone for the last three years to the hearings, the joint judiciary committee and sat there all day and all night all three years. This past year I went and I got to testify. And it's frustrating because even though there are so few Republicans in the state government, they're mighty, they really are and this last time, one, I can name him if you want me to but it doesn't matter... well his name is [state representative name], [spells out name slowly], he is so anti- this bill and he is so attuned to the opposition which really, they say really despicable things that he doesn't listen to - he didn't listen to any of the testimony. He just would ask the same questions over and over and over and over and I could give you an example, but that's frustrating because they're just not hearing us.

Eleven parents were asked to respond to the third prompt. This prompt asked

parents to explain how they overcame challenges related to initiating and pursuing advocacy initiatives. Table 17 provides a breakdown of parent responses.

Table 17

How did you end up dealing with those challenges?

Categories n $\quad n$ (\%)

Persistent civil rights advocacy

$9(81.8 \%)$

Supports and successes

$8(72.7 \%)$

Accepting the situation and/or seeing the best in people

$6(54.5 \%)$

Communication is key

Time management

$2(18.2 \%)$

Note: Total does not equal $11(100 \%)$ because some parents reported more than one 
response category.

Persistent civil rights advocacy. When encountering challenges, one parent noted, "You keep doing it. You just keep at it. You just keep at it." This approach was taken by a majority of parent participants as they stressed the importance of fighting for civil rights. Another parent noted,

It makes me pleased that people can, you know, live their true life earlier. But, there's work to be done and I feel that it's our responsibility-look, I can make the world better for my kid, a little bit, but I can make the world a lot better for the next generation that comes through and I think I owe that to the world, you know...I think a lot of it was... Those challenges - I just - sometimes you have to do things beyond your comfort zone, and I had to force myself... So, you know, it's kind of like you hit a barrier and then you force yourself over it.

One parent explained the significance of pushing forward in the fight for civil rights:

But when you have - well when you have no civil rights, you realize, like, you don't care if you have more money. Like, as long as you have enough to live on and like enough to be comfortable. Like, you can't live without civil rights, you can live with less money, but you can't live without civil rights. That's, like, so much worse. And so, I realize that's just so much more important and there's nothing that I could do that would have more significance than working on that, civil rights.

Supports and successes. Several parents reflected on their personal successes and support systems as a means of coping with the challenges they faced as an advocate. One parent explained how the support of other parents provided a safe space in which they felt validated and understood:

To me, you know, I guess I'd have a group of other people who agree with me and so it's easy to talk about it and say-and kind of, I guess I - it helps me to talk about it. And it helps me to talk about it with somebody who kind of agrees with me, and then I can kind of figure out where it's coming from. And I think that's kind of what I did, I can feel where it's coming from.

Another parent noted that the support of the school, particularly the school principal, was crucial to their ability to navigate the day-to-day: 
So he would call us and say, "Here's how I handled this, or want to handle this, what do you think?" or "I don't know how I'm going to handle this." And it made it so that the communication channels were open, and if there's going to be sex ed class and they don't know whether to put [my child] in one or the other because a lot of the sex ed class is around biology and it might be the case that [my child] needs to hear the biology with his - with a group of people whose genders are not the same as his. And, I like that they talk to us, and that they ask us. And I think that's been an effective way to cope with the challenge.

Another parent stated that the support of others helped them to feel more able and willing to address the challenges in front of them. They noted, "and when things-discussions and conversations turned out well, it gave me more confidence to do 'em the next time."

Accepting the situation and/or seeing the best in people. Half of parent

participants indicated the importance of accepting the current situation, but not necessarily approving of it. When possible, parents noted the importance of assuming innocence and trying to give others the benefit of the doubt. One parent explained how he came to radically accept the challenge that lay in front of him:

Sure, sure. I think I realized that, I think what helped me the most was coming to the realization that the challenge, whatever was in my way, was not gonna change overnight. So, my tendency to sit back and feel like oh, this is a burden to go do something...I felt like motivated enough to go do what I needed to do but not under some starry-eyed impression that it's all going away.

Another parent discussed their attempts to see the best in people:

Yeah, I try to do what we always say we should do, which is assume innocence. So you know, I look for it to just be an educational opportunity. And you know, I don't - it doesn't have to be the only thing I talk about it when I talk to people either...so it's not like it - it's just, you know, if something comes up in passing and you mention your kid or you mention [my child] and you know, somebody might ask a question and the next thing you know, we're talking about it, but yeah. More likely that they end up talking about it would be with somebody who is more accepting, more easily accepting of all things in general than with somebody who you might know has a variety of things that they're not always cool with. From race to (laughs) religion to, you know sexuality, etcetera. 
Communication is key. Three parents indicated the importance of bridging communication with those in the community. One parent explained how reaching out to the school helped to recreate a working relationship in which challenges could be addressed as a team:

How do I overcome those challenges...I don't have a prepared answer for that. I think one thing that we've used is in - say the school, for example, which is where a lot of challenges come up for [my child], or could come up for [my child]. We-both [my wife] and I- have been, I think, good about communicating early and communicating often and being patient. So, in the very first phone call I had with the head of the school that [my child] is at, I made a joke about, "Hey, how come I haven't received the packet yet you guys have prepared for parents with transgender students?" And it went over, he laughed, he got that I was like communicating to him like I know you don't have a complete, prepared program, and you don't have all the answers for me immediately. I think it made him feel like we're working on this together in a transparent, open situation.

Time management. Two parents discussed how time management played a role in overcoming obstacles. One parent stressed the importance of time management when advocating:

Have you ever seen that like four square of like "How urgent is it and how important is it?" And those very important but non-urgent things are the hardest thing - the most important things to make sure you schedule into your schedule, but they're also the hardest things. 'Cause like the urgent things (ooooooh) are really, you know... yeah. The urgent things take precedence, but it's those nonurgent, important things that are really important. So it's like okay I should make it - I should go out of my way to make time for those non-urgent important things. And I manage to do that most of the time. I think there was a recent, there was a recent lobby day that like snuck up on me that I didn't know was going to happen and I'm like (uhh). Like to reorganize everything at work is, is challenging sort of at short notice.

The final research question asked parents to reflect on ways their relationship with themselves and others has changed throughout their experiences as an advocate. Parents also had the opportunity to share advice and recommendations to future LGBTQ advocates. 
Research Question \#3: How have parents' views of themselves and their relationships with others (e.g., family, children, and community members) changed throughout their experiences as $L G B T Q$ parent advocates?

Participants indicated how their view of themselves and their relationships with others has changed throughout their advocacy experiences. Table 18 provides a summary of parents' responses.

Table 18

Do you think your view of yourself has changed throughout your advocacy experiences? Do you think your relationships with others has changed?

Categories n $n(\%)$

From quiet ally to active advocate $7(58.3 \%)$

More understanding

Challenged myself $6(50 \%)$

Priorities as a parent $6(50 \%)$

Expert/valued leader

Choosing your battles

Miscellaneous

$4(33.3 \%)$

Note: Total does not equal $12(100 \%)$ because some parents reported more than one response category.

From quiet ally to active advocate. Parents discussed their personal development from a supportive ally into an active advocate. A majority of parents 
reported experiencing personal growth and increased confidence over time. One parent described this gradual change in more detail:

You know, here I was quietly supportive, having had gay friends since college. And, you know, never thinking anything about it. I don't even notice who's who because it doesn't matter to me...And, so that was interesting. But I was quietly supportive, you know, I was individually supportive... You know, and a couple of years ago when I joined the board of PFLAG, they said. "You should march in the pride parade." The thought of doing that, you know, years ago would've been very frightening to me. And now I've done it three times and I think it's wonderful.

Another parent added that their personal growth also coincided with changes in the community at large:

I do think I'm more confident in my advocacy. And I don't know if that's partly that over the course of the 20 years I've been working on it, GLBTQ issues have become more acceptable, it would be very hard to believe the principal today would be able to say "No you can't have that event in our school," even though at that time they could get away with it. So, but I also think that I have more confidence and more willingness to simply do the thing that's right, because it's right.

More understanding. Parent advocates also expressed becoming more understanding of different views and experiences. One parent explained how their broadened sense of self-awareness and increased understanding changed their personal perspective:

Well, I was thinking about that sort of question just this past weekend when I dropped off information for my friends of the child who's on the autism spectrum and identifies as transgender. I wrote a letter to a company the information and I said to them "You know, I've been working with PFLAG now," I said to them, "For three and a half years, and while that work doesn't make me an expert in any of the things that we talk about, and less still about transgender," I said "It has made me more sensitive to what we go through as families and so, I think certainly there's been a lot of learning that's taken place. I mean clearly, I know more about, you know, what people go through, both the individuals and their families, when they break the news, when they come out of the closet. So it's given me a deeper appreciation. I mean if I was to watch the Matthew Sheppard, you know, the Laramie Project play again today, I think I would be looking at it a little bit differently. You know, when I saw it the first time, you know, my heart was just with the parents ultimately, who chose to forgive. I mean it was really-I 
don't know if I could've been that charitable as they. I mean at least thinking about it back then. And of course I wasn't looking at it thinking 'what if that was one of my children?' I certainly imagine what it would be like to have any of your children beaten up near death and die from their injuries for whatever reason, but not because of my child's sexual orientation.

Another parent explained how becoming an advocate led to an increased understanding, acceptance, and tolerance:

I'm a lot more tolerant too, of points of view that maybe I wouldn't have understood before. You know, I would never have not been accepting of a person who is trans, or whatever, but there are people whose gender expressions don't match the norms, and this is something that I would have thought was a little on the outrageous side before, but now I understand that's a legitimate expression for some people. So, I would say I'm a lot more tolerant to the, you know, the people I meet, and a lot - I try to be a lot more understanding. I don't necessarily understand everything...but I understand their right to live their authentic lives, whatever that is.

Challenged myself. Half of the parents reported experiencing personal growth throughout their advocacy journey. These parents often reported being able to see the world in a different perspective. One parent explained, "Just by facilitating groups, being a facilitator. I enjoy doing that and I think that's made me grow and change." Another parent was challenged to develop a broader outlook:

Well my outlook is much broader than it ever would've been. I was a stay-athome mom, we have a farm, I was the girl-scout leader, I did, you know, all those traditional mom things and so basically going to state house or being an advocate for LGBT group is not what was fitting into what you would think of for me... So it's been an outreach that's been a positive - it's been very broadening; it's exciting!

Priorities as a parent. Parents explained that often times becoming an advocate led them to shift their outlook on what it means to be a parent. One parent discussed the role advocacy played in helping her understand her own priorities as parent:

I'm glad I'm doing it. I'm not just doing it because it needs to be done. I'm glad that I'm doing it and I'm really glad that I have I think the personality to do it. But it also makes me think that I - no matter what that kid says I'm doing it to be the 
parent that you're supposed to be. You know, we talk about this in the support groups all the time people - especially when someone's new, you get new parents almost every meeting hardly enough, and someone will always say, "You're so onboard, you're so this, you're so that, you're such a good parent," and we all say, "No we're not, this is just what you do, it's just a given." It's not because we're so wonderful, people don't understand that. But in a way, it's like, I'm glad I'm able to do this for this kid who drives me crazy.

Another parented noted that being a parent served as the strongest motivator for her to become an advocate. She stated, "Although when it comes to your child, I find that's the strongest passion. But just really evokes a lot of passion so other things may be interesting to me or I'd want to change, but when you get as passionate as your own child, yeah."

Expert/valued leader. Parents described feeling valued and appreciated through their advocacy efforts. Parents also noted that others in the community have started see them as a valuable resource and leader. As a result, parents reported experiencing a sense of pride associated with their experiences. One parent explained, "I feel like there have been people who really look up to me and value my advice and my support, and so that's been nice." Another parent reported gaining a sense of belonging and value:

I like feeling like I belong. And maybe I'm a person who generally struggles with feeling like I belong. And doing service is a tremendous way (laughs) to gain a sense of belonging. And I actually, so this is more of a self-identity, so maybe this will answer some other question that you already asked, so I think I like, I also like feeling like I am doing my best to make a difference in the world. So I think that helps me feel like I have value as a person. Although being a mother helps me feel like I have value as being a person.

Choosing your battles. Five parents noticed changes in the way they chose to respond to various situations. They noted choosing their battles, and deciding how to balance their values with their ability to make change. One parent discussed the process of deciding when to advocate and when to show restraint: 
If I - now I have to choose my battles - so, you know I work for a company where one of my superiors didn't necessarily come out and say "I hate gay people" or anything but it was clear that they had a very conservative viewpoint that wasn't been keeping with my viewpoint. I chose not to say something to them, mostly because they were my boss so I didn't feel that that was a good thing; I just hoped it never came up again and indeed it did not. But, pretty much anyone else I, for example, met some people for the first time the other day and I was asked to tell them a little bit about myself and so I, for the first time in such a situation, shared you know, I had two kids, you know, a daughter who has graduated from college and a son who is in college and by the way my son's also gay and one of the things I do in support of him and the LGBTQ community is that I'm a parent facilitator.

Miscellaneous. Four parents discussed information that did not fit into an identified category. Two described positive outcomes related to advocacy, such as making "good friends in the advocacy community" and receiving positive responses from a speaking engagement. The other two described the importance of advocating for others. One parent noted their interest in advocacy for those who "choose to remain silent" or "have not come out yet." Another parent discussed interest in continued advocacy beyond their role as a parent:

I am very sad that there are so many queer kids that are homeless. That makes me very sad. And so someday (laughs) someday when I have more energy, I don't know whether that will ever happen but, I would - that feels, like I don't, I haven't quite been able to imagine what I could do. There is an easy route for me to help parents. If there were a way to help homeless queer kids, that would be something that I could do. I don't know.

Nine parents were asked how their experiences impacted who they were as an individual.

This prompt led to three categories detailed in Table 19. The responses to this follow-up question appear consistent with the categories previously identified under questions four and five.

\section{Table 19}

How have your experiences as an advocate impacted who are you are as an individual? 
Categories $n(\%)$

Improved understanding of others

$4(66.7 \%)$

Stronger and more courageous

Miscellaneous

$1(16.7 \%)$

Note: Total does not equal $6(100 \%)$ because some parents reported more than one response category.

Improved understanding of others. Consistent with previous responses, parents indicated that their experiences as advocates led to an increased understanding of others. One parent described how becoming an advocate led to increased insight and selfreflection:

Well it's just understanding what it's like to be marginalized when you do itbecoming marginalized when you start out privileged and become in the marginalized category because your child is transgender. Yeah, so that changes you, you're like wow...that really - that's amazing.

Another parent explained how becoming an advocate helped him to become more forgiving and understanding of his own faults:

Consequently, you know, in terms of all that, feeling those things about myself. You know... less reactive about myself or you know beating up on myself 'cause you know it's 'oh, your crazy person, you did something wrong,' you know...More tolerant you know, of others and myself maybe.

Stronger and more courageous. Three parents reported that their experiences as an advocate helped them to become stronger and more courageous. One parent described the personal growth that developed through his advocacy experiences:

I think it's made me stronger as an individual, it's made me feel better about myself. It's made me more inter-personally competent. And it's hard because I've had to deal with this all my life, but somehow this is more personal, this is more, it's getting to it. And I can't say how much of my own personal growth would 
have happened otherwise, 'cause I'm always working on that.

Miscellaneous. One parent provided responses that did not fit into a specific category. The parent explained how advocacy helped her to become more able and willing to go outside of her comfort zone:

Yeah, it's just helped me grow more in working with people. Because it does take interacting with people, you can't isolate and get the job done. I mean, you stuff envelopes, you can send out emails so, it's a little isolating so you can a little bit, but generally it has pushed me to interact with groups of people who I wouldn't have been interacting with.

The same parent reported that her advocacy experiences changed her perspective of politics from what it once was:

So, I kind of grew up not being-politics wasn't that important I guess to our family or interesting or something. And now I see it totally different and I see how important these people are and how hard they work.

The second prompt focused on identifying ways in which the parents' relationship with their child has changed since becoming an advocate. Table 20 provides a breakdown of parent responses.

Table 20

Has your relationship with your child changed since becoming an advocate? How has it impacted your relationship with them?

Categories n $n(\%)$

Promoted honest and open relationships $6(50 \%)$

They know we support them $6(50 \%)$

This is "our" path $5(41.7 \%)$

Miscellaneous $4(33.3 \%)$ 
Note: Total does not equal $12(100 \%)$ because some parents reported more than one response category.

Promoted honest and open relationships. Often parents indicated that their advocacy experiences led to a more honest and open relationship with their child. One parent explained how his relationship with his son developed overtime:

And we have probably been more expressive with each other about that since he came out. So it's not - it actually isn't that uncommon for him to kind of give me a hug and tell me he loves me and initiate that which, you know, is an interesting transition for me because certainly when they're kids, as parents we do that all the time... but not so much when you become adults. I don't think - it's just-I don't - there's no particular reason that I wouldn't say it, just not something I would generally come and go out of my way to say. So I think it has changed in a positive way. I mean it wasn't like it was a terrible relationship to begin with, but of course it's a totally honest and open relationship at this point.

They know we support them. Parents also reported that they believed their LGBTQ child is both proud and comforted by their participation in advocacy-related initiatives. Parents noted that although their children may not express gratitude at times, ultimately their children know that their parents love and support them. For example, one parent noted that his daughter posted to social media on Father's day to thank him for the work that he's done:

And you know, she's posted pictures on Facebook of-she came with me to a PFLAG event and took a picture and posted it on Facebook for Father's Day and said, you know, “My Dad's standing up for me and everybody like me I'm so proud" - that kind of thing.

Another parent recalled an experience in which her son expressed pride as a result of her advocacy efforts: 
Actually my husband and I did get an award from a local group of Parent or Trans Parent of the Year or something... and my daughter came and her boyfriend. My son's actually in the Peace Corps in [undisclosed country] so he wasn't, but he emailed something and my daughter read it, and it was very sweet and he was very proud and happy of the friends I've met he said through these groups. So he's aware and he's happy but-about it, I think he understands that on some level he feels the support.

This is 'our' path. Five parents described navigating their own personal journey, unique to their relationship with their child. For example, one parent recalled:

So, we had a good relationship before and I think, you know, my being in support of LGBTQ rights is, you know, it means that we're sort of, we're still, we're walking the same path together, which is great.

Another parent discussed trying to follow his daughter's lead throughout this process:

Like I said, you know, it's closer. It's not perfect. I think there's still a lot of baggage from, you know what the relationship was before with all of us in the family. You know, [child's name] at age - if [child's name] was doing - if a child today was doing what [child's name] was doing when she was three, we might've been involved in this issue way longer, way sooner than we were. She started to tell us when she was three years old that she was not our son [child's previous name], she was our daughter [child's previous name] or she was our daughter [child's previous name]....And then it passed, kind of, and she was always so creative in other ways so we just assumed it was part of her creativity.

He continued:

In many ways we probably began a long period of time in her life when she was a little more shut down and not willing to share what she was truly feeling inside because she would think she would get ridiculed or pooh-poohed by her brother or her parents. So I think we're all kind of dealing with some long-simmering stuff under that in our relationships with [child's name], but I know that she's told me how important it is to her to see me do it [to advocate for LGBTQ issues], yeah. And I know that that has been the entree to have a deeper, more loving relationship.

Miscellaneous. Three other parents provided responses that did not fit into a particular category. One parent described her son as taking time to work on himself:

He's still in that stage, I would say, of figuring out who he is and working that out. So he-and a lot of this time, he lived at home. He lived at home for a while, maybe almost a year out of the four years, and one summer (laughs) and probably 
nine months or something, but so I think he's you know.

Another parent reported their child is also an outspoken advocate for others, independent of their relationship:

They're doing some like lobbying for Black and Pink like queer people in prison and stuff. When they are around in the summer time, they're involved in that. They'd love to get a job as a LGBTQ...You know, as an activist for LGBTQ rights in different places.

The remaining parent described an unchanged relationship with her child. The parent did not, however, indicate indifference on behalf of her son. Instead, this parent described being close to her son, prior to advocating on their behalf and maintaining that closeness over time:

I mean I think possibly, possibly that's maybe the least amount of change because he's the same person that he was before we were advocating for this particular aspect of him... and he's not really present for a lot of the actual advocacy activities. They're about him but he's not there; he's not necessarily in the room with the people who I'm talking to or... He's just doing his thing; he's just being the same person he was... and in that way we have really kind of the same relationship we did....and so interestingly I think our relationship with him or my relationship with him is one of the least changed.

Being 'out.' A few parents reported that since becoming an advocate they have become more outspoken about their own experiences, as well as their pride in the LGBTQ community. One parent described her experience 'coming out' to those in her community.

And I notice it's a big difference is when you're comfortable with your kid, you're comfortable with it and you're like good with it, then nobody gives a shit! Everyone thinks it's great. But if you're like ambivalent, then it opens up the door for them to make bullying comments. But, if you're like "That's my boy!" that's it.

Another parent described her experience balancing her child's need for privacy with her interest in advocating for the LGBTQ community: 
While she was in high school, even though she had come out to me and a small group of friends, she was mostly still in the closet-I think not so many people knew her identity. And I needed to be discrete because of that. And I think over time, she has come out more and been, you know, more willing to identify as lesbian and therefore I've been able to talk about her as being lesbian. So, I think that has changed over time.

Indifferent. Two parents indicated that their children were uninterested or indifferent about their contributions to the LGBTQ community. One parent added that her child always knew he would be supported, regardless of their advocacy work. She explained, "But he knows that we'd have supported him whether it's doing this or not I think so. So, I would say not really. It hasn't changed our relationship."

The third probe asked parents to describe how their relationship with family members has changed since becoming an LGBTQ advocate. Table 21 provides a breakdown of parent responses into seven categories.

Table 21

Have your relationships with your other family members changed since becoming an LGBTQ advocate?

Categories n $n(\%)$

Not applicable

Deeper/stronger relationships

Conversation topics and advice

They are allies

We are at different points in our journey $3(25 \%)$

Miscellaneous 
Note: Total does not equal $12(100 \%)$ because some parents reported more than one response category.

Not applicable. A total of five parents indicated that the prompt did not apply to their experience, noting that their relationships with family members had not changed since becoming an LGBTQ advocate:

Well, other than the three people who don't talk to me anymore, I don't have any other family. So there's no, I mean really, there's nobody else. And as far as my husband goes, has it changed? We don't deal with [my child] the same way. We're not on the same page pretty often, but in terms of the advocacy part, I don't know, that hasn't really altered it really. I don't think so.

Deeper/stronger relationships. A number of parents indicated that after

becoming an advocate they were able to develop deeper and stronger relationships with other family members. One parent explained the relationship she developed with her family, "so I would say in some ways it's strengthened because they were there for me. Yeah, I'd say strengthened." Another parent described how he built a deeper connection with his wife by participating in advocacy initiatives in college:

[My wife] and I met in an advocacy program and for us to continue to be advocates together has been a great thing for us to share. It reinforces that we have values that match and make us compatible and make it fun to be around each other and it makes us feel open and productive and positive and it gives us a good thing to share. So it's really contributed there.

Another parent indicated that she was able to create a deeper and stronger bond with family that supported her after her child 'came out':

So there are some - so the family members that are just immediately and overtly and enthusiastically supportive, I've, you know I've-it's made our bond even stronger because we're, you know, together against a, you know against atogether trying to right something, you know, right a wrong, and support someone we care about. 
Conversation topics and advice. Several parents indicated that since becoming an LGBTQ advocate they have been able to talk more openly about LGBTQ issues and provide advice for other family members. One parent described a situation in which her Mom felt comfortable asking for advice regarding the LGBTQ community:

I do remember when I was involved in the welcoming congregation committee at my church and my mother is in the congregational church in [local town] and they were doing the equivalent program in their church. She said, well she came to me one day to ask me about "Can you explain bisexual to me, I'm really having trouble with that one," and I was able to explain to her the best I understood of what that meant in a way that she was able to be comfortable with and so I think it was interesting to have my mother coming to me for advice as opposed to the other way around, you know so, a little bit, you know, I was now the expert on that subject.

They are allies. Some parents indicated that their family members have become supportive allies for the LGBTQ community. One parent described it in terms of "like either you're with us, or not—-that's it...At that point, it was like that. Like, at one point it got to like okay you're with us or you're not. So, and in the end, my whole family —alleveryone now is an advocate." Another parent described the difference between acceptance and advocacy, in regards to both supportive and unsupportive family members:

And so the people who have been—not unsupportive—but just less enthusiastic or less overt and sort of more like "I'll just kind of accept this change, not embrace it, sort of accept it," they're not really big on the advocacy piece, they're just big on the acceptance which is different than advocacy, right?

We are at different points in our journey. Three parents described situations in which their family members expressed differing levels of acceptance. One parent explained that although his wife was supportive, she was not ready to become an advocate to the same extent:

Yeah, so my wife, [wife's name], I mentioned that she's from [another country] 
originally. She, by the way, has not told any of her family members, yet. I've been trying to encourage her to tell them, at least to her sisters anyway, because it would give her people to speak to, not that she feels this urgent need to speak to people about it; she's already gone through that with PFLAG and in fact she doesn't come to the PFLAG meetings very often anymore because she feels like she's gotten everything out of it that she needed and also because, you know, on those occasions when it's the same six, seven people that go to the group she just kind of finds that boring in the nicest possible way.

Miscellaneous. Three parents reported responses that did not fit into the present categories for this prompt. One parent processed out-loud how they might talk to their family about recent changes to her child's preferred pronouns:

And it's funny because, you know, [my child] transitioned from female to male and we, we all got really good at using male pronouns. And now they really identify more in the middle, non-binary, and have asked us to use "they/them/theirs", well they asked me to use "ey/em/eirs" pronouns and I'm like, "Oh my God that's really...can I just try with 'they/them/theirs/ and see if I can even get my head around that to start with?" And so I'm getting better with that, I still like, I think I use male pronouns half the time and "they/them/theirs" half the time. And I'm like, I'm not quite sure, like whether and how to spring that on all the rest of our family and how important it is to [my child]. Maybe at this point, it's like, that's [my child's] job to do? Maybe not so much mine.

Another parent discussed their own personal growth stating, "Advocacy helped me to get past some of my habitual stuff...like inertia or reactivity to certain people with certain habits or anything like that. You know, it wasn't just you know, the trans stuff, it's personal growth." Meanwhile, another parent referred back to the definition of advocacy adding, "Acceptance is kind of being okay; advocacy is using your voice to change something about the way everyone feels about it or the way people think about it."

Relationship with non-LGBTQ child has changed. Two parents reported instances where their relationship with their child, who does not identify as LGBTQ, changed in some manner. One parent reported difficulty connecting with her child who does not fully understand her decision to become an active advocate: 
But my daughter-I think she's a little jealous of all the attention my son got. Like all of my energy went to him (laughs) and everything was about him. And even though she was older and not living at home for a while-she lived at home too but I think she doesn't totally get it... but she hasn't really lived with him since the transition and so, so again she's not-and she's getting - so she's got her world and it's fine and she doesn't mind, you know she's supportive at some level. So for my advocacy, I mean she showed up the time we got the award. I didn't know about it, it was a surprise so they-people and friends contacted her and she-and she was very nice, she was very pleasant. But she's not out there doing-she's not advocating herself, I would say.

The final prompt for question four asked parents to describe how their

relationships with those in the community have changed since becoming an LGBTQ

advocate. Parent responses fell into five categories, detailed in Table 22.

Table 22

Have your relationships with those in your community, both the LGBTQ community and the larger community you referred to previously, changed since becoming an LGBTQ advocate?

Categories n $n(\%)$

More established community connections $9(75 \%)$

Relationships give strength

Being a source of support

$4(33.3 \%)$

Little to no change

Miscellaneous

$3(25 \%)$

Note: Total does not equal $12(100 \%)$ because some parents reported more than one response category.

More established community connections. A majority of parents reported 
creating more established community connections, both within the LGBTQ community

and the community at large. One parent described her experience going from an ally and

outsider to developing sense of greater belonging within the LGBTQ community:

I think with the LGBT community-LGBTQ community-I feel that I've been let in a little bit. As like a white, middle class heterosexual woman, I don't-you know-I didn't — and - but as a, you know, supporter... an ally of the LGBT community, there was nothing-I don't think there was anything specific about me allowed me entry into the LGBT community; I was just, you know, your average ally. Being someone who's advocating for their child, who's speaking out publicly, I feel more embraced by that community. Kind of like, when I talk about my experiences, it's kind of accepted by them as opposed to if I weren't any kind of advocate or if I didn't have any kind of special tie, I feel like my opinions might have been a little more but, you know, ignored, written off, not really embraced. Just by the fact that I am a part of that now I feel like all of a sudden my fears are more important. I mean I-so I guess I didn't honestly feel a part of the LGBT community at all before this, more like an outsider who's trying to be supportive... and this has put us more as an insider, you know, who's more accepted and I guess there's times that I felt, you know, LGBT-the LGBT community that people are or can view those who are not in the community with somewhat-like somewhat suspicion or a guardedness, you know like, "I don't know what your views are so I'm not gonna put myself out there at all because I have no idea how you're going to react."...Well, when you start advocating, or you start you know, being an active member of a community, that wall comes down... and people are no longer sort of afraid to be themselves with you because they get signs from your advocacy that you're an ally and that you're one of them, not, you know, an outsider.

Parents also established new connections within a variety of environments, including community networks, schools, and churches. One parent reported being able to create new connections at work as a result of her advocacy:

Anyway, my experiences elsewhere doing advocacy...is like, "Oh, maybe I can help out and do trans education and trans advocacy at work." They're getting gender neutral bathrooms at work and there was like a page that one of my colleagues said "Why do they have people's genders on this page that they're advertising all the brand new employees? They're putting their names and their gender on there, like why is that important?" And so, like emailing the head of HR and saying, "Hey, do people's genders really need to be on there? What if people's genders don't match their legal genders and their preferred gender?" And she's like, "Good point, let me look into that." So anyway, so I'm doing some stuff at work too. 
Another parent described her increased visibility and expertise within the larger

community:

I think, mainly with the larger community I feel more - a little bit more - what's the word? It's kind of like you know, I feel a little less invisible so as part of the larger community where people, you know, know who I am and have an opinion on my thoughts, you know, without sort of being involved in any advocacy, no not really. I feel like when I do put myself out there and do advocate, that there's a different level of respect and connection with the larger community that I am an expert on something or I have - my thoughts come with some sort of level of like, you know, validation because I'm an advocate, I have a child.

Relationships give strength. Several parents indicated that their relationships

with those in the community provide the strength needed to continue their advocacy efforts. One parent described how those within the community provided the validating environment she needed to feel connected. She noted, "I have like-so your thoughts must be, you know, you must be a valid person, so there's some sense of validating like place in the community...opposed to sort of being a little more invisible I guess."

Another parent described his development and growth that resulted from his relationships with those in the community:

I think that's across the board but, you know clearly I look back and over the course of my life and I mean I have the curse of somebody who's written all along the way, kind of a journaler and all that and I found some stuff even recently that I wrote when I was first in the workforce and first working with, you know, gay people and they were not-I'm not proud of the things I wrote and said...to, you know the younger me. And so some of that is realizing that okay you know what? These are not like different types of creatures, they're fellow human beings. They're not so foreign, you know? Loving another person regardless of the gender identity, sexuality, whatever is really no big deal, you know, and it just seemed like it was a much bigger deal... when I was younger. You know.

Being a source of support. Four parents indicated that since becoming an advocate they have become a source of support within the community. Parents reported being able to point others in the direction of resources and information. They also felt 
more easily recognized within their community as a safe and supportive ally. One parent identified being a source of support for others:

I may get a call from somebody who needs support. I've had several mothers who I've spent an hour or more on the phone with and they have said that I've helped them understand better, feel better about everything. So, that's good...I've had a positive impact on the lives of some other parents in our community. That's a good feeling.

Little to no change. Three parents reported little to no change in their

relationship with those in the community. One parent explained how her relationship with those in the LGBTQ community did not change following their decision to advocate:

Now some of them, their kids are getting older and they don't really need to be so involved anymore, but we're still friends. So I don't think anything's really changed. Some of 'em don't advocate as much or, now I'm working full-time when I wasn't before so I'm not doing quite as much.

Another parent explained how their connection to the church also remained unchanged:

Well church, that's a no... [the] church got to know that I was an advocate for the pastor being a member of their physical church of getting pride set up, getting their group together, no...He came to [local university], but unfortunately not many people came to hear him but, anyway...Their loss.

Miscellaneous. Three miscellaneous responses by parents did not fit into any particular category. Interestingly, many of the responses that fell within the current miscellaneous category, more closely correspond with previous questions and prompts. One parent described taking their child's needs into account prior to advocating in the community:

But a lot of people I know really would be an advocate, but don't because they don't want to out their kids. And I always ask [my child], "Can I, do you mind if I do x?" before I do it. I- I have to say, I didn't think of that before, but I don't want - and he used to say yes or no, and now it's like, "Do what you want." He's lightening up a little...But so, they're grateful for the people who do something because they can't even though they want to. So, that's a positive thing.

Another parent described himself as being a voice for change: 
I'm not a supporter of any of the restrictive politics. I'm not a supporter of anything that is getting labeled, you know 'hate laws,' or 'hate politics.' And I think I'm one more voice added to the larger community, speaking up about that. So, whereas we went from our current president, who when he came into office was not a supporter of gay marriage. And, you know the - one of the next presidents who's running who is not too much of a career supporter of gay marriage. To all of a sudden - you know, these laws have passed, a lot of other laws have passed, the Pentagon is saying gays are okay in the military, transgender people are okay in the military. Like this whiplash of change in that larger community, I think I'm one more voice in that. So, people, you know, if certain groups are feeling threatened by that, then I'm certainly one of those voices that wants them to know, well there's something big happening, but it's not a threat to you...But, I'm one of those voices.

Additionally, another parent reported being less judgmental of others as a result of their advocacy experiences.

I would say for sure in the LGBT community just because I now know so many people that I think I have finally achieved that place where it's not even like I don't sit there "I wonder if they're gay, I wonder if they're bi," you know what I mean? Like it's just a person. And I also don't go out of my way to try to be accommodating... or you know. No I'm gonna treat you just the same (laughs), you know... as I treat anybody else which is really the breakthrough I wanted to make, you know....and just accept people on their own terms and not be constantly wondering if I'm saying the right thing, doing the right thing, thinking the right thing when I'm interacting with somebody.

The last interview question asked parents to describe what advice they would tell other parents of LGBTQ children. Parents were also asked to provide guidance on becoming an LGBTQ parent advocate. This question, although initially combined, was divided into two subsections: Advice for parents of LGBTQ youth (Table 23) and advice for future advocates (Table 24). Their responses are detailed below.

Table 23

If you were in a room with other parents whose child identifies as LGBTQ, what would you want to tell them now?

Categories $n(\%)$


Provide validation

$9(75 \%)$

Tell them our story

$8(66.7 \%)$

Offer education and resources

$6(50 \%)$

Miscellaneous

$2(16.7 \%)$

Note: Total does not equal $12(100 \%)$ because some parents reported more than one response category.

Provide validation. A majority of parents indicated the importance of providing validation to parents, and encouraging parents to provide validation to their children. One parent described how he would initially support other parents of LGBTQ youth by meeting them where they are at on their personal journey:

I think the first thing that I would tell you if you were a brand new parent to this, I would before I said anything I would probably just kind of ask how you feel. I'd actually be concerned about just kind of knowing where you're at emotionally. How are you? How is your husband or wife? How is your child?

Other parent participants also emphasized telling other parents of LGBTQ youth that everything would be okay and workout in the end. One parent stated that his first response would be, "I would say, number one, 'Its going to be okay.' " Another parent encouraged interactions with parents that instilled hope:

It's very important for new families to come in and see that you can get over that hell that you're gonna be going through. That it's at least possible and that you hear about trans kids making the transition and trans kids holding jobs and finding partners and having a happy life sometimes.

Parents stressed the importance of providing validation for parents of LGBTQ youth. One parent explained:

And I always say if the parent says to me "I told my kid I will always love you no matter what," I say, that's the most important thing for you to say, you know, that 
"You're doing it right, you've done the right thing."

Parent participants also emphasized the importance of providing validation to LGBTQ children. One participant shared their advice for parents of LGBTQ children by noting "It's really important to let your kid know that you will always love them. And, everything else doesn't matter, you know." Another parent also suggested reminding parents "That your child is still your child and the same child you had before they told you that news and love them and be supportive. That's all." Similarly, one parent emphasized the importance of parental acceptance of LGBTQ youth:

It is that if you care about your child's happiness and their acceptance of themselves and their-you know, about their success, like you care about those things, then it's important to know that being an advocate for them is, I think, and I don't know-I'm not speaking from studies and scientific data—I'm speaking from a lot of different sources of data, that the parents' acceptance of advocacy for their children is possibly the single most important element in those kids having happy, you know, confident, normal lives.

Tell them our story. Parents also discussed sharing their own personal experiences and providing accurate information to other parents of LGBTQ youth. One parent recalled an event in which she and her husband were able to share their story and educate others:

And then I was there, my husband was there, and this friend I told you who might call you, and her husband, and one other woman who I never met before, and we got up to talk about our experiences as parents. And then, tell our story, and then field any question. And the questions just kept coming, and it was great. And I think people really had a good time in terms of, they learned stuff.

Another parent shared how he instills hope in others trying to process their child's 'coming out' by sharing his own story. He expressed:

I know it's a really tough thing at first but what I can tell you today, is that even though I was where you're at right now, I'm where I am today, and where I am today is a great place. And so, I can't tell you how long your journey will take, I can't tell you how easy or difficult it will be, but I can tell you that you will get to 
the end of it. You will get to where I'm at and you'll wake up one day when you're not thinking about this all the time.

Provide education and resources. Six parents indicated that their initial reaction to meeting another parent, whose child identifies as LGBTQ, would be to provide education and resources:

But if they were parents of gay kids, then I would have to try and explain to them what the difference is because a lot of people, like we used to say LGB and then we added the $\mathrm{T}$ and then we added the $\mathrm{Q}$ now and now apparently there's 24 more letters that I don't even know what they are, you know, you can't have them all in there. But most people, even if they have a gay child, they don't understand what anything else is and unfortunately the greater percentage of people who are gay are very anti-trans, interestingly. So the parents may either not understand, not know, or also so you have to educate them.

One parent explained how he would use community resources to respond to a variety of questions from another parent:

What if my child wants to make changes to their body and could give them some information about, well you don't have to-you really - that's not that important for you to think about until $\mathrm{X}$ and if you're at $\mathrm{X}$, here are the things that you would think about and here's some people you could talk to.

Miscellaneous. Two parents responded in a manner that did not fit into any particular category. One parent discussed the frequency at which people seek their help and advice since their child 'came out':

There's been a lot of - my buddy, one of my close friends who I thought was a little bit mediocre in terms of his support and his conversations, man he- the truth is he was just thinking out loud and...investigating stuff in his mind and it wasn't that he was unsure in some resisting, negative way, but he was just unfamiliar. Like I wondered where he was one day, but the next, he's calling me from, you know, his girlfriend's boss's party, you know, where like he overhead this couple whose, you know, four year old is saying that they're a different gender and he's like, "Oh I wanted to put you on the phone with them just on the spot and like you could share so much with them," but that happened and then something like that happens probably every three weeks... Well yeah, since I mean since our son came out... Since probably three weeks. From three weeks when after he came out 'til within the last week... There's just been another family to talk to every...yeah. And I mean really, some of them we've just talked to once and some of them we 
really connected with.

Another parent discussed his struggle to understand parent's who are not accepting of their child's identity:

I wonder too, you know, parents of larger families, you know I have two kids, I will tell you at times I have fallen victim, personally, to the well at least the one kid is quote unquote perfect. They don't have any of these issues...they are somebody I'm never going to have to worry about. Thank goodness I only have one to focus on. I can see a parent who has four or five kids and one of them comes out as gay or transgender and they could say "Well at least four were fine, get out." You know, I don't-I can't deal with this. You became one of those, bad luck on me, almost like bad luck a kid was, you know, born with a physical disability that would cause their life expectancy to only be 24 years, spina bifida or whatever. These things, crazy things happen in every family. You know...I mean I said crazy things, things that are challenges happen to lots of children. Some parents have Down syndrome children, some parents have kids with cerebral palsy or in a wheelchair before they're four and some have kids who come out as gay in high school, you know? We all have issues. Some kids have learning disabilities and you have to navigate that. All of us deal with things, why is this the one where parents think it's okay to throw the kid away?

Finally, parent participants were asked to provide share their advice to future parent advocates. Table 24 represents the four categories that emerged from their experiences.

Table 24

If you were in a room with other parents whose child identifies as LGBTQ, what would you like them to know about becoming an advocate?

\begin{tabular}{lc}
\hline Categories & $n(\%)$ \\
\hline It's not hard & $9(75 \%)$ \\
It's crucial and urgent & $7(58.3 \%)$ \\
It's rewarding & $7(58.3 \%)$ \\
Your story is important & $4(33.3 \%)$
\end{tabular}


Note: Total does not equal $12(100 \%)$ because some parents reported more than one response category.

It's not hard. A majority of parents framed advocacy as something that is both easy and doable, from making an impact one person at a time to connecting parents to resources. One parent explained, "Becoming an advocate is not that hard actually." For example, another parent noted:

It doesn't necessarily take a ton of your time, and that —oh, and you don't have to dive in and do a ton of things at once... You can start advocating by, you know, one little thing. You know, [local LGBTQ equality organization], they send out an email that says, "Put your name here and push this button," and the email is gonna go to the state house. Couldn't make it easier.

Parents explained that future advocates should not be overwhelmed when attempting to advocate on behalf of LGBTQ issues. Instead future advocates should work on making small gains, one person at a time. One parent described this approach in greater detail:

Not to have big - not to have, not to be overwhelmed because they have - they think they need to change a lot. You know, you like when you go to a ceremony, you light one candle, and then that one person lights one candle and then the candle goes to the next person. And with at Easter it's like that, and then one candle lights the entire like hundreds of people in no time. But you just give it to one person next to you and then they light the person next to you and so it just takes-you just need to light one candle. Like, there's no-you know, just one person. Even if you do it for one person, you've changed everything. So, it just takes one person. One person at a time.

One parent recommended connecting to PFLAG as a starting point for future parent advocates:

PFLAG is always looking for additional parent advocates. We would happily take a new advocate at our group meeting because there are times when one of us is traveling and, you know, it's good to have more than one facilitator there. If you are interested, we would simply connect you to the folks at PFLAG in [city] and we would have you attend one of the facilitator trainings, which is basically kind of teaching you how you handle different types of situations in a meeting, how you kind of moderate - keep things moving along, and which different resources exist for parents so that when you meet someone like you in the future, you'll 
know what to say to them.

It's crucial and urgent. In order to emphasize the importance of advocacy, parent participants framed advocacy as an urgent matter that was necessary for their child's safety. One parent discussed the gravity of the situation in their fight for civil rights:

I want them - I want people to understand that first and foremost, just right now because it's so time sensitive, that if you think you have a transgender child, or a gender who is - a gender, a child who is gender, I'll call it neutral in a way. They're on the spectrum somewhere, you know they're not identified, you understand all that, that they have to now be very vocal and conta - we say this over and over, contact the senators and the congress people, the reps, not congress, the reps, and the governor because it's now or never. It's do or die. And in a way, we try and almost scare them by saying, "Do you realize how unsafe your child can — " and nobody gets it. So that's, that would be number one. You have to be an advocate for your - for the safety of your child. And that works, because the first time anyone comes to a group, the very first thing they say is, "I don't get this. Maybe I'll figure it out, but I'm worried, is my kid gonna be safe?" So that's what I would do.

Another parent described the urgency of advocating on behalf of an upcoming transgender rights bill in their state:

On the legislative level, I mean I still feel like that's really important and it doesn't...It's interesting that there's sort of this hypothesis that like will the law stop discrimination and violence? And it may not, but it sure as hell feels good to know that you've got the law. Like the law's at your back, like that feels important. So it's an urgent-it's important.

It's rewarding. Seven parents discussed the rewards and benefits of participating in advocacy initiatives. One parent explained simply, "I guess just that it's really rewarding work. You know, it feels good to be able to speak up and make the world a better place." Parents also noted the benefits of parent advocacy for their children. One parent explained:

I think even if your child says that they don't want you to go to a PFLAG meeting, it's not that important, it really does mean a lot to them for you to be getting 
educated and becoming an advocate. You know, especially teenagers who are always, you know, a little bit contradictory, you know. They might say "oh, no I've got it all under control," but they really do notice when you do things like that and, you know, going to a PFLAG meeting, marching in a pride parade, those kinds of things mean a lot to your kids even if they aren't willing to tell you they do.

Your story is important. Four parents encouraged future LGBTQ parent advocates to share their personal journey with others in the community. Parents explained that sharing these experiences serve to inform, educate and inspire. One parent explained how sharing her story, although difficult, was an important aspect of her work as an advocate:

Someone has to be bigger than their own family and going to [the local newsradio station] was not easy for me. Like I was nervous and I didn't like having to hear myself on the radio and I felt like I sounded stupid and all this stuff. I didn't do that for myself and I didn't even do it for my son because he knew everything I said. Everything I said I've said to him. I did it so that other people would hear that and maybe change how they approached their kid or someone else's. So I guess that'd be my message to them. 


\section{CHAPTER 4}

\section{DISCUSSION}

The current study used semi-structured interviews to explore the individual, family, and community level experiences that help parents of LGBTQ children to initiate and facilitate advocacy efforts on behalf of the LGBTQ community. The study also examined the barriers to advocacy and the impact of parent advocacy on parents' view of themselves and their relationships with others. The qualitative interviews produced valuable insights into the unique experiences and challenges facing parent advocates, as well as the meaning of those experiences to their relationships and development as an advocate for LGBTQ issues. The parent participants also provided recommendations for parents of LGBTQ youth seeking to pursue future advocacy efforts.

\section{Defining Advocacy}

It is important to determine what the term "advocacy" meant to parent participants before exploring their advocacy-related experiences. The majority of participants stated that advocacy means working towards change. In particular, participants emphasized the importance of working towards equal rights for marginalized groups. Participants also expressed that being an advocate includes being a supportive and accepting ally, standing by your beliefs, and educating others. By using this definition, parents differentiated between the role of an advocate and the role of an ally. Parents indicated that an ally is one who is both an accepting and supportive of LGBTQ issues, while an advocate educates others and speaks out for marginalized groups in an effort to ensure equal rights. Interestingly, this definition of advocacy is more consistent with the term "ally" within the research literature (Barnes \& Ederer, 2000; Washington \& Evans, 1991). More 
specifically, Washington and Evans (2001) note that an ally is someone from a majority/dominant group who works to end oppression through support and advocacy for an otherwise marginalized group. Barnes and Ederer (2000) add that an ally is also motivated to take action in order to establish a sense of equity for all groups. Conversely, parents in the present study appear to indicate a contrast between what it means to be an advocate and what it means to be an ally.

\section{Initiating Advocacy}

Parents described in detail experiences that led to their development as an LGBTQ advocate. Throughout the interviews, parents recounted emotionally processing their child's coming out and other experiences related to 'coming out' to family. Across interview questions, a total of nine parents $(75 \%)$ recounted the ways in which 'coming out' impacted their development as an advocate. In order to help process their child's 'coming out,' parents sought community resources to help them become better informed. A majority of parents reported that learning from the community led them to pursue advocacy-related initiatives. In particular, parents reported witnessing injustice in the community, learning from those within the LGBTQ community, and finding community resources in order to support their child. Parents emphasized this when discussing the value of community connections and working together with those in the community. Similarly, Saltzberg (2009) documented the experiences of parent allies who reported longing for connectedness, community, and resources during the 'coming out' process. For many parents, these types of community supports, coupled with individual and familial background, allowed them to more easily advocate on behalf of their children and provided the foundation for future advocacy. 
Several parents also expressed experiencing invalidation and non-acceptance from their family, but these experiences did not deter them from fighting from LGBTQ rights. Most parents, however, indicated that having a supportive or beyond supportive family encouraged their development as an advocate. It is also important to note that half of the participants expressed finding value in the support provided by their spouse and immediate family. Interestingly, all parent participants recruited for this study identified being married. Conversely, previous research indicates that married parents may show less willingness to participate in mobilization efforts when compared to unmarried parents (Beyerlein \& Hipp, 2004). Beyerlein and Hipp (2004) note that married individuals may be less willing to participate in protest action because of potential negative sanctions from their partner or potential damage to their relationship. Women, in particular, may show less willingness to participate in mobilization efforts based on their marital status (Beyerlein \& Hipp, 2004). In the present study, married women accounted for $58.3 \%$ of the overall sample. Further, none of the participants in the study expressed negativity from their partners as they pursued advocacy-related initiatives. The overall experiences of both mothers and fathers in the present study indicate that marital status was not a sole predictor of parents' willingness to advocate on behalf of LGBTQ issues. Therefore, the present findings may also indicate that supportive or beyond supportive partners and immediate family members may be necessary for parents to advocate on behalf of their children.

More than half of parent participants reported being an advocate for marginalized groups before their child came out as a member of the LGBTQ community. Two parents added that after their child came out, they simply shifted their advocacy efforts to focus 
specifically on transgender rights. Parents' previous experiences in advocacy align closely with Vernaglia’s (1999) Social Justice Pathway. Additionally, parents reported pursuing advocacy based on a need to support and protect their child. They noted that advocacy offered an opportunity to show support for their child and share in their journey by learning and growing alongside their child. Similar experiences may exist among parents who identify as LGBT and advocate on behalf of LGBTQ issues. More specifically, Blackwell, Hardy, Ammari, Veinot, Lampe, and Schonebeck (2016) found that parent social media advocacy is guided by the need to support and protect their children, particularly as it relates to their relationships in the larger community. LGBTQ parents have utilized social media to identify allies, advocate on behalf of LGBTQ community, while also working to protect their child's privacy within online forums (Blackwell et al., 2016). This crossover of experiences among both parents of LGBTQ youth and LGBTQ parents may provide insight into parent advocacy at a larger level.

These findings are also consistent with Vernaglia's (1999) research study that identified a 'Parent Loyalty' and a 'Social Justice' pathway to advocacy. However, the present findings indicate less distinct pathways to becoming a parent advocate. More specifically, most parents who expressed a history of social justice and advocacy also represented the majority parents who reported pursuing advocacy as a way to support and protect their child. Therefore, these findings build upon Vernaglia's (1999) study to outline a more transactional and dynamic approach to understanding the pathways the lead to parent advocacy.

Additionally, parent advocates reported that awareness of self and others impacted their development as a parent advocate. In particular, parents expressed self- 
awareness, understanding of community climate/culture, and recognition of needs in the community. In a study of adolescent LGBTQ allies, Poteat (2015) found that students who most often engaged in advocacy also demonstrated a greater level of critical thinking and self-reflection, as well as lower levels of sexual prejudice and a history of more LGBTQ friends and more discussions with peers associated with advocacy for LGBTQ issues. Advocates across age groups may therefore display common traits, such as the ability to display self-reflection and critical thinking. Moreover, all of the parent participants reported some level of higher education, with half of parents with a master's degree background. This may suggest that college-related experiences may provide opportunities for greater self-awareness through increase exposure to diverse groups and experiences, which may result in an increased likelihood to become an advocate. Further research in this area may be beneficial to understanding the common experiences that help individuals to become advocates, including educational background.

Five parents reported that their experiences with discrimination and isolation had little to no influence on their decision to become an advocate. Conversely, experiences with witnessing discrimination and an increased level of multicultural awareness were also reported to impact advocacy development. Likewise, Duhigg et al. (2010) and Phillips and Ancis (2008) found that allies often shared previous experiences with marginalization, witnessing discrimination, and a heightened sense of multicultural awareness that helped their development as an advocate. From an ecologicaltransactional perspective, this level of awareness at both the individual and community level coupled with support from community resources and family, particularly spouses and immediate family, may allow parents to feel more able and willing to speak up for 
what they believe. Moreover, parents reported that the need to speak up for what they believe was an important part of their decision to become an advocate.

\section{Facilitating Advocacy}

Parents shared experiences that facilitated their continued involvement in LGBTQ advocacy efforts. Consistent with previous findings, all parents in the present study emphasized the role strong community relationships, including relationships with the LGBTQ community and larger community, played in their experience as an advocate. Parents reported that becoming a "leader" in the community, seeing a need for change in the community, and identifying community supports helped them to continue their advocacy efforts. Parents were able to roll with resistance from other members of the community, as many were motivated by the opportunity to impact others and produce positive outcomes for the LGBTQ community. These community-level factors appeared to influence individual decisions to advocate on behalf of LGBTQ rights. Based on these findings, community-level factors continue to provide the support necessary for parents to pursue advocacy. Glennon (2012) notes that through community and parent-based support groups, parents are able to develop pride in themselves and their child, while also working to change societal norms.

A supportive family also appeared to play a critical role in a parent's experiences as an advocate. In particular, parents reported gaining insight and inspiration from their child, which helped them to continue their advocacy efforts. Many added that their overall parent-child relationship positively changed as a result of their advocacy. Parents reported feeling closer to their child through their endeavors. Parents also expressed being further motivated to make their child proud by continuing advocating on behalf of 
LGBTQ issues. Similarly, two parents expressed that they now advocate alongside their child, in essence they are "doing it together." In contrast, several parents reported that their advocacy efforts were independent of their child and that their family played little to no influence on their decision to continue advocating on behalf of the LGBTQ community. In most cases, the parent-child relationship appeared to be core component of each parents' experiences as an advocate.

Parents in the present study also reported that their experience as an advocate was influenced by the concept of role models. Although only three people fit the category, outlined in Table 13, a total of six parent participants overall reported that role models played a role in their development and experience as an advocate. Two parents reported benefiting from family members who served as advocacy role models, while the remaining four participants expressed wanting to serve as an advocacy role model for their child and for other families. Duhigg et al. (2010) notes that heterosexual allies are often influenced by early modeling of advocacy by other family members. In the future, it may be beneficial to explore the ways in which advocacy is modeled for LGBTQ children of parent advocates, as well as its impact of their likelihood of participating in future advocacy-efforts.

\section{Barriers to Advocacy}

Parents experienced challenges and barriers in pursuing their advocacy-related efforts. Most often, parents reported struggling to work with people that had differing opinions. Parents identified that different personalities and beliefs were the most common barrier they encountered through their advocacy work. Parents noted that those with differing opinions included family, community members, and even fellow allies. The 
second most common challenge parents encountered was related to organizational and logistical issues, such as time management. For some parents, being able to overcome personal fears and insecurities, overall frustration, as well as navigating the political and legislative system was among the most daunting tasks to overcome. These sociocultural problems and psychological challenges are common challenges highlighted in the literature (Ji et al., 2009; Watson et al., 2010). These barriers may be both permeable and enduring characteristics that hinder or slow progress towards advocating on behalf of LGBTQ issues.

Parents also reflected on negative reactions they encountered by others in the community and in their own family. Parents reported encountering family and/or community members who "just don't get it." They expressed encountering people who expressed subtle negativity or a lack of understanding regarding their child's identity and/or their efforts to advocate for LGBTQ issues. Some parents suspected that their friends and family may have negative reactions to their advocacy and/or child's identity, but insisted that "they wouldn't say anything" to them if it was negative. Parents also reported diversity-related concerns and/or fear of discrimination for their child. This fear of discrimination or experience of subtle negativity by others may prevent parents from pursuing advocacy efforts (Glennon, 2012). Parents appeared to negotiate their need to support and protect their child with the potential negative reactions by family and community members. In contrast, other parents reported an absence of negative reactions by those within the family and community. For these parents, the community climate created a positive environment that fostered advocacy and acceptance. This allowed 
parents to more easily pursue advocacy related efforts without fear of potential repercussions.

Additionally, parents recognized personal challenges they faced initiating and pursuing advocacy-related efforts on behalf of the LGBTQ community. Although three parents denied encountering and overcoming personal challenges, five parents reported overcoming their need for knowledge. Parents reported that prior to becoming an advocate, they needed to identify reliable sources of information regarding LGBTQ issues. These findings are consistent with previous literature, thus reiterating the importance of identifying community-level supports that can provide parents with the validation and resources necessary to overcome their fears (Getz \& Kirkley, 2003; Ji et al., 2009; Watson et al., 2010). Several parents reported difficulty finding the time and emotional energy to advocate, as well as overcoming discomfort. Given this information, parents may need additional support from both family and community resources in order to effectively balance their individual needs with their desire to contribute to the larger community. Despite these experiences, parents reported a motivation to push past their personal challenges in order to advocate on behalf of LGBTQ rights.

Parents actively worked to address the challenges they faced as they advocated. In order to overcome challenges, parents most often reported the need to push forward and be persistent in their fight for civil rights. Parents emphasized the importance of community supports and personal successes in helping to move forward with their advocacy initiatives. Half of parents indicated a need to accept the reality of a situation and see the best in people even when they may disagree with them. These outcomes indicate that parents are able to move forward despite the significant community, family, 
and individual-level barriers they encounter when pursuing advocacy-related activities. Consistent with Social Identity Theory, the costs and benefits of advocacy appeared to be outweighed by their identity as a parent and member of the LGBTQ community (van Zomeren et al., 2008). More specifically, for parents the potential costs associated with participating in advocacy efforts was outweighed by the critical and urgent nature of pursuing civil rights on behalf of their children and the larger community.

Interestingly, parents also reported that through their advocacy experiences they learned to "choose their battles," a common concept within the microaggression literature. Microaggressions are defined as brief and common verbal, behavioral, and environmental indignities based on status (Sue, Capodilupo, Torino, Bucceri, Holder, Nadal, \& Esquilin, 2007). Microaggressions may occur both intentionally and unintentionally by others. Microaggressions are also seen as the most common form of discrimination (Sue et al., 2007). Within the microaggression literature, Black and African American women have reported having to "choose their battles" when trying to decide whether to respond to a microaggression (Lewis, Mendenhall, Harwood, and Browne Huntt, 2013; Shorter-Gooden, 2014). Similarly, participants in the present study appeared to evaluate situations in which "subtle negativity" from family or community members occurred in response to their advocacy and/or their child's identity. Given this information, it may be beneficial to explore the types of discrimination experienced by parents of LGBTQ youth, and how they respond when having to "choose their battles." In the present study, parents appeared to respond by pushing forward to educate and advocate. While other parents responded to these microaggressions by accepting reality 
and seeing the best in people. Overall, these findings reveal new and unique insights into parent advocacy that have not been reported in past studies on parent LGBTQ advocates.

\section{Change through Advocacy}

By advocating on behalf of LGBTQ issues, parent's views of themselves and their relationships with others (e.g., family, children, and community members) changed throughout their experiences. Parents reported going from a quiet ally to an active advocate through their experiences. At the individual level parents went from a quiet supporter of LGBTQ rights to valued community leaders in the LGBTQ community. Utilizing Social Identity Theory (van Zomeren et al., 2008), this change demonstrates the evolving nature of a parent advocate's social identity. As parents recounted their advocacy development, they appeared to gain a greater understanding of their own privilege, and the injustices faced by the LGBTQ community. Parents reported becoming more understanding of different views/experiences, challenging themselves to see the world from a different perspective, and shifting their priorities as a parent. Parents also developed into expert and valued leaders within the community. Six parents were asked follow-up questions regarding how advocacy impacted them at the individual level. Similar to previous points, participants reported improving their understanding of others and becoming stronger/more courageous in their ability to advocate on behalf of LGBTQ issues. Based on these findings, the transaction between individual, family, and community level experiences appeared to move parents from their original in-group identification towards creating a sense of identification as a member of the LGBTQ community, further motivating them to advocate on behalf of LGBTQ issues. These 
individual level changes also altered the dynamic between both parents and their children.

Half of parents reported that becoming an advocate helped to promote an honest and open relationship with their children. Parents also reported that they thought their children felt more supported through their advocacy efforts. Overtime, parents developed more established community connections that provided them with continued strength and support. These community, family, and individual level changes are consistent with previous research on the experiences of parents of LGBTQ children. More specifically, in a study of 142 parents of LGBTQ youth, Gonzalez, Rostosky, Odom, and Riggle (2012) found that paticipants reported a number of positive aspects associated with being a parent of an LGBTQ child, including: personal growth, positive emotions, social connection, closer relationships, and activism. Therefore, the changes parents experienced in the present study may also be associated with changes that naturally occur as a result of being a parent of an LGBTQ child. These changes may then evolve and grow through their advocacy experiences. Future research in this area may seek to determine the role of advocacy in contributing to these experiences compared to the changes experienced by parents of LGBTQ children who are not advocates in the community.

Relationships with other family members also changed for some parents, forming deeper and stronger relationships with those around them. A number of parents reported that their family members became LGBTQ allies and that over time conversation topics between family members changed to include LGBTQ-related issues. Conversely, five parents denied any changes within their family as a result of their advocacy. Of note, two 
parents reported that their relationships with their child who does not identify as LGBTQ also changed over time. These findings may indicate a change in family dynamics that result from participating in advocacy initiatives. This is an area that has not been previously explored in the literature, and may add insight into the transactional nature of individual and family relationships when pursuing change within the larger community.

\section{Recommendations for Other Parents of LGBTQ Children}

Finally, parents were asked to provide advice for other parents of LGBTQ children. Parents emphasized that when working with other parents of LGBTQ children it is important to provide validation and reassurance, as well as to encourage them to provide validation and reassurance to their children. Parents noted that it is also important to tell other parents about their experiences coming to terms with their child's identity and provide appropriate education and resources that may guide them throughout the "coming out" process. Through sharing this advice, parents continued to highlight factors that facilitated their development as advocates for the LGBTQ community. This advice points to the benefits of supporting parents of LGBTQ in various contexts. According to parent participants, other parents of LGBTQ may benefit from receiving validation thus providing individual level support. At the family level, parents may also be guided towards strategies that promote positive parent-child interactions through the reassurance of their LGBTQ child. Finally, parents in the study incorporated community level advice by encouraging a greater sense of understanding and acceptance through the sharing of personal experiences and community resources. By incorporating multiple levels of support, parents may feel better able and willing to advocate on behalf of both their child and the larger LGBTQ community. 
When approaching other parents about advocacy, parents explained that advocacy is doable and is not hard. They also emphasized urgency when advocating for LGBTQ rights given the recent policies and legislation that may prevent equal access for their children. Additionally, parents noted the rewarding nature of participating in advocacy, from finding community support to seeing positive and encouraging results through their advocacy experiences. Four parents in the study concluded that sharing personal stories and experiences as a parent of an LGBTQ person greatly contributed to their advocacy efforts. Together these findings expand on the recent work of Brookman and Kalla (2016) who found that a 10-minute conversation promoting perspective-taking can produce lasting effects in reducing transphobia. Similarly, parents in the present study described advocacy as an experience that values individual perspectives and has the ability to produce lasting changes at both the individual and community level.

In many ways, this study highlights various ways professionals can support parent allies throughout the coming out process. Through increased social supports, communities may be better able to identify resources for both parent advocates and LGBTQ/ally families. Overall, the results of this study provide a greater understanding of ally development and helps to identify effective advocacy strategies for both parents and LGBTQ rights organizations.

\section{Limitations and Methodological Considerations}

There are a number of limitations and methodological considerations that should be considered when interpreting the findings of the current study. In particular, this study employed a small sample size to understand the experiences of parent advocates. A larger sample size would have allowed for a diverse group of participants of different 
ethnic/cultural and educational backgrounds, as well as parents from different regions and experiences. Additionally, the sample size limited the representation of parents with children of differing identities. By employing a larger sample size, the results may have revealed a greater understanding of advocacy for parents of children with differing identities, as well as additional information of what experiences at the individual, family, and community level helped them to initiate and facilitate their advocacy-related efforts. Another limitation of this study was the recruitment strategies utilized to obtain research participants. The networking and snowballing sampling approach allowed for recruitment of parents in the New England region. Additionally, the study utilized faceto-face interviews, rather than other methods, such as phone interviews or online surveys. As a result, potential parent participants may have been deterred by personal time constraints and physical distance. This approach also limited the ability of the researcher to recruit and obtain participants outside of the New England region. It is possible that by recruiting participants only in this region may have led to a more limited understanding of parent advocacy. In particular, the New England region of the U.S. has been historically more accepting and willing to adopt LGBTQ equality legislation. Parent advocates from other regions may have differing experiences that are not represented through these findings. Therefore, the findings of this study cannot be generalized to represent the experiences of all parents who advocate on behalf of LGBTQ rights. Moreover, the findings of this study reflect the individual experiences of 12 parent advocates in the New England area. 


\section{Directions for Future Research}

Moving forward, future research seeking to understand parent advocacy may examine the experiences of parent advocates from different regions and states. This information will allow researchers to compare the experiences of parent LGBTQ advocates based on different policies and environmental factors that may differ from state and region. In order to accomplish this task, researchers may seek to use phone interviews, which would allow for greater flexibility in recruiting potential parent participants across regions and states. Further, researchers may explore the specific experiences of parents of children who identify with specific sexual orientation or gender identities. For example, a number of parents expressed specific concerns related to transgender rights. These concerns differed from the experiences of parents of gay and lesbian children. However, due to the small sample size and the limited diversity of the sample, conclusions for specific populations were not ascertained. Therefore, it may be beneficial for future research to examine the ways in which parent advocates differ in their advocacy experiences based on both their regional differences and the differences among their children's identities.

In addition, it would be helpful to obtain information about how parents advocate in various settings. Parents expressed participating in legislative, medical, and school advocacy, among other advocacy-related experiences. Within these settings, researchers may be better able to explore the various types of discrimination parent advocates experience, including further exploration of microaggressions and the ways in which advocates to respond to them. Given the different settings and experiences of parents, it will also be helpful to identify specific advocacy-related strategies that parents found to 
be most effective in pursuing and achieving their stated mission, to advocate on behalf of LGBTQ rights. This information may be combined with previous advocacy research to create a blueprint for understanding parent advocacy on behalf of the LGBTQ community. Finally, future research should seek to understand the experiences of LGBTQ youth whose parents participate in advocacy initiatives for the LGBTQ community. In doing so, the research may be better able to support both parents and their children in pursuing advocacy-related efforts. 


\section{Appendix A \\ Demographic Questionnaire}

Instructions: Please answer the demographic questions listed below.

1. What is your gender?

2. Please indicate your gender identity:

(Gender identity is a person's sense of their own gender, which may or may not conflict with their biological sex given at birth.)

3. Please indicate your sexual orientation:

4. How many children do you have?

5. Do any of your children identify as LGBTQ?

6. If so, how old are they?

7. Please indicate your child or children's gender identity:

8. Please indicate your child or children's sexual orientation:

9. Which race/ethnicity best describes you (circle all that apply):
A. White or European American
B. Asian or Pacific Islander
C. Black or African American
D. Latino/a or Hispanic
E. American Indian or Alaska Native
F. Multi-ethnic
G. Other, please specify:

10. What is your current marital status (Circle your response)?
A. Single, never married
B. Married or domestic partnership
C. Widowed
D. Divorced
E. Separated

11. What is the highest level of education you have completed (Circle your response)? 

A. Elementary and middle school
B. Some high school, no diploma
C. High school graduate
D. Some college, but no degree
E. Vocational/technical school
F. Associate's degree
G. Bachelor's degree
H. Master's degree
I. Doctorate degree
J. Other, please specify:

12. What is your age Circle your response)
A. 18-24 years old
B. 25-34 years old
C. 34-44 years old
D. 45-54 years old
E. 55-64 years old
F. 65-74 years old
G. 75 years or older

13. Please indicate which, if any, advocacy groups and/or organizations you are currently involved in:

14. Please describe your advocacy-related experiences up to this point: 


\section{Appendix B \\ Interview Protocol}

1. A lot of people use the word "advocacy" in my work. I am trying to understand what that means to people. What does that mean to you?

2. Can you identify what influenced you to become an LGBTQ parent advocate? Probes include:

a. Has your relationship with your child who identifies as LGBTQ influenced your decision to become an advocate?

b. What about your other family members, how have they influenced your decision to become an advocate?

c. Has your relationship with others in your community influenced your decision to become an advocate?

d. Have you experienced discrimination or isolation in your life? Was that before you become an advocate? Did that come later? Do you think those experiences influenced you being an advocate now?

3. Once you became an advocate, what experiences facilitated your continued involvement in LGBTQ advocacy efforts?

Probes include:

a. How has your relationship with your child influenced your experiences as an advocate?

b. What about your other family members and members of the community?

4. What kinds of challenges did you encounter initiating and pursuing advocacyrelated efforts among parents of LGBTQ youth?

Probes include: 
a. What personal challenges did you overcome during this process?

b. Did you ever find negative reactions by others in the community or in your family?

c. How did you end up dealing with those challenges?

5. Do you think your view of yourself has changed throughout your advocacy experiences? Do you think your view of your relationships with others has changed?

Probes include:

a. How have your experiences as an advocate impacted who you are as an individual?

b. Has your relationship with your child changed since becoming an advocate? How has this impacted your relationship with them?

c. Have your relationships with your other family members changed since becoming an LGBTQ advocate?

d. Have your relationships with those in your community, both the LGBTQ community and the larger community you referred to previously, changed since becoming an LGBTQ advocate?

6. If you were in a room with other parents whose child identifies as LGBTQ, what would you want to tell them now? What would you like them to know about becoming an advocate? 


\section{Appendix C \\ Recruitment E-mail Script}

Call for Participation: Parents of LGBTQ Youth

To Whom It May Concern,

My name is Amanda Ramirez, MSW. I am currently a school psychology doctoral student at the University of Rhode Island under the supervision of Dr. Margaret Rogers. I am seeking participants in my dissertation study examining the LGBTQ advocacy experiences of heterosexual parent allies. This research will hopefully lead to a better understanding of parent and LGBTQ advocacy efforts.

Interested participants are sought who meet the following criteria: a) are parents of LGBTQ children and b) participate in LGBTQ advocacy efforts (e.g., actively participates in LGBTQ advocacy group(s), engages in conversations with educators and teachers about creating a welcome school/class, takes a public stance on marriage equality and participates in advocacy-related activities). If you know of anyone who might meet these criteria, I encourage you to forward them this information. I have also attached a recruitment flyer for your distribution.

Study volunteers will be asked to participate in one interview (about 60 minutes in length) and one follow-up contact. All information provided in the interview will be confidential and will only be seen by Amanda Ramirez, Dr. Margaret Rogers, and trained research assistants at the University of Rhode Island. Your personal identifying information will not be shared with any organization. Participants will receive a $\$ 25$ as an expression of gratitude for their interest in the study.

The University of Rhode Island's Institutional Review Board ethics committee has reviewed and approved this study (IRB: \#). However, the final decision about participation is yours.

If you would like to participate in this study or have any further questions, please contact me at ramirez.amanda04@gmail.com or you may contact Dr. Margaret Rogers at mrogers@uri.edu.

Thank you very much for your time and consideration.

Sincerely,

Amanda Ramirez, MSW

Student Investigator

Psychology Department

University of Rhode Island

Kingston, RI, 02881

ramirez.amanda04@gmail.com

(210)386-2852
Margaret Rogers, Ph.D.

Principal Investigator

Psychology Department

University of Rhode Island

Kingston, RI, 02881

mrogers@uri.edu

(401) 874-7999 
Appendix D: Recruitment Flyer

\section{Seeking Parent Advocates of LGBTQ Youth}

\section{Are you a parent of a child who identifies as LGBTQ?}

2. Are you a 21 years or older?

\section{Do you participate in LGBTQ advocacy efforts?}

For example:

- Do you actively participate in LGBTQ advocacy group(s)

- Do you have conversations with teachers about creating a welcoming school/class?

- Do you take a public stance on marriage equality?

- Do you participate in advocacy-related activities?

\section{If you answered "Yes" to these three questions, we would like to talk to you!}

We are conducting a dissertation research study on LGBTQ advocacy experiences of parent allies.

\section{Participation includes:}

- One 60-minute confidential interview discussing what led you to become an LGBTQ advocate, your experiences as an LGBTQ advocate, and how those experiences have changed your relationship with those around you.

- Follow-up communication (about 30-minutes) to review the transcription of the interview

- Receive $\$ 25$ as an expression of gratitude for interest in the study

To learn more about the LGBTQ Parent Advocate dissertation research project, please contact Amanda Ramirez, student investigator at the University of Rhode Island at email: ramirez.amanda04@gmail.com, phone: (210) 386-2852 or principal investigator, Dr. Margaret Rogers at email: mrogers@uri.edu, phone: (401) 874-7999.

The University of Rhode Island's Institutional Review Board ethics committee has reviewed and approved this study (IRB \#).

\begin{tabular}{|c|c|c|c|c|c|c|}
\hline $\begin{array}{c}\text { Parent } \\
\text { Advocacy } \\
\text { Study } \\
\end{array}$ & $\begin{array}{c}\text { Parent } \\
\text { Advocacy } \\
\text { Study } \\
\end{array}$ & $\begin{array}{c}\text { Parent } \\
\text { Advocacy } \\
\text { Study } \\
\end{array}$ & $\begin{array}{c}\text { Parent } \\
\text { Advocacy } \\
\text { Study } \\
\end{array}$ & $\begin{array}{c}\text { Parent } \\
\text { Advocacy } \\
\text { Study } \\
\end{array}$ & $\begin{array}{c}\text { Parent } \\
\text { Advocacy } \\
\text { Study } \\
\end{array}$ & $\begin{array}{c}\text { Parent } \\
\text { Advocacy } \\
\text { Study }\end{array}$ \\
\hline 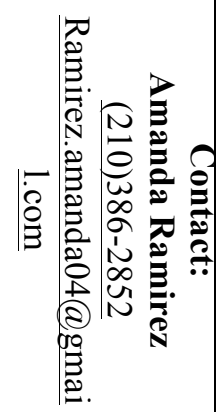 & 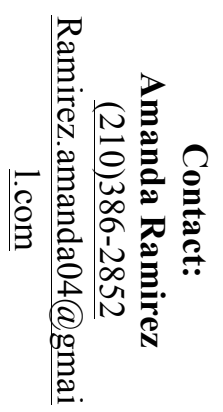 & 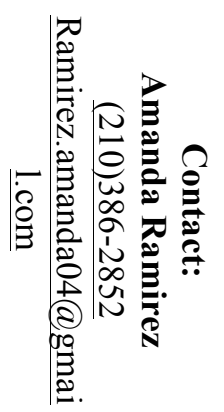 & 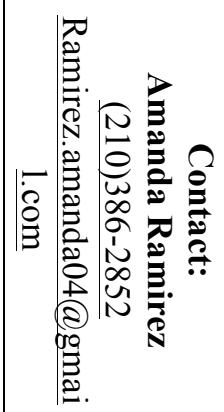 & 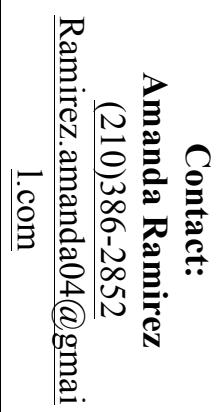 & 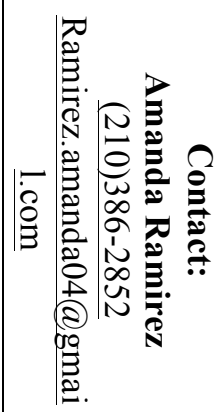 & 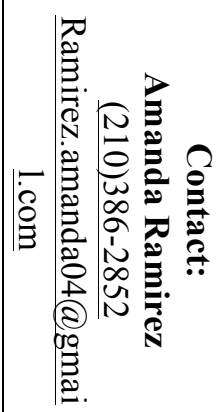 \\
\hline
\end{tabular}


University of Rhode Island

Appendix E

Consent Form

Department of Psychology

Kingston, RI 02881

LGBTQ Advocacy Among Heterosexual Parent Allies

Dear Participant,

You have been invited to participate in a research project described below. If you have any questions about this study, feel free to contact Amanda Ramirez, Student Investigator, at (401) 874-7400 or ramirez.amanda04@gmail.com. You may also contact Dr. Margaret Rogers, Principal Investigator, at (401) 874-7999 or mrogers@mail.uri.edu.

Description of the project: The purpose of this qualitative study is to examine the individual, family, and community level experiences of heterosexual parent allies engaged in LGBTQ advocacy. The study will consist of one in-person, semi-structured interview, as well as follow-up communication regarding what led you to become an LGBTQ advocate, your experiences as an LGBTQ advocate, and how those experiences have changed your relationship with those around you. All participants in this study must be 21 years or older to participate.

What will be done: If you decide to take part in this study, it will involve participating in one in-person semi-structured interview, with the opportunity to call you after the interview if additional questions arise. The interview questions will pertain to your process of becoming an LGBTQ advocate, as well as the meaning of those experiences at the individual, family, and community level. The interview will take approximately 60 -minutes and will be audiorecorded. Following the interview, your interview will be transcribed and de-identified. You may then be contacted to review the transcription to ensure that information was appropriately written and represented. An email with the transcript attached will be sent to you. This email and all transmissions will be immediately deleted once confirmation is received. After the transcript is reviewed, you will be asked to participate in a follow-up discussion. This discussion can occur in-person, over the phone, or via email. At that time, you may be asked additional follow-up questions for clarification purposes. Together, the follow-up communication will last approximately 30 -minutes in length.

Risks or discomforts: The possible risks or discomforts of the study are minimal, although you may feel some embarrassment, stress, or anxiety answering questions about some private matters.

Benefits: Your participation will increase the knowledge regarding LGBTQ parent advocacy efforts.

Confidentiality: Your participation in this study is confidential and will only be seen by Amanda Ramirez, her major professor, Dr. Margaret Rogers, and trained research assistants at the University of Rhode Island. Your personal information will not be shared with any organization. The results of the study may be presented at professional conferences and published in a scientific journal, but all identifying information will be removed. 
Decision to quit at any time: The decision to participate in this research project is up to you. You do not have to participate and can refuse to answer any question. There are no consequences for withdrawing from the study at any time.

Rights and complaints: If you have other concerns about this study or if you have questions about your rights as a research participant, you may contact Amanda Ramirez, Student Investigator, at (401) 874-7400 or ramirez.amanda04@gmail.com, Dr. Margaret Rogers, Principal Investigator, at (401)874-7999 or mrogers@uri.edu, or the University of Rhode Island's Vice President for Research, 70 Lower College Road, Suite 2, University of Rhode Island, Kingston, Rhode Island, 02881, (401) 874-4328. You may do this anonymously if you prefer.

In case there is any injury to the subject: Participation in this study is not expected to be harmful or injurious to you. However, if this study causes you any harm, you should write or call Amanda Ramirez at (401) 874-7400 or ramirez.amanda04@gmail.com or Dr. Margaret Rogers at (401) 874-7999 or mrogers@uri.edu.

Giving of Consent: I have read this consent form and I understand fully what is being requested of me as a participant in this project. I certify that I am at least 21 years of age.

Participant Name (Print)

Participant Signature

Date

Researcher Name (Print)

Researcher Signature

Date

The researcher will use a digital recording device in order to audio record the full interview between the participant and the researcher. Please indicate your decision to be recorded by placing an " $\mathrm{X}$ " on one of the lines below followed by your signature.

I agree___ or I decline___ to be recorded.

Signature of Participant

Please sign both consent forms, keeping one copy for yourself. 


\section{BIBLIOGRAPHY}

Barnes, L., \& Ederer, J. (2000, April). From agents to allies: Active citizenship in our multicultural communities. Workshop presented at the American College Personnel Association Conference, Washington, DC.

Barry, C. A., Britten, N., Barbar, N., Bradley, C., \& Stevenson, F. (1999). Using reflexivity to optimize teamwork in qualitative research. Qualitative Health Research, 9(1), 26-44. doi:10.1177/104973299129121677

Beyerlein, K., \& Hipp, J. R. (2004). A two-stage model for a two-stage process: How biographical availability matters for social movement mobilization. Mobilization: An International Journal, 11(3), 219-240.

Blackwell, L., Hardy, J. Ammari, T., Veinot, T., Lampe, C., \& Schoenbeck, S. (2016). LGBTQ Parents and social media: Advocacy, privacy, and disclosure during shifting social movements. Paper presented at the 2016 CHI Conference on Human Factors in Computing Systems, Santa Clara, CA.

Bouris, A., Guilamo-Ramos, V., Pickard, A., Shiu, C., Loosier, P. S., Dittus, P., ...\& Waldmiller, J. M. (2010). A systematic review of parental influences on the health and well being of lesbian, gay, and bisexual youth: Time for a new public health research and practice agenda. Journal of Primary Prevention, 31(5-6): 273-309. doi: $10.1007 / \mathrm{s} 10935-010-0229-1$

Bronfenbrenner, U. (1979). The ecology of human development: Experiments in nature and design. Cambridge, MA: Harvard University Press. 
Broad, K. L. (2011). Coming out for parents, families, and friends of lesbian and gays: From support group grieving to love advocacy. Sexualities, 14(4), 399-415. doi: $10.1177 / 1363460711406792$

Brookman, D., \& Kalla, J. (2016). Durably reducing transphobia: A field experiment on door-to-door canvassing. Science, 352(6282), 220-224. doi:

\subsection{6/science.aad9713}

Cavanagh, S. (1997). Content analysis: Concepts, methods and applications. Nurse Researcher, 4(3), 5-16. doi: 10.7748/nr1997.04.4.3.5.c5869

Cicchetti, D., \& Lynch, M. (1993). Toward and ecological/transactional model of community violence and child maltreatment: Consequences for children's development. Psychiatry, 56(1), 96-117. doi: 10.1080/00332747.1993.11024624

Coker, T. R., Austin, S. B., \& Schuster, M. A. (2010). The health and health care of lesbian, gay, and bisexual adolescents. Annual Review of Public Health, 31(1), 457-477. doi: 10.1146/annurev.publhealth.012809.103636

D’Augelli, A. R., Grossman, A. H., \& Starks, M. T. (2005). Parents' awareness of gay, lesbian, and bisexual youths' sexual orientation. Journal of Marriage of Family, 67(2), 474-482. doi: 10.1111/j.0022-2445.2005.00129.x

Denzin, N. K., \& Lincoln, Y. S. (2004). Introduction: The discipline and practice of qualitative research. In N. K. Denzin and Y. S. Lincoln (Eds.), Handbook of qualitative research, (pp. 1-19). Thousand Oaks: Sage Publications.

Duhigg, J. M., Rostosky, S. S., Gray, B. E., \& Wimsatt, M. K. (2010). Development of heterosexuals into sexual-minority allies: A qualitative exploration. Sexual Research and Social Policy, 7(1), 2-14. doi: 10.1007/s13178-010-0005-2 
Fields, J. (2001). Normal queers: Straight parents respond to their children's coming out. Symbolic Interaction 24(2), 165-187. doi: 10.1525/si.2001.24.2.165

Getz, C., \& Kirkley, E. A. (2003, April). Identity development models: One size fits all? Heterosexual identity development and the search for "allies" in higher education. Paper presented at the annual meeting of the American Educational Research Association, Chicago, IL.

Glennon, B. (2012). Heterosexual parents of gay and lesbian individuals: Social interaction issues. Family Theory and Review, 4(4), 332-353. doi: 10.1111/j.17562589.2012.00138.x

Gonzales, K. A., Rostosky, S. D., \& Odom, R. D. (2012). Positive aspects of being the parent of an LGBTQ child. Family Process, 1-13. doi: 10.1111/famp.12009

Graneheim, U. H., \& Lundman, B. (2004). Qualitative content analysis in nursing research: Concepts, procedures, and measures to achieve trustworthiness. Nurse Education Today, 24, 105-112. doi: 10.1177/2158244014522633

Iyer, A., \& Ryan, M. K. (2009). Why do men and women challenge gender discrimination in the workplace? The role of group status and in-group identification in predicting pathways to collective action. Journal of Social Issues, 65(4), 791-814. doi: 10.1111/j.1540-4560.2009.01625.x

Iyer, A., Schmader, T., \& Lickel, B. (2007). Why individuals protest the perceived transgressions of their country: The role of anger, shame, and guilt. Personality and Social Psychology Bulletin, 33(4), 572 - 587. doi: $10.1177 / 0146167206297402$

Iyer, A., \& van Zomeren, M. (2009). Introduction to the social and psychological 
dynamics of collective action. Journal of Social Issues, 65(4), 645-660. doi: $10.1111 / \mathrm{j} .1540-4560.2009 .01618 . x$

Ji, P., DuBois, S., \& Finnessy, P. (2009). An academic course that teaches heterosexual students to be allies to LGBT communities: A qualitative analysis. Journal of Gay and Lesbian Studies, 21(5), 402-429. doi: 10.1080/10538720802690001

Kosciw, J. G., Greytak, E. A., Giga, N. M., Villenas, C., \& Danischewski, D. J. (2016). The 2015 National School Climate Survey: The experiences of lesbian, gay, bisexual, transgender, and queer youth in our nation's schools. New York, NY: GLSEN.

Lewis, J. A., Mendenhall, R., Harwood, S. A., \& Huntt, M. B. (2013). Coping with gendered racial microaggressions among Black women college students. Journal of African American Studies, 17(1), 51-73. doi: 10.1007/s12111-012-9219-0

Lynch, M., \& Cicchetti, D. (1998). An ecological-transactional analysis of children and contexts: The longitudinal interplay among child maltreatment, community violence, and children's symptomatology. Development and Psychopathology, 10(2), 235-257. doi: 10.1023/B:CCFP.0000006293.77143.e1

McAdam, D. (1986). Recruitment to high-risk activism: The case of freedom summer. American Journal of Sociology, 92(1), 64-90. doi: 10.1086/228463

Mio, J. S. (2007, May). Allies and their motivations to intervene. Invited address delivered to the Western Psychological Association Convention, Vancouver, BC.

Raifman J, Moscoe E, Austin SB, McConnell M. (2017). Difference-in-Differences Analysis of the Association Between State Same-Sex Marriage Policies and 
Adolescent Suicide Attempts. JAMA Pediatrics. Published online February 20, 2017. doi:10.1001/jamapediatrics.2016.4529

Munin, A., \& Speight, S. L. (2010). Factors influencing ally development of college students. Equity \& Excellence in Education, 43(2), 249-264. doi: $10.1080 / 10665681003704337$

Needham, B. L., \& Austin, E. L. (2010). Sexual orientation, parental support, and health during the transition to young adulthood. Journal of Youth and Adolescence, 39(10), 1189-1198. doi: 10.1007/s10964-010-9533-6

Obergefell v. Hodges, 576 U.S. _ (2015).

Oegema, D., \& Klandermans, B. (1994). Why social movement sympathizers don’t participate: Erosion and nonconversion of support. American Sociological Review, 59(5), 703-722. doi: 10.2307/2096444

Poteat, P. (2015). Individual psychological factors and complex interpersonal conditions that predict LGBTQ-Affirming behavior. Journal of Youth and Adolescence, 44(8), 1494-1507. doi:10.1007/s10964-015-0257-5

Phillips, M. J., \& Ancis, J. R. (2008). The process of identity development as the parent of a lesbian and gay male. Journal of LGBTQ Issues in Counseling, 2(2), 126158. doi: $10.1080 / 15538600802125605$

Roades, L. A., \& Mio, J. S. (2000). Allies: How they are created and what are their experiences? In J. S. Mio \& G. I. Awakuni (Eds.), Resistance to multiculturalism: Issues and interventions (pp. 63-82). Philadelphia, PA: Brunner/Mazel.

Resnick, M. D., Bearman, P. S., Blum, R. W., Bauman, K. E., Harris, K. M., Jones, J., ...\& Udry, J. R. (1997). Protecting adolescents from harm: Findings from the 
National Longitudinal Study of Adolescent Health. Journal of the American Medical Association, 278(10), 823-832. doi: 10.1001/jama.1997.03550100049038 Riffkin, R. (2014). New record high in moral acceptability. Gallup Poll. Retrieved from http://www.gallup.com/poll/170789/new-record-highs-moralacceptability.aspx?utm_source=gay\&utm_medium=search\&utm_campaign=tiles

Ryan, C. (2009). Supportive families, healthy children: Helping families with lesbian, gay, bisexual \& transgender children. San Francisco, Family Acceptance Project, San Francisco State University. Retrieved from http://familyproject.sfsu.edu/sites/default/files/FAP_English\%20Booklet_pst.pdf

Ryan, C., Huebner, D., Diaz, R. M., \& Sanchez, J. (2009). Family rejection as a predictor of negative health outcomes in White and Latino lesbian, gay and bisexual young adults. Pediatrics, 123(1), 346-352. doi: 10.1542/peds.2007-3524

Saltzerg, S. (2009). Parents' experiences of feeling socially supported as adolescents come out as lesbian or gay: A phenomenological study. Journal of Family Social Work, 12(4), 340-358. doi: 10.1080/10522150903261932

Sandelowski, M. (2000). Whatever happened to qualitative description? Research in Nursing and Health, 23, 334-340. doi: 10.1002/1098240X(200008)23:4<334::AID-NUR9>3.0.CO;2-G

Sandelowski, M. (1995). Qualitative analysis: What it is and how to begin. Research in Nursing and Health, 18(4), 371-375. doi: 10.1002/nur.4770180411

Shorter-Gooden, K. (2004). Multiple resistance strategies: How African American women cope with racism and sexism. Journal of Black Psychology, 30(3), 406425. doi: $10.1177 / 0095798404266050$ 
Sidanius, J., \& Pratto, F. (1999). Social dominance: An inter-group theory of social hierarchy and oppression. New York: Cambridge University Press.

Sue, D. W., Bucceri, J., Lin, A. I., Nadal, K. L., \& Torino, G. C. (2007). Racial microaggressions and the Asian American experience. Cultural Diversity \& Ethnic Minority Psychology, 13(1), 72-81. doi: 10.1037/1099-9809.13.1.72

Sullivan-Bolyai, S., Bova, C., \& Harper, D. (2005). Developing and refining interventions in persons with health disparities: The use of qualitative description. Nursing Outlook, 53, 127-133. doi: 10.1016/j.outlook.2005.03.005

Tajfel, H., \& Turner, J. C. (1979). An integrative theory of group conflict. In W. G. Austin \& S. Worchel (Eds.), The social psychology of inter-group relations (pp. 7-24). Chicago, IL: Nelson-Hall.

The Public Facilities Privacy and Security Act, N.C. Gen. Stat. § 143 (2016-3).

van Zomeren, M., Postmes, T., \& Spears, R. (2008). Toward an integrative social identity model of collective action: A quantitative research synthesis of three sociopsychological perspectives. Psychological Bulletin, 134(4), 504-535. doi: $10.1037 / 0033-2909.134 .4 .504$

Vernaglia, E. R. (1999). Parents as straight allies: A qualitative study of the experiences of heterosexual parents in the gay rights movement. (Unpublished doctoral dissertation). Boston College, Boston, MA.

Wang, M., Mannan, H., Poston, D., Turnbull, A. P., \& Summer, J. A. (2004). Parents' perceptions of advocacy activities and their impact on family quality of life. Research \& Practice for Persons with Severe Disabilities, 29(2), 144-155. doi: 10.2511/rpsd.29.2.144 
Washington, J., \& Evans, N. J. (1991). Becoming an ally. In N. J. Evans \& V. A. Wall (Eds.), Beyond tolerance: Gays, lesbians, and bisexuals on campus (pp. 195-204). Alexandria, VA: American College Personnel Association.

Watson, L. B., Varjas, K., Meyers, J., \& Graybill, E. C. (2010). Gay-straight alliance advisors: Negotiating multiple ecological systems when advocating for LGBTQ youth. Journal of LGBT Youth, 7(2), 100-128. doi: 10.1080/19361651003799700

Wolf, R. (2015). Supreme court agrees to rule on gay marriage. USA Today. Retrieved from http://www.usatoday.com/story/news/nation/2015/01/16/supreme-court-gaymarriage/21867355/ 